\title{
Hydrodynamic Modelling and Experimental Analysis of FE-DMFC Stacks
}

\author{
by \\ Yashar Kablou \\ A thesis submitted to the
Faculty of Graduate and Postdoctoral Affairs
in partial fulfillment of the requirements for the degree of
}

Master of Applied Science in Mechanical Engineering

Ottawa-Carleton Institute for Mechanical and Aerospace Engineering Department of Mechanical and Aerospace Engineering Carleton University Ottawa, Ontario

May, 2012

(C)Copyright

Yashar Kablou, 2012 
Library and Archives

Canada

Published Heritage

Branch

395 Wellington Street

Ottawa ON K1A ON4

Canada
Bibliothèque et

Archives Canada

Direction du

Patrimoine de l'édition

395 , rue Wellington

Ottawa ON K1A ON4

Canada
Your file Votre référence

ISBN: 978-0-494-91503-5

Our file Notre référence

ISBN: $978-0-494-91503-5$
NOTICE:

The author has granted a nonexclusive license allowing Library and Archives Canada to reproduce, publish, archive, preserve, conserve, communicate to the public by telecommunication or on the Internet, loan, distrbute and sell theses worldwide, for commercial or noncommercial purposes, in microform, paper, electronic and/or any other formats.

The author retains copyright ownership and moral rights in this thesis. Neither the thesis nor substantial extracts from it may be printed or otherwise reproduced without the author's permission.
AVIS:

L'auteur a accordé une licence non exclusive permettant à la Bibliothèque et Archives Canada de reproduire, publier, archiver, sauvegarder, conserver, transmettre au public par télécommunication ou par l'Internet, prêter, distribuer et vendre des thèses partout dans le monde, à des fins commerciales ou autres, sur support microforme, papier, électronique et/ou autres formats.

L'auteur conserve la propriété du droit d'auteur et des droits moraux qui protege cette thèse. $\mathrm{Ni}$ la thèse ni des extraits substantiels de celle-ci ne doivent être imprimés ou autrement reproduits sans son autorisation.
In compliance with the Canadian Privacy Act some supporting forms may have been removed from this thesis.

While these forms may be included in the document page count, their removal does not represent any loss of content from the thesis.
Conformément à la loi canadienne sur la protection de la vie privée, quelques formulaires secondaires ont été enlevés de cette thèse.

Bien que ces formulaires aient inclus dans la pagination, il n'y aura aucun contenu manquant. 


\section{Abstract}

Direct methanol fuel cells (DMFCs) present some unique features such as having liquid fuel, quick refueling process, compact design and high energy density. These characteristics make them incredibly suitable as a promising power source for portable electronic applications, such as cell phones or laptop computers. Despite of these positive aspects, the commercial development of DMFCs has nevertheless been hindered by some important issues such as, carbon dioxide formation at the anode compartment and, methanol crossover through the membrane.

Many researchers have tried to model the two-phase flow behavior inside the DMFC anode compartment using the "homogenous flow modelling" approach, which has proven to be inaccurate specially when dealing with DMFC stacks. On the other hand, several strategies to prevent methanol crossover have been suggested in the literature, including the use of a flowing electrolyte between the DMFC anode and cathode compartments. Preliminary tests on flowing electrolyte direct methanol fuel cells (FE-DMFCs) have shown promising results; however, further investigation should be carried out on the stack level.

In the first part of this study, a quasi two-dimensional numerical model was developed, to predict the two-phase flow behavior within the DMFC anode compartment, both in single cell and stack levels. Various types of flow modelling approaches and void fraction correlations were utilized to estimate the pressure drop across the anode compartment. It was found that the "separated flow modelling" approach, as well as CISE correlation for void fraction (developed at the CISE labs in Milan), yield the best results. In the second part, a five-cell FE-DMFC stack unit with a parallel serpentine flow bed design and U-type manifold configuration, was developed and tested at various operating conditions. It was found that, the flowing electrolyte effectively reduced methanol crossover and, improved the stack performance. 


\section{Acknowledgments}

This work was made possible by the support, time, and commitment of a number of individuals. First, I would like to thank my supervisors, Dr. Edgar Matida and Dr. Cynthia Ann Cruickshank from the Mechanical and Aerospace Engineering Department at Carleton University, and Dr. Feridun Hamdullahpur from the University of Waterloo, for the opportunity to work on the FE-DMFC project. As mentors, they provided me with excellent support and guidance throughout all aspects of this research.

I want to express my gratitude to the office staff and the machine shop in the MAE department, for their advice and support. I wish to extend my warmest appreciation to my team members at the Carleton University Fuel Cell Laboratory.

Furthermore, I would like to acknowledge the financial support from the Ontario Centres of Excellence (OCE) and the Natural Sciences and Engineering Research Council of Canada (NSERC).

Finally, I dedicate this work to my parents, Siamak and Shokoufeh and my loving wife, Sanaz, for their unconditional love, encouragement and support. They are the sun and the moon that bring light to my life. 


\section{Table of Contents}

Abstract $\quad$ iii

Acknowledgments $\quad$ iv

Table of Contents $\quad$ v

List of Tables $\quad$ x

List of Figures $\quad$ xi

Nomenclature $\quad$ xiii

1 Introduction 1

1.1 Fuel Cell Technology . . . . . . . . . . . . . . . . . 1

1.1.1 Types of Fuel Cells . . . . . . . . . . . . . . . . 2

1.2 Direct Methanol Fuel Cells . . . . . . . . . . . . . . . . 3

1.2.1 DMFC Components ................ 4

1.2.2 Polarization Curve ................ 7

1.3 Direct Methanol Fuel Cell Stack . . . . . . . . . . . . . . . 8

1.3.1 Types of Manifold Systems . . . . . . . . . . . . . . . 9

1.3.2 Reactant Flow Configurations . . . . . . . . . . . . . . . . 10

1.4 Challenges with Direct Methanol Fuel Cells . . . . . . . . . . . 11

1.4.1 CO Poisoning . . . . . . . . . . . . . . . . . 12

1.4.2 Methanol Crossover . . . . . . . . . . . . . . . 12

1.4.3 Gas Management ... . . . . . . . . . . . . . 13

1.5 DMFC Hydrodynamics . . . . . . . . . . . . . . . . 14

1.5.1 Volumetric Void Fraction . . . . . . . . . . . . . 15

1.5 .2 Surface Tension . . . . . . . . . . . . . 15 
1.5.3 Two-Phase Pressure Drop Modelling $\ldots \ldots \ldots \ldots$

2 Literature Review $\quad 17$

2.1 Two-Phase Flow Modelling . . . . . . . . . . . . . . . . 17

2.1.1 Homogeneous Flow Models . . . . . . . . . . . . . . . . 17

2.1.2 Separated Flow Models . . . . . . . . . . . . . . . . 19

2.2 DMFC Hydrodynamic Studies . . . . . . . . . . . . . . . 22

2.2.1 Carbon Dioxide Visualization Studies in DMFCs . . . . . . . 23

2.2.2 Two-Phase Flow Modelling in DMFCs . . . . . . . . . . 23

2.3 Methanol Crossover Studies in DMFCs . . . . . . . . . . . 25

2.3.1 Preventative Strategies . . . . . . . . . . . . . . 25

2.3.2 Direct Methanol Fuel Cell with Flowing Electrolyte . . . . . . 27

2.4 Thesis Objectives . . . . . . . . . . . . . . . . . . 28

3 DMFC Anode Hydrodynamic Modelling (Single Cell) 30

3.1 Modelling Approach $\ldots \ldots \ldots \ldots \ldots$

3.1 .1 Assumptions . . . . . . . . . . . . . . . . 30

3.1 .2 Control Volume Setup . . . . . . . . . . . . . . . . 32

3.2 Mass Flow Rate and Concentration . . . . . . . . . . . . . . 32

3.2 .1 Methanol . . . . . . . . . . . . . . . 33

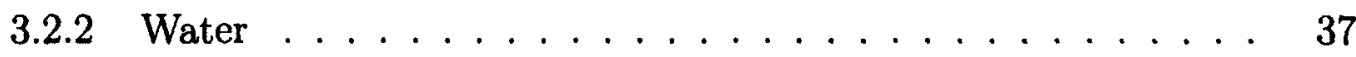

3.2 .3 Carbon Dioxide . . . . . . . . . . . . . . . . . . 40 40

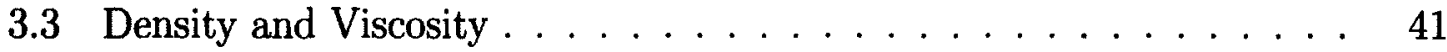

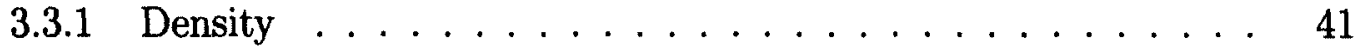

3.3 .2 Viscosity . . . . . . . . . . . . . . . . 43

3.4 Volumetric Void Fraction . . . . . . . . . . . . . . . . 44

3.4.1 Homogenous Void Fraction . . . . . . . . . . . . . . . . 44

3.4.2 Void Fraction Correlations for Separated Flow Regimes . . . . 45

3.5 Two-Phase Pressure Drop . . . . . . . . . . . . . . . 47

3.5.1 Gravitational Pressure Drop . . . . . . . . . . . . . . 47

3.5.2 Acceleration Pressure Drop . . . . . . . . . . . . . 48

3.5.3 Frictional Pressure Drop . . . . . . . . . . . . . . . . 48

3.5 .4 Form Pressure Drop . . . . . . . . . . . . . . . . 50

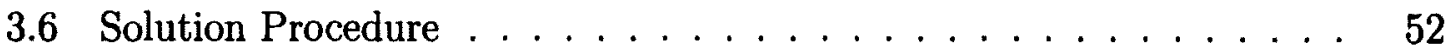

3.7 Experimental Setup . . . . . . . . . . . . . . . . . . 52 
3.7.1 Repeatability of Experimental Results . . . . . . . . 54

3.8 Results and Discussions . . . . . . . . . . . . . . 55

3.8.1 Overall Steady State Pressure Drop Variations . . . . . . . 55

3.8.2 Temperature Effects . . . . . . . . . . . . . 60

3.8.3 Overall Transient Pressure Drop Variations . . . . . . . . . 62

3.8.4 Anode Fuel Channel Hydrodynamics . . . . . . . . . . 63

4 DMFC Anode Hydrodynamic Modelling (Stack) 69

4.1 Background . . . . . . . . . . . . . . . . 69

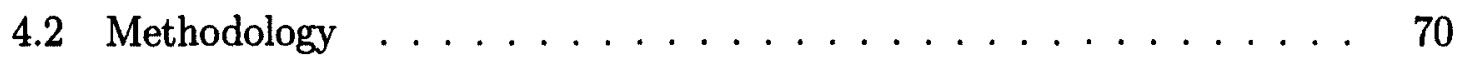

4.2.1 Hardy Cross Algorithm . . . . . . . . . . . . . . 71

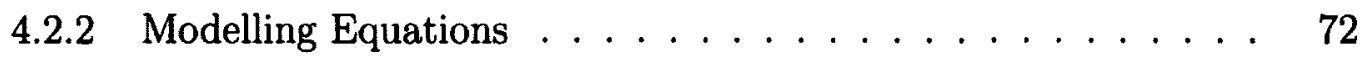

4.3 Solution Procedure $\ldots \ldots \ldots \ldots \ldots \ldots \ldots$

4.4 Results and Discussions . . . . . . . . . . . . . 78

4.4.1 Repeatability of Experimental Results . . . . . . . . 78

4.4.2 Stack Outlet Steady State Pressure Drop Variations . . . . . 79

4.4.3 Stack Outlet Transient Pressure Drop Variations . . . . . . . . 81

4.4.4 Stack Anode Compartment Hydrodynamics . . . . . . . . 82

5 FE-DMFC Stack Experimental Analysis $\quad \mathbf{8 7}$

5.1 FE-DMFC Stack Components . . . . . . . . . . . . . . 87

5.1 .1 Current Collectors $\ldots \ldots \ldots \ldots$. . . . . . . 87

5.1 .2 Flow Distribution Plates . . . . . . . . . . . . . 88

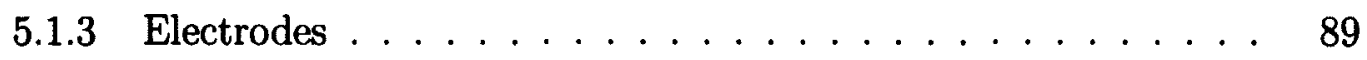

5.1 .4 Membranes . . . . . . . . . . . . . . 9 90

5.1 .5 Gaskets . . . . . . . . . . . . . . . 91

5.1.6 Flowing Electrolyte Channel . . . . . . . . . . . . . . . . 91

5.1.7 Stack Fabrication and Assembly . . . . . . . . . . . . . . 92

5.2 Experimental Setup . . . . . . . . . . . . . . . . 96

5.3 Uncertainty Analysis $\ldots \ldots \ldots \ldots$

5.4 Results and Discussions $\ldots \ldots \ldots \ldots \ldots$

5.4 .1 Repeatability of Results . . . . . . . . . . . . . 99

5.4 .2 Temperature Effects $\ldots \ldots \ldots \ldots$

5.4.3 Methanol Concentration Effects . . . . . . . . . . . 100

5.4.4 Methanol Solution Flow Rate Effects . . . . . . . . . . 102 
5.4.5 Flowing Electrolyte Flow Rate Effects . . . . . . . . . . 103

5.4.6 Air Flow Rate Effects . . . . . . . . . . . . . . . . . . 104

5.4 .7 Stack Voltage Distribution . . . . . . . . . . . . . 105

5.4.8 FE Effects on Stack Startup/Shutdown . . . . . . . . . 106

6 Conclusions and Recommendations 108

6.1 Contributions and Conclusions . . . . . . . . . . . . . . 109

6.2 Recommendations . . . . . . . . . . . . . . . . . . . 112

$\begin{array}{ll}\text { List of References } & 114\end{array}$

Appendix A Stack Bi-Polar Plate Three View Drawings 119

Appendix B Details of Stack Experimental Setup 121

B.1 Fluid Control . . . . . . . . . . . . . . . . . . . 121

B.1.1 Pumps . . . . . . . . . . . . . . . . . . 121

B.1.2 Rotameter . . . . . . . . . . . . . . . . . . 122

B.1.3 Air Filter . . . . . . . . . . . . . . . . . . . . . 122

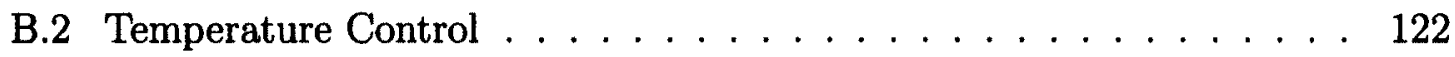

B.2.1 Temperature Controller . . . . . . . . . . . . . 122

B.2.2 Thermocouple . . . . . . . . . . . . . . . . . . . 123

B.2.3 Heaters . . . . . . . . . . . . . . . . . . . . . 123

B.3 Load Control . . . . . . . . . . . . . . . . . . . . . . . . 124

B.3.1 Load Bank . . . . . . . . . . . . . . . . . . . . . . . . 124

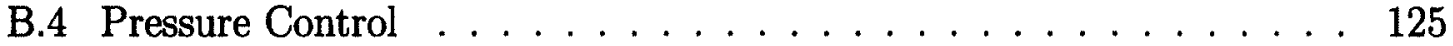

B.4.1 Differential Pressure Transducer . . . . . . . . . . . . . 125

B.4.2 Data Acquisition (DAQ) Card . . . . . . . . . . . 125

Appendix C Pressure Signal Fast Fourier Transform (FFT) Analysis 127

C.1 In-House FE-DMFC Single Cell . . . . . . . . . . . . . . 127

C.2 In-House FE-DMFC Stack . . . . . . . . . . . . . . . . 129

$\begin{array}{ll}\text { Appendix D Uncertainty Analysis } & 131\end{array}$

D.1 Stack Uncertainty Analysis . . . . . . . . . . . . . . . . . . . . 132

D.1.1 List of Elemental Errors . . . . . . . . . . . . . . . . . 132

D.1.2 Estimation of The Elemental Errors . . . . . . . . . . . . 132 
D.1.3 Stack Power Error Analysis _. . . . . . . . . . . . . 135

D.2 Pressure Uncertainty Analysis . . . . . . . . . . . . . . 136

D.2.1 Pressure Measurement Uncertainty Analysis . . . . . . . . 137

D.2.2 Pressure Drop Modelling Uncertainty Analysis . . . . . . . . 138 


\section{List of Tables}

3.1 Density correlation values for liquid methanol and water . . . . . . 42

3.2 Table of constants . . . . . . . . . . . . . . . . . . . . . . 42

3.3 Viscosity correlation values for methanol, water and carbon dioxide - 44

3.4 List of correlation values for $C \ldots \ldots \ldots$. . . . . . . . . 50

3.5 List of acronyms used in pressure drop modelling . . . . . . . . 56

5.1 Electrode percent composition . . . . . . . . . . . . . 90

5.2 POREX specifications . . . . . . . . . . . . . . . 92

A.1 Properties of grade AR-08 graphite plate . . . . . . . . . . . . 119

B.1 Pumping system specifications . . . . . . . . . . . . . . 121

B.2 Rotameter specifications . . . . . . . . . . . . . . . 122

B.3 Air filter specifications . . . . . . . . . . . . . . . . . 122

B.4 Temperature controller specifications . . . . . . . . . . . . . 123

B.5 Thermocouple specifications . . . . . . . . . . . . . . 123

B.6 Heater specifications . . . . . . . . . . . . . . . . . . . . 124

B.7 Load bank specifications . . . . . . . . . . . . . . . . . . 124

B.8 Pressure transducer specifications . . . . . . . . . . . . . . . . . 125

D.1 Elemental error effects on stack current and voltage . . . . . . . . . . 134

D.2 Elemental error effects on pressure measurement across the anode . 138

D.3 Correlation error values for water . . . . . . . . . . . . . . . . 139 


\section{List of Figures}

1.1 Schematic of a DMFC unit . . . . . . . . . . . . 4

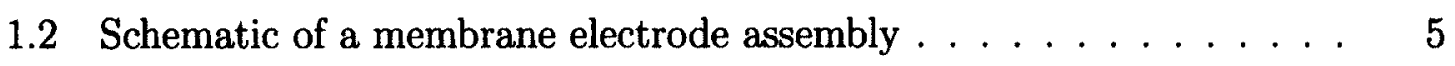

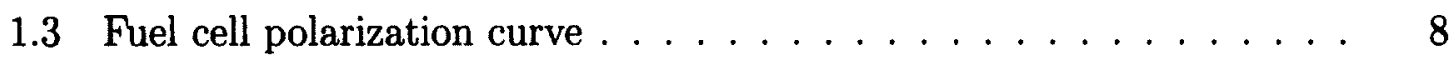

1.4 Different types of stack manifold designs $\ldots \ldots \ldots \ldots \ldots$

1.5 Different types of internal manifold designs . . . . . . . . . . 11

1.6 Schematic of different types of flow regimes . . . . . . . . . . . . 14

2.1 Viscosity-damper arrangements (Field et al.) . . . . . . . . 19

2.2 Schematic of a FE-DMFC unit . . . . . . . . . . . . . 27

3.1 Schematic of the flow bed design $\ldots \ldots \ldots \ldots \ldots \ldots$

3.2 Anode fuel channel control volume $\ldots \ldots \ldots \ldots$

3.3 Gas diffusion layer control volume . . . . . . . . . . . . 33

3.4 Schematic of the in-house FE-DMFC test loop . . . . . . . . . 53

3.5 Views of differential pressure transducer (left) and DAQ card (right) . 54

3.6 Pressure drop versus current density at $1 \mathrm{ml} / \mathrm{min}$ fuel flow rate . . . 57

3.7 Pressure drop versus current density at $5 \mathrm{ml} / \mathrm{min}$ fuel flow rate . . . . 57

3.8 Pressure drop versus current density at $10 \mathrm{ml} / \mathrm{min}$ fuel flow rate $\ldots 58$

3.9 Pressure drop versus current density at $2 \mathrm{ml} / \mathrm{min}$ fuel flow rate . . . 60

3.10 Pressure drop versus current density at $4 \mathrm{ml} / \mathrm{min}$ fuel flow rate . . . 60

3.11 Pressure drop versus current density at various temperatures . . . . 61

3.12 Transient pressure drop vs. current density at $1 \mathrm{ml} / \mathrm{min}$ fuel flow rate 62

3.13 Methanol concentration variations along the fuel channel . . . . . . 64

3.14 Volumetric void fraction variations along the fuel channel . . . . . . 65

3.15 Two-phase pressure drop components along the fuel channel $\ldots . .66$

3.16 Total two-phase pressure variations along the fuel channel $\ldots \ldots 68$

4.1 Schematic of stack fuel channels and manifold configuration . . . . 70

4.2 Stack pressure and flow rate variables . . . . . . . . . . 72

4.3 Pressure drop versus current density at $10 \mathrm{ml} / \mathrm{min}$ fuel flow rate . . 80 
4.4 Pressure drop versus current density at $15 \mathrm{ml} / \mathrm{min}$ fuel flow rate . . 80

4.5 Transient pressure drop vs. current density at $10 \mathrm{ml} / \mathrm{min}$ fuel flow rate 81

4.6 Methanol concentration profile variations within stack outlet manifold 83

4.7 Volumetric void fraction variations within stack outlet manifold ... 84

4.8 Cell inlet flow rate variations within the stack . . . . . . . . 85

4.9 Stack overall pressure distributions at various current densities . . . 86

5.1 FE-DMFC current collectors . . . . . . . . . . . . . 88

5.2 FE-DMFC flow distribution plate $\ldots \ldots \ldots \ldots \ldots \ldots$

5.3 Three-dimensional solid model views of the graphite plates . . . . . 89

5.4 Membrane electrode assembly used in FE-DMFC stack . . . . . . 90

5.5 Viton gasket (left) and PTFE tape (right) used in FE-DMFC stack . 91

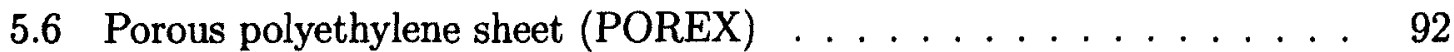

5.7 Heat press instrument for MEA fabrication . . . . . . . . . . 93

5.8 Three-dimensional solid model view of the stack bi-polar plate . . . . 94

5.9 Half-cell assembly . . . . . . . . . . . . . . . . . 95

5.10 Full stack assembly $\ldots \ldots \ldots \ldots \ldots \ldots \ldots$

5.11 Schematic of the experimental setup $\ldots \ldots \ldots \ldots 97$

5.12 Experimental setup . . . . . . . . . . . . . . . . . 97

5.13 Polarization/power curve variations with temperature $\ldots \ldots \ldots 100$

5.14 Polarization/power curve variations with methanol concentration . . . 101

5.15 Polarization/power curve variations with methanol solution flow rate 102

5.16 Polarization/power curve variations with flowing electrolyte flow rate 103

5.17 Polarization/power curve variations with air flow rate . . . . . . . 104

5.18 Stack voltage distributions at various operating currents . . . . . 105

5.19 Stack temperature distribution . . . . . . . . . . . . . 106

5.20 Stack startup/shutdown curves at various operating currents . . . . 107

A.1 Three view drawings of the bi-polar plate . . . . . . . . . . 120

C.1 FE-DMFC single cell frequency spectrums at various currents $\ldots \ldots 128$

C.2 FE-DMFC stack frequency spectrums at various currents . . . . . 129 


\section{Nomenclature}

\begin{tabular}{ll}
\hline Acronym & Description \\
\hline DC & Direct Current \\
AC & Alternating Current \\
SOFC & Solid Oxide Fuel Cell \\
MCFC & Molten Carbonate Fuel Cell \\
PAFC & Phosphoric Acid Fuel Cell \\
AFC & Alkaline Fuel Cell \\
PEMFC & Proton Exchange Membrane Fuel Cell \\
DMFC & Direct Methanol Fuel Cell \\
FE-DMFC & Flowing Electrolyte Direct Methanol Fuel Cell \\
MEA & Membrane Electrode Assembly \\
GDL & Gas Diffusion Layer \\
PEM & Polymer Electrolyte Membrane \\
MOR & Methanol Oxidation Reaction \\
ORR & Oxygen Reduction Reaction \\
CFD & Computational Fluid Dynamics \\
\hline
\end{tabular}




\begin{tabular}{|c|c|}
\hline Acronym & Description \\
\hline $\mathrm{FE}$ & Flowing Electrolyte \\
\hline SPE & Solid Polymer Electrolyte \\
\hline ABL & Anode Backing Layer \\
\hline $\mathrm{ACL}$ & Anode Catalyst Layer \\
\hline NIST & National Institute of Standards and Technology \\
\hline $\mathrm{OCV}$ & Open Circuit Voltage \\
\hline $\mathrm{S}$ & Systematic Error \\
\hline $\mathrm{R}$ & Random Error \\
\hline e & Uncertainty \\
\hline \multirow[t]{2}{*}{$\mathrm{H}$} & Homogenous Model (Pressure) \\
\hline & Homogenous Model (Void Fraction) \\
\hline \multirow[t]{2}{*}{$\mathrm{MD}$} & Lockhart-Martinelli Model (Pressure) \\
\hline & Drift Flux Model (Void Fraction) \\
\hline \multirow[t]{2}{*}{ MM } & Lockhart-Martinelli Model (Pressure) \\
\hline & Lockhart-Martinelli Model (Void Fraction) \\
\hline \multirow[t]{2}{*}{$\mathrm{MC}$} & Lockhart-Martinelli Model (Pressure) \\
\hline & CISE Model (Void Fraction) \\
\hline
\end{tabular}




\begin{tabular}{ll}
\hline Dimensional Parameters & Description \\
\hline$E^{o}$ & Reaction potential $[\mathrm{V}]$ \\
$E_{r e v}$ & Cell reversible potential $[\mathrm{V}]$ \\
$\bar{g}$ & Molar Gibbs free energy $[\mathrm{J} / \mathrm{mol}]$ \\
$F$ & Faraday's constant $[$ A.s $/ \mathrm{mol}]$ \\
$T$ & Temperature $\left[{ }^{\circ} \mathrm{C}\right]$ \\
$P$ & Pressure $[\mathrm{Pa}]$ \\
$V$ & Volume $\left[\mathrm{m}^{3}\right]$ \\
$E$ & Helmholtz free energy $[\mathrm{J}]$ \\
$A$ & Area $\left[\mathrm{m}^{2}\right]$ \\
$\sigma$ & Surface tension $[\mathrm{N} / \mathrm{m}]$ \\
$\rho$ & Density $\left[\mathrm{kg} / \mathrm{m}^{3}\right]$ \\
$\mu$ & Viscosity $[\mathrm{kg} / \mathrm{m} . \mathrm{s}]$ \\
$d_{h}$ & Hydraulic diameter $[\mathrm{m}]$ \\
$V_{s}$ & Mixture velocity $[\mathrm{m} / \mathrm{s}]$ \\
$L$ & Channel length $[\mathrm{m}]$ \\
$W$ & Channel width $[\mathrm{m}]$ \\
$M_{i}$ & Mass flow rate $[\mathrm{kg} / \mathrm{s}]$ \\
$C_{i}$ & Molecular weight of species i $[\mathrm{gr} / \mathrm{mol}]$ \\
\hline & Oxidation reaction current $[\mathrm{A}]$ \\
\hline & Current density $\left[\mathrm{A} / \mathrm{m}^{2}\right]$ \\
\hline & Diffusion coefficient of species i $\left[\mathrm{m}^{2} / \mathrm{s}\right]$ \\
\hline & Concentration of species i $\left[\mathrm{mol} / \mathrm{m}^{3}\right]$ \\
\hline & \\
\hline & Thickness $[\mathrm{m}]$ \\
\hline & \\
\hline &
\end{tabular}




\begin{tabular}{ll}
\hline Dimensional Parameters & Description \\
\hline$Q$ & Volume flow rate $\left[\mathrm{m}^{3} / \mathrm{s}\right]$ \\
$G$ & Total mass flux $\left[\mathrm{kg} / \mathrm{m}^{2} . \mathrm{s}\right]$ \\
$A_{\text {cross }}$ & Channel cross-sectional area $\left[\mathrm{m}^{2}\right]$ \\
$R$ & Universal gas constant $[\mathrm{J} / \mathrm{mol.K}]$ \\
$U$ & Superficial velocity $[\mathrm{m} / \mathrm{s}]$ \\
$g$ & Gravitational acceleration $\left[\mathrm{m} / \mathrm{s}^{2}\right]$ \\
$\Delta h$ & Vertical displacement $[\mathrm{m}]$ \\
$R$ & Bend radius $[\mathrm{m}]$ \\
\hline
\end{tabular}




\begin{tabular}{|c|c|}
\hline Dimensionless Parameters & Description \\
\hline$n$ & Number of electrons \\
\hline$\alpha$ & Volumetric void fraction \\
\hline$N$ & Number of molecules \\
\hline$R e$ & Reynolds number \\
\hline$x$ & Mixture quality \\
\hline$X$ & Lockhart-Martinelli parameter \\
\hline$\phi$ & Pressure multiplier \\
\hline$C$ & Interaction parameter \\
\hline$\lambda$ & Fluid constant \\
\hline$\psi$ & Fluid constant \\
\hline$W e$ & Weber number \\
\hline$z$ & Reaction area correction factor \\
\hline$\varepsilon$ & Porosity \\
\hline$\chi$ & Methanol molar fraction \\
\hline$n_{d}$ & Electro-osmotic drag coefficient \\
\hline$\lambda^{*}$ & Membrane water content \\
\hline$C_{o}$ & Distribution factor \\
\hline$a$ & Channel cross-section aspect ratio \\
\hline$S$ & Slip ratio \\
\hline$C_{f}$ & Friction parameter \\
\hline$K$ & Pressure loss factor \\
\hline$Z$ & Form pressure factor \\
\hline$\Psi$ & Form pressure parameter \\
\hline$N_{\mathrm{p}}$ & Number of nodes \\
\hline
\end{tabular}




\begin{tabular}{ll}
\hline Dimensionless Parameters & Description \\
\hline$f$ & Friction factor \\
$\eta$ & Normalized pressure parameter \\
$\xi$ & Convergence limit \\
\hline
\end{tabular}

xviii 


\begin{tabular}{|c|c|}
\hline List of Subscripts & Description \\
\hline anode & Anode side \\
\hline cathode & Cathode side \\
\hline rev & Reversible \\
\hline$l$ & Liquid phase \\
\hline$g$ & Gaseous phase \\
\hline$a v g$ & Average \\
\hline lo & Liquid only \\
\hline laminar & Laminar regime \\
\hline turbulent & Turbulent regime \\
\hline me & Methanol \\
\hline$w$ & Water \\
\hline $\mathrm{CO}_{2}$ & Carbon dioxide \\
\hline$d i f$ & Amount diffused \\
\hline cons & Amount consumed \\
\hline crossover & Amount crossed-over \\
\hline gen & Amount generated \\
\hline cons - dif & Concentration diffusion \\
\hline$d r a g$ & Electro-osmotic drag \\
\hline mem & Membrane \\
\hline$C h$ & Fuel channel \\
\hline inlet & Inlet section \\
\hline outlet & Outlet section \\
\hline sat & Saturated \\
\hline
\end{tabular}

xix 


\begin{tabular}{ll}
\hline List of Subscripts & Description \\
\hline$r e f$ & Reference \\
$t p$ & Two phase \\
grav & Gravitational \\
acc & Acceleration \\
fric & Frictional \\
form & Form \\
$M$ & Stack manifolds \\
$C$ & Cell channels \\
in & Inlet \\
out & Outlet \\
sol & Solution \\
std & Standard deviation \\
cor & Correction \\
new & New value \\
$V$ & Voltage \\
$I$ & Current \\
$P$ & Power \\
\hline
\end{tabular}




\section{Chapter 1}

\section{Introduction}

\section{$1.1 \quad$ Fuel Cell Technology}

A fuel cell is an electrochemical energy conversion device [1]. It converts the chemical energy of its fuel into electricity and heat through a chemical reaction with oxygen or another oxidizing agent. The other familiar electrochemical device is the battery. In fact, fuel cells and batteries follow the same electrochemical principle, however; unlike batteries, the fuel cell does not store its chemicals (fuel) within the housing but can work continuously as long as fuel is supplied $[1,2]$.

Nowadays, various types of fuel cell technologies exist in the market. They all consist of an anode (negative side), a cathode (positive side) and an electrolyte which allows charges to move between the anode and cathode compartments. The fuel is usually pumped through the anode compartment where it participates in an oxidation reaction to produce electrons, protons and other by-products such as carbon dioxide. An external circuit is used to draw the electrons from the anode to the cathode, producing direct current (DC) electricity. Protons on the other hand, travel internally through the electrolyte to reach the cathode compartment, where they participate in a reduction reaction with oxygen and electrons to form water [3]. The overall fuel cell reaction is the summation of the two redox (oxidation/reduction) reactions. The redox reactions occur with the aid of catalysts and at elevated operating temperatures $[4,5]$.

Fuel cells can produce high quality electricity at high electrical efficiencies. The performance of the fuel cell is defined by its output voltage at a given operating current [3]. 


\subsubsection{Types of Fuel Cells}

Depending on the electrolyte type and operating temperature, five different types of fuel cells exist. These are: the solid oxide fuel cell (SOFC), molten carbonate fuel cell (MCFC), phosphoric acid fuel cell (PAFC), alkaline fuel cell (AFC), and proton exchange membrane fuel cell (PEMFC). A brief description of each fuel cell type is described below:

SOFC: This type of fuel cell has the highest operating temperature among the various kinds of fuel cells, which ranges from 600 to $1000^{\circ} \mathrm{C}$, allowing a number of fuels to be used. The electrolyte consists of a solid, nonporous metal oxide (ceramic) and conducts oxygen ions. Their operating efficiency in generating electricity is among the highest. In addition, the high operating temperature of SOFCs enables them to tolerate relatively impure fuels, such as those obtained from the gasification of coal or gases from industrial processes and other sources. On the other hand, the high operating temperatures require more technologically advanced and therefore, expensive materials for constructing a SOFC unit $[4,5]$.

MCFC: Similar to the SOFC, the MCFC operates at high temperatures (600 to $700^{\circ} \mathrm{C}$ ), which results in fast electrode kinetics and no need for noble metals as a catalyst. The electrolyte is usually a combination of alkali carbonates, which are immobilized in a ceramic matrix of lithium aluminate. The melting point of the electrolyte is approximately $480^{\circ} \mathrm{C}$ and therefore, a highly conductive molten salt with carbonate ions as charge carriers is formed at the operating temperature. The high-grade heat makes the MCFC suitable for stationary applications and for the usage by utilities $[4,5]$.

PAFC: The electrolyte of the PAFC consists of concentrated phosphoric acid, which is held typically at an operating temperature of $195^{\circ} \mathrm{C}$. This operating temperature allows to compensate for the relatively poor ionic conduction of phosphoric acid and to tolerate impurities in the hydrogen gas $[4,5]$.

AFC: The AFC features high specific power and energy density when used as hydrogen/oxygen $\left(\mathrm{H}_{2} / \mathrm{O}_{2}\right)$ fuel cell. In addition, less cost-intensive catalysts such as, Ag-based catalysts could be used. However, the choices on fuels and 
oxidants are limited to those that do not contain and produce carbon dioxide $\left(\mathrm{CO}_{2}\right)$, since concentrated potassium hydroxide is used as the electrolyte. This is because potassium hydroxide does not reject $\mathrm{CO}_{2}$. As a result, the AFC usually operates on $\mathrm{H}_{2} / \mathrm{O}_{2}$, which, in principle, restricts its range of possible applications $[4,5]$.

PEMFC: The PEMFC is probably the most commonly used type of fuel cell. It consists of a proton-conducting membrane, which requires sorbed water to achieve adequate conductivities. Therefore, the operating temperature is usually limited to less than $120^{\circ} \mathrm{C}$. Because of the relatively low operating temperatures, noble metal catalysts are required and the carbon monoxide tolerance of the PEMFC is very limited. The direct methanol fuel cell (DMFC), directly converts methanol (fuel) together with oxygen (oxidant) to electricity. The DMFC is usually based on the PEMFC, i.e., in principle the cell assembly is the same $[4,5]$.

\subsection{Direct Methanol Fuel Cells}

As mentioned earlier, proton exchange membrane fuel cells (PEMFCs) operate at low temperatures (around $80^{\circ} \mathrm{C}$ ), and use a solid proton-conducting membrane as the electrolyte. These fuel cells have a high theoretical efficiency, quick startup capability, and relatively small toxic emissions.

The direct methanol fuel cell (DMFC) is a type of PEMFC which uses liquid methanol as fuel. It is an attractive energy technology for applications in portable electronic systems. This is partly due to the fact that, methanol is an energy dense fuel with a gravimetric power density that is at least double that of hydrogen [1]. Additionally, methanol is much easier and safer to store than compressed hydrogen. These characteristics along with low operating temperature, lend to portability since methanol does not require bulky storage capsules. A light-weight and compact DMFC that operates at relatively low temperatures, with easy refueling process, can be a promising energy conversion technology in the future with benefits far exceeding the conventional batteries $[4,5]$. 


\subsubsection{DMFC Components}

A schematic of a DMFC is shown in Figure 1.1. The fuel for the cell is an aqueous methanol solution while the oxidant is oxygen, provided in the form of air or pure oxygen. A regular DMFC unit is made from two bipolar plates, or flow distribution plates, and a single membrane electrode assembly (MEA).

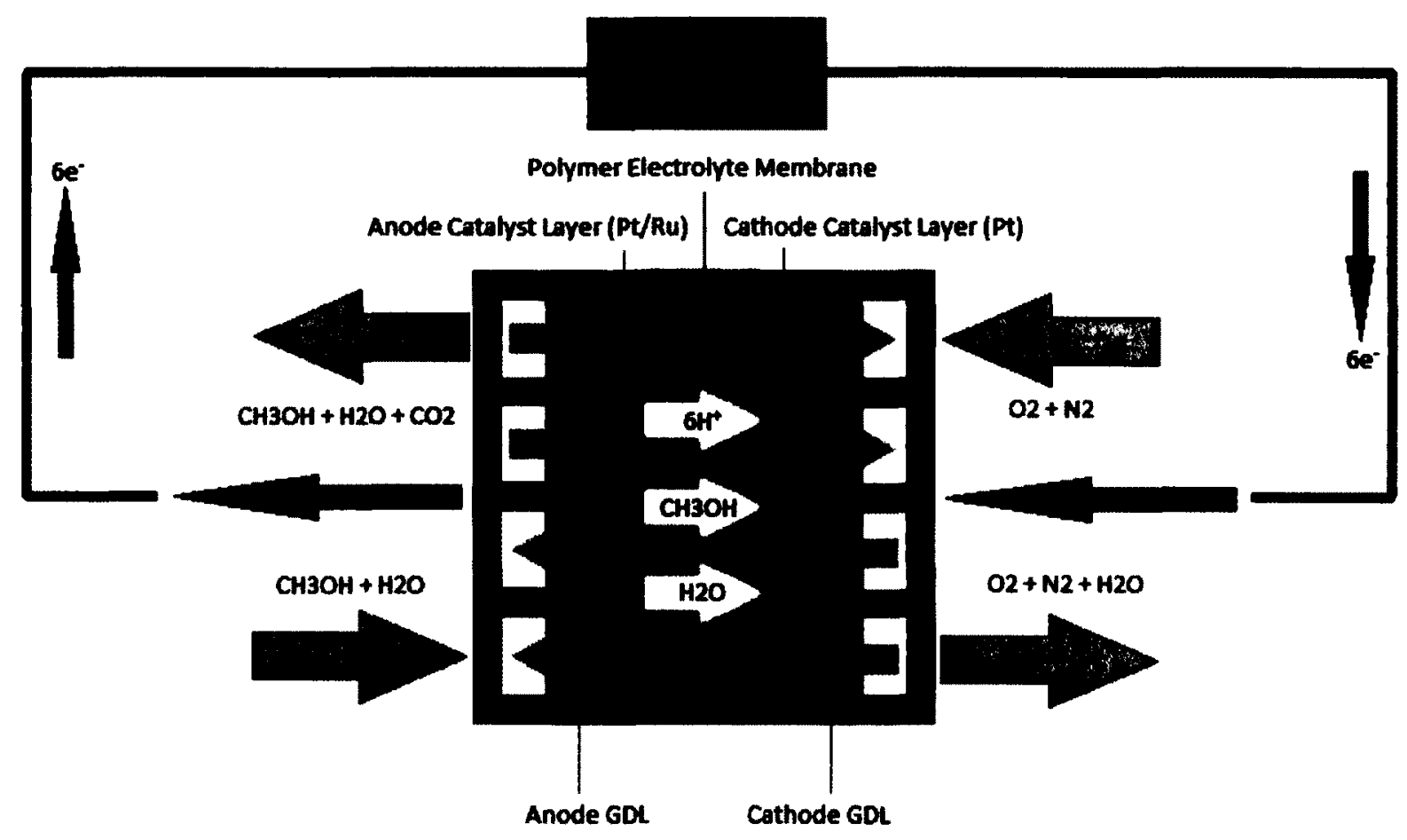

Figure 1.1: Schematic of a DMFC unit

The function of the bipolar plates is to deliver the cathode and anode reactant flows through their respective channels while also allowing for current conduction away from the reaction surfaces. For this reason, the plates are made from an electrically conductive material, typically graphite or metal. The flow channel is rectangular and is approximately $1 \mathrm{~mm}$ in width and depth, or smaller. The channel layout has a number of common configurations, including serpentine, interdigitated, and parallel. The channels are laid out in a manner so as to ensure that the reactants will be distributed evenly over the reaction surfaces [6]. 
The electrochemical reaction, which generates the electricity extracted from the fuel cell, occurs within the MEA. The MEA consists of five layers: two gas diffusion layers (GDLs), or porous electrodes, two catalyst layers, and a polymer electrolyte membrane (PEM) layer, as illustrated in Figure 1.2. While the catalyst and electrolyte layers are almost always attached to one another, the GDL can be fastened or is frequently provided as a separate entity within the cell [6].

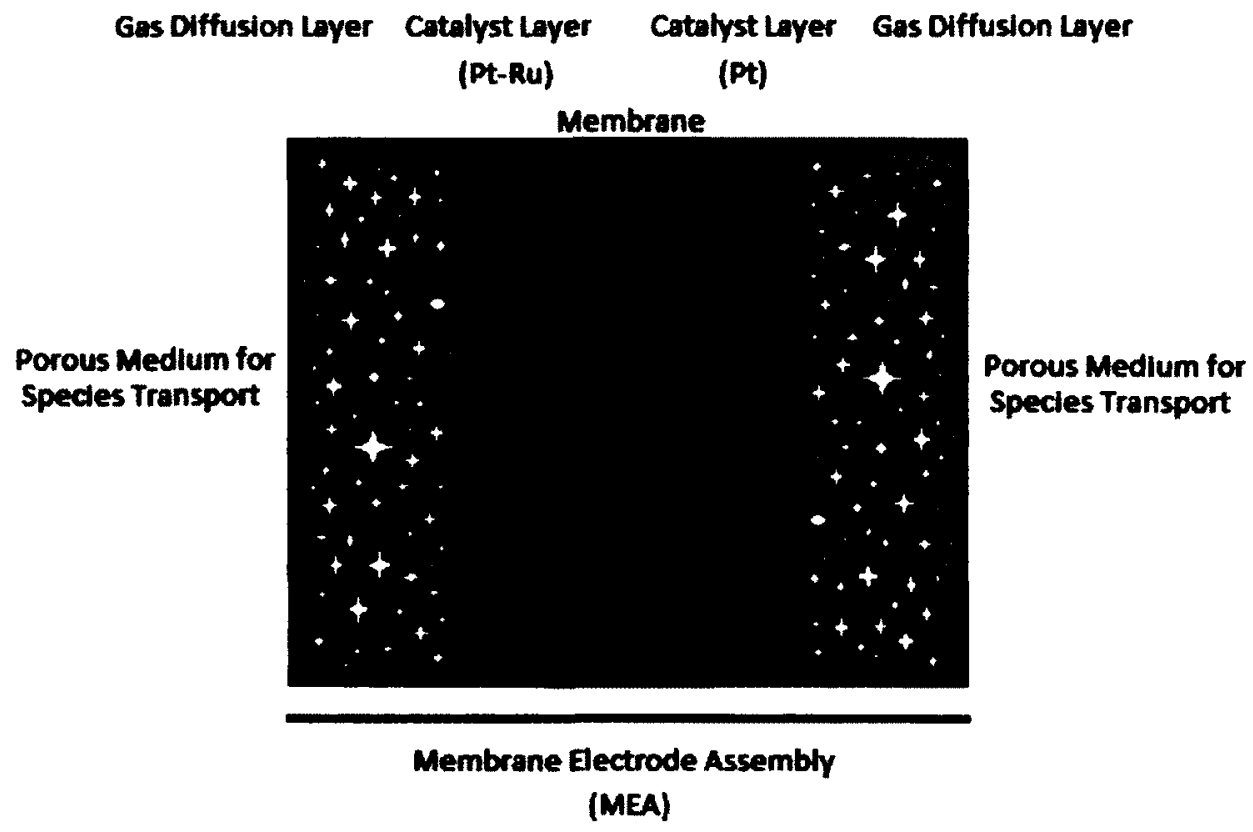

Figure 1.2: Schematic of a membrane electrode assembly

The gas diffusion layers, as the name suggests, facilitate mass transfer from the flow channel to the catalyst layer (the reaction site). In addition, the GDL is the electrical conductor that transports electrons to and from the catalyst layer. Typically, diffusion layers are constructed from porous carbon paper, or carbon cloth, with a thickness in the range of 100 to $300 \mu \mathrm{m}$ [2]. They also assist in gas management by draining out the generated $\mathrm{CO}_{2}$ from the anode catalyst layer to anode flow channels. The GDL layers are typically designed to be hydrophobic and are treated with a polytetrafluoroethylene (PTFE or Teflon) coating to ensure that, the pores of the GDL do not become congested with liquid water [6]. 
The catalyst layer is made from a carbon film laced with platinum-ruthenium (Pt$\mathrm{Ru})$ for the anode side and platinum $(\mathrm{Pt})$ for the cathode side. The platinum loading is typically below $0.4 \mathrm{mgPt} / \mathrm{cm}^{2}$, with values reported as low as $0.014 \mathrm{mgPt} / \mathrm{cm}^{2}$ attained through the use of sputtering techniques [7].

The anode and cathode catalyst layers are divided by the polymer electrolyte membrane (PEM). The polymer electrolyte membrane facilitates the transfer of the positive ions from the anode to the cathode, and is made of a sulphonated fluoropolymer similar to Teflon. It also serves as a barrier to the transfer of electrons, which are forced away from the anode catalyst layer, through the current collection pathway, to the cathode catalyst layer [2]. In order for proton conduction to occur, the membrane layer must be hydrated. The hydrogen protons become mobile only after bonding to water molecules, becoming hydronium ions. Hydronium ions are then capable of moving between the sulphonic acid sites, through the membrane. The most commonly employed polymer electrolyte membrane is Nafion ${ }^{\circledR}$, manufactured by DuPont $[5,7]$.

The net fuel cell reaction occurs in two parts inside the reaction sites at the anode and cathode catalyst layers. The reactions at these sites are referred to as "half-cell reactions". The anode reaction is the oxidation of a methanol molecule into hydrogen protons, electrons, and carbon dioxide gas as illustrated below [5]:

$$
\mathrm{CH}_{3} \mathrm{OH}_{(l)}+\mathrm{H}_{2} \mathrm{O}_{(l)} \rightarrow \mathrm{CO}_{2(g)}+6 \mathrm{H}^{+}+6 e^{-} \quad E_{\text {anode }}^{o}=0.02 \mathrm{~V}
$$

Following the methanol oxidation reaction (MOR), the hydrogen protons are transported through the electrolyte layer, while the electrons are forced to travel through an external electrical circuit. At the cathode reaction site, an oxygen molecule is reduced to produce a water molecule. This half-cell reaction is referred to as the oxygen reduction reaction (ORR) [5]:

$$
\frac{3}{2} \mathrm{O}_{2(g)}+6 \mathrm{H}^{+}+6 e^{-} \rightarrow 3 \mathrm{H}_{2} \mathrm{O}_{(l)} \quad E_{\text {cathode }}^{o}=1.23 \mathrm{~V}
$$

The combination of the two half-cell reactions, the MOR and the ORR, results in the overall DMFC reaction [5]:

$$
\mathrm{CH}_{3} \mathrm{OH}_{(a q)}+\frac{3}{2} \mathrm{O}_{2(g)} \rightarrow 2 \mathrm{H}_{2} \mathrm{O}_{(l)}+\mathrm{CO}_{2(g)}+\mathrm{Heat} \quad E_{D M F C}^{o}=1.21 \mathrm{~V}
$$




\subsubsection{Polarization Curve}

The reversible cell potential for the full cell reaction is $1.21 \mathrm{~V}$ [4]. This reversible potential corresponds to the ideal case where there are no losses in the system, and can be determined as a function of Gibbs free energy, as illustrated in the following equation [8]:

$$
E_{\text {rev }}=-\frac{\Delta \bar{g}(P, T)}{n F}
$$

where $E_{\text {rev }}$ is the cell reversible potential, $\Delta \bar{g}(P, T)$ is the Gibbs free energy at certain pressure and temperature, $n$ is the number of exchanged electrons and $F$ is the Faraday constant.

In reality, due to the presence of a number of irreversibilities, the cell does not operate at this reversible potential. Figure 1.3 illustrates a comparison between the cell's reversible potential and the actual potential, or polarization curve, of a typical DMFC. It can be seen that, the actual potential is a function of the current drawn, or current density, while the reversible potential is independent of the current density, and remains constant over the entire domain [8].

As current is initially drawn, in the low current density portion of the curve, losses are due to activation overpotential. This overpotential is caused by the slow moving reactions on the electrode surfaces. Since these reactions do not occur readily, a proportion of the voltage generated is lost as these electrochemical reactions are driven from equilibrium. This voltage drop, as illustrated in Figure 1.3, is highly non-linear [9].

As the electrical current load increases, activation overpotential is less of a factor and ohmic losses increase at a greater rate. In this situation, the curve enters the region characterized by ohmic overpotential. This voltage loss is caused by the resistance to the flow of electrons through the electrode material and the various connections in the current collection pathway, as well as, the resistance to the flow of ions through the electrolyte. These losses are proportional to current density and are essentially linear $[2,8]$. 


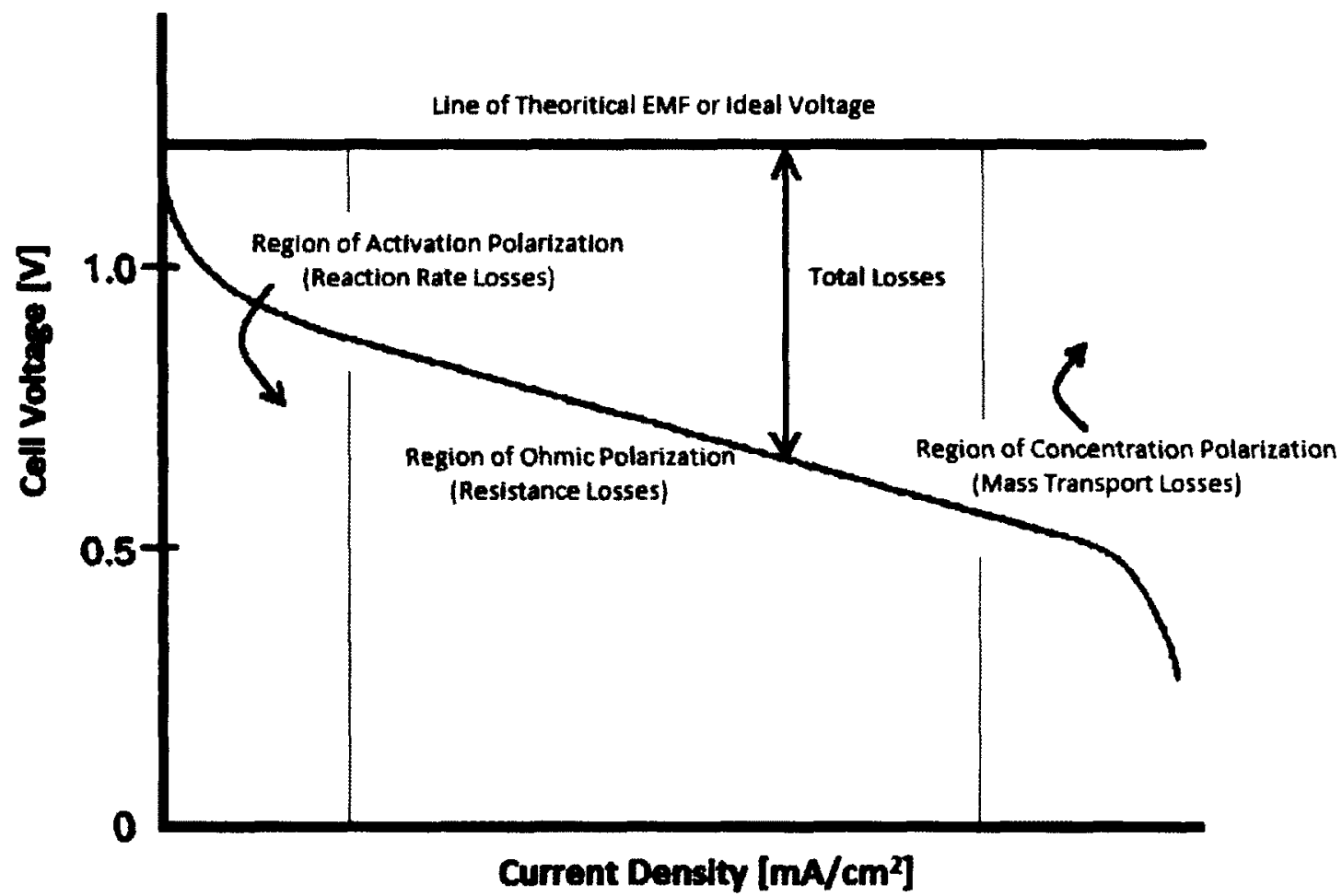

Figure 1.3: Fuel cell polarization curve

The high current density voltage losses in the cell, can be mainly attributed to concentration overpotential. This rapid voltage drop is caused by the depletion of the reactants in the vicinity of the catalyst layers, as mass transport is limited. The mass transport limitations are due to diffusion limitations in the electrode backing and catalyst layers, and the phenomena of water flooding. At high current densities, the amount of water produced at the cathode catalyst layer, is greater than the amount that can be removed by the flow moving through the flow channels. The accumulation of liquid water in the porous diffusion layer limits the amount of oxygen that can reach the reaction surfaces, effectively choking the ORR $[2,9]$.

\subsection{Direct Methanol Fuel Cell Stack}

A single DMFC can only offer a voltage of approximately 0.6 to $1.0 \mathrm{~V}$. In order to sufficiently increase the voltage output for practical applications, many single cells are serially connected to form a DMFC stack [10]. 
In a typical DMFC stack, the individual cells are connected thermally and electrically in series. The reactants (fuel and oxidant) are supplied to the unit cells through a complex network of manifolds and cell channels. Generally, two input manifolds supply the DMFC stack with fuel (aqueous methanol solution) and oxidant (air or pure oxygen). Once the fuel and oxidant streams are passed through the stack individual cell channels, two output manifolds collect the reaction by-products (carbon dioxide and water), and direct them towards the stack outlet [10].

\subsubsection{Types of Manifold Systems}

In order to deliver the reactants into the individual cells of the stack, two types of manifold systems are utilized: internal and external. In the internal manifold design, reactants are distributed by means of a central channel which pass through all the individual cells; whereas, in the external manifold design, the reactants are delivered separately to every individual cell, via external channels [11].

The external manifold design is simpler and less expensive; however, its major drawback is the issue of leakage and sealing. The internal manifold design on the other hand, does not have the leakage problem since it is often embedded inside the stack unit and thus, the sealing is consistent. In general, many small-scale fuel cell stacks with low reactant flow rates utilize the internal manifold design [11].

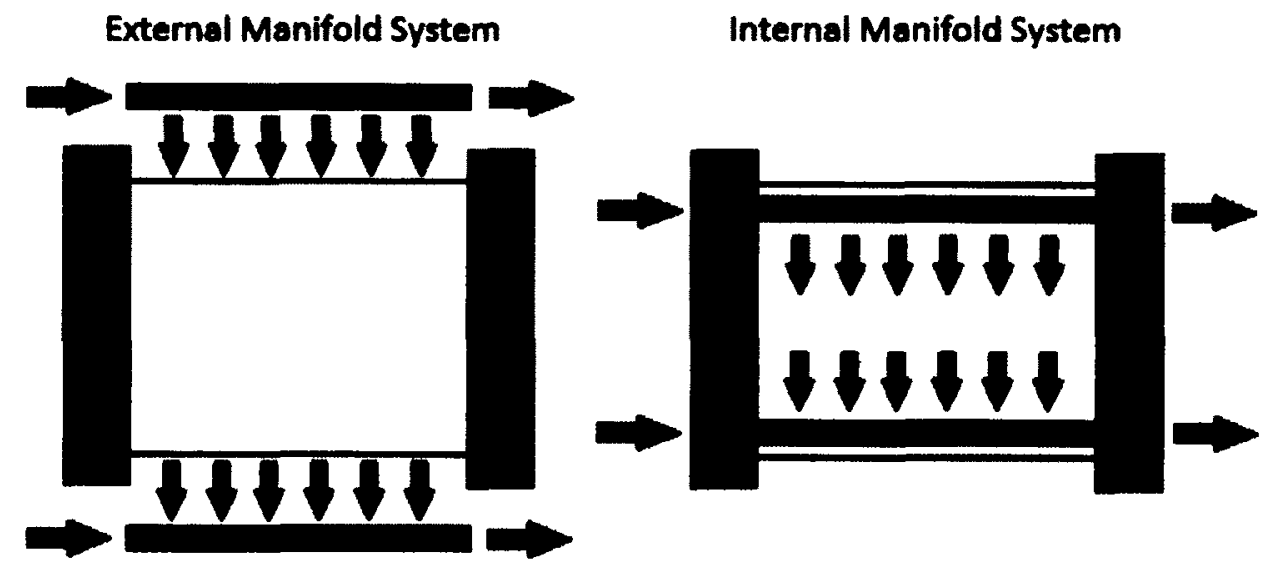

Figure 1.4: Different types of stack manifold designs 


\subsubsection{Reactant Flow Configurations}

As mentioned earlier, many individual fuel cell units are clustered together to form a stack. The unit cells are normally connected in series to provide a useful stack output voltage. Every fuel cell stack, requires a reactant distribution system in order to supply fresh reactants to the unit cells and subsequently, remove the reaction byproducts from the unit cells. In every stack unit, the configuration of the reactant flow is one of the key design aspects since the supply of reactants and the removal of reaction by-products have a significant impact on the stack operation and performance. In fact, the gas flow configuration has to be carefully chosen and optimized with respect to the requirements of a certain application in order to provide an efficient and uniform operation of unit cells within the fuel cell stack [10].

In general, there are three possible reactant flow arrangements in a fuel cell stack:

1. A parallel reactant flow configuration where each cell is supplied with identical input reactant streams;

2. A serial reactant flow configuration where the output flow of one cell is utilized as input reactant flow of the downstream cell;

3. A mixed reactant flow configuration where some cells are installed in a parallel, and some cells are installed in a serial reactant flow arrangement.

Most fuel cell stacks with medium and high power outputs are based on parallel gas flow configuration where, the stack inlet reactant stream is divided into relatively identical streams that are fed to the individual cells. One inevitable problem when using such flow configuration is the flow maldistribution. In order to reduce or even completely eliminate this issue, a serial reactant flow configuration is applied; however, this type of flow configuration also has its own shortcomings. For instance, since the reactants have to travel in long pathways to reach every individual cell, higher flow rates and thus, pressure drops are inevitable [10].

There are two types of parallel reactant flow configurations. The U-type or reverse flow, where the outlet reactants flow in opposite direction to the inlet reactants, and the Z-type or parallel flow, where both inlet/outlet reactant flow streams have the same direction, as shown in Figure 1.5. In both arrangements, the flow streams 
through the manifolds are perpendicular to the flow streams through the cell channels [10].
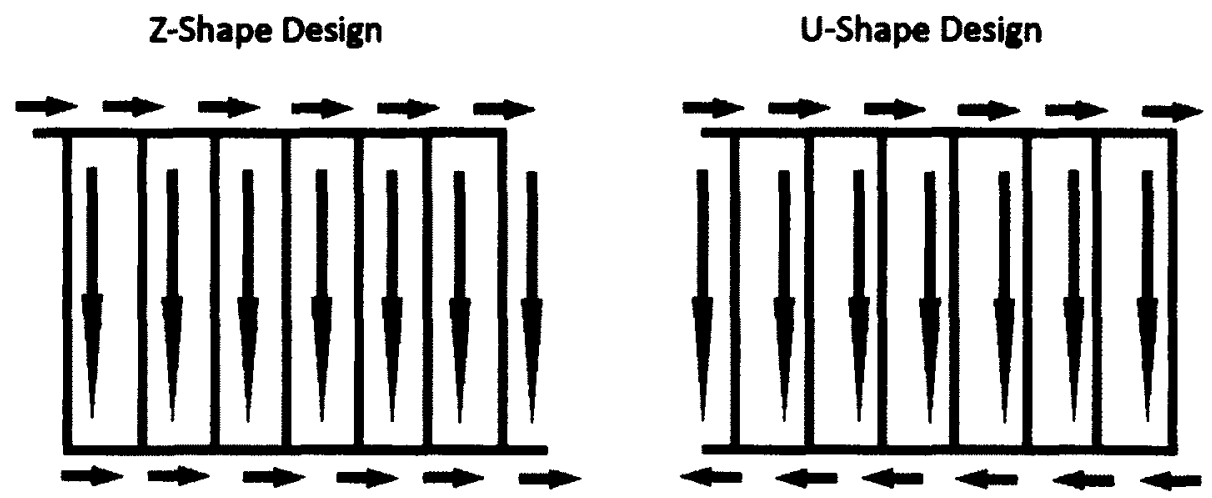

Figure 1.5: Different types of internal manifold designs

In addition to manifold configuration, the flow distribution in a fuel cell stack is also influenced by geometrical considerations and operating conditions. The geometrical design parameters usually include: manifold structure, manifold size, number of manifolds, reactant channel size, number of reactant channels and flow resistance. The operating conditions include: the feed reactant flow rate, types of reactants, stoichiometry of the air stream, temperature and operating current density [10].

\subsection{Challenges with Direct Methanol Fuel Cells}

DMFC performance is generally affected by three main problems [4]:

1. Slow anodic oxidation reaction due to carbon monoxide $(\mathrm{CO})$ poisoning of the anode catalyst;

2. High methanol permeation from the anode to the cathode side (methanol crossover);

3. Obstruction of the fuel flow at the anode fuel channels by carbon dioxide $\left(\mathrm{CO}_{2}\right)$. 


\subsubsection{CO Poisoning}

One stable intermediate species that is formed during the electro-oxidation of methanol, is carbon monoxide. It reduces the overall amount of active catalytic reaction surfaces by clinging to platinum catalysts and thus, poisoning the anode [12]. In order to maintain the high reaction kinetics at the anode, carbon monoxide must be removed from the reaction sites. One solution is to add ruthenium to the platinum catalyst. This is due to the fact that, ruthenium forms powerful hydroxyl radicals with water which can then oxidize the produced carbon monoxide and free up the catalytic sites. Different studies have also shown that high operating temperatures reduce the amount of carbon monoxide poisoning at the anode [13]. The effects of methanol crossover and carbon dioxide management at the anode are described in the following sections.

\subsubsection{Methanol Crossover}

As mentioned earlier, one major function of the electrolyte membrane is to physically separate the anode and cathode compartments in order to prevent the anode fuel from directly contacting the cathode and thus, getting oxidized. In reality, most available membranes are good proton conductors but not very efficient as fuel separators. For instance, the Nafion ${ }^{\circledR}$ membrane, which is one of the most commonly used membranes for DMFCs, has poor water uptake and methanol permeation characteristics [14-16].

The mechanical strength of the membrane is compromised by water uptake. It causes unmanageable swelling and contraction of the membrane material which in return, exerts excessive amounts of stress to the membrane structure and promotes methanol transport from the anode to the cathode compartment $[14,16]$.

Due to the high concentration of methanol molecules at the anode, methanol tends to go through the membrane and thus contact the cathode. The transport of methanol molecules from the anode compartment to the cathode compartment is called "methanol crossover". This phenomenon not only causes parasitic fuel loss, but also results in a short circuit within the DMFC unit. This is because the electrons generated by the oxidation reaction at the cathode do not follow the current path 
between the electrodes and as a result, the cell voltage drops. In addition, the crossedover methanol molecules contaminate the catalyst site at the cathode and change its structure. Electro-osmotic drag and diffusion are the two main mechanisms which facilitate the methanol crossover through the membrane $[17,18]$.

During DMFC operation, the transfer of hydrated protons from the anode to the cathode side (through the membrane) tends to drag water and methanol molecules along. This phenomenon, termed electro-osmotic drag of water/methanol, results in water/methanol accumulation at the cathode side. In addition, the diffusion of methanol molecules through the membrane, is derived by the concentration gradient of methanol between the anode and cathode compartments. It is also important to note that, the rates of methanol electro-osmotic drag and diffusion through the membrane increase with temperature $[17,19]$.

\subsubsection{Gas Management}

When methanol is oxidized at the anode catalyst layer, carbon dioxide $\left(\mathrm{CO}_{2}\right)$ gas is generated, which diffuses back to the anode fuel channels and form a two-phase flow regime. Depending on the operating current density, various types of two-phase flow patterns can exist inside the fuel channels. It has been experimentally verified that, when the fuel cell operates at small current densities, $\mathrm{CO}_{2}$ generation rate is relatively small and thus, a uniform mixture of $\mathrm{CO}_{2}$ bubbles and methanol solution is formed. As the operating current density increases, more methanol is consumed (oxidized) and thus, $\mathrm{CO}_{2}$ generation rate becomes significant compared to the methanol solution flow rate within the fuel channels. This situation often leads to the formation of "slug/plug" flow regime inside the fuel channels. This type of flow regime, potentially requires higher pressure loadings from the fuel pump and, hinders the incoming methanol molecules to effectively reach the anode catalyst sites, and reduces the overall fuel cell performance [20-22].

In order to address the gas management problem within the DMFC anode fuel channels, the flow and pressure distributions have to be investigated with accurate modelling and experimental techniques to find the optimal channel geometry and methanol solution flow rate for effective removal of $\mathrm{CO}_{2}$ gas from the system. The 
following section, provides a brief background regarding the key aspects of the twophase flow modelling in DMFCs.

\subsection{DMFC Hydrodynamics}

One important aspect in describing the gas-liquid phase flow within a system, is the "respective distribution" of liquid and gas phases. Depending on the fuel cell operating current density, two types of flow structures may form inside the anode fuel channels:

Bubbly Flow: The bubbly flow regime is observed when the fuel cell is operating at small current densities and when the $\mathrm{CO}_{2}$ generation rate is small, compared to methanol solution flow rate. In this type of flow, the gas phase is dispersed in the form of discrete bubbles in the continuous liquid phase. The bubbles have spherical shape and their diameter is much smaller than the channel width (Figure 1.6) $[12,22]$.

Slug/Plug Flow: This type of flow pattern is mainly observed at higher operating current densities when the $\mathrm{CO}_{2}$ production rate is relatively high, compared to methanol solution flow rate. As the gas volume increases, the bubble proximity becomes smaller to an extent that, larger bubbles are formed. The gas bubbles are separated from one another by slugs of liquid and their shapes are hemispherical (Figure 1.6) $[12,22]$.

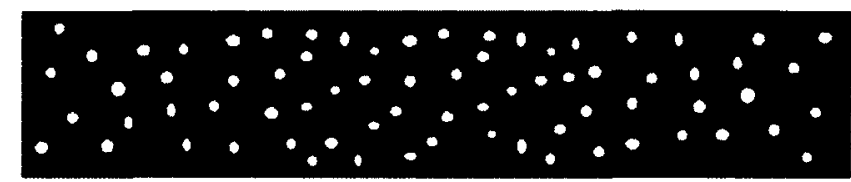

Bubbly Flow Regime

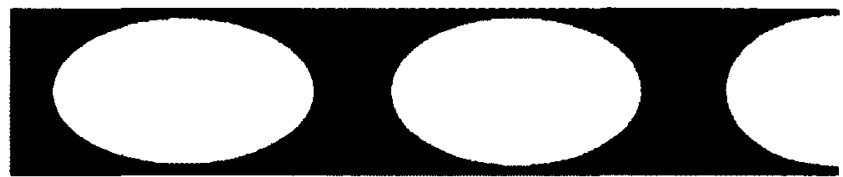

Slug-Plug Flow Regime

Figure 1.6: Schematic of different types of flow regimes 
As mentioned earlier, the formation of slug/plug flow regime inside the anode fuel channel must be circumvented, since the large $\mathrm{CO}_{2}$ bubbles would reduce the channel cross-sectional area and eventually, block the methanol solution stream. Furthermore, they hinder methanol molecules from effectively diffusing through the GDL and reach the anode catalyst layer. In addition to the channel geometry and methanol solution flow rate, other factors such as fuel cell temperature, volumetric void fraction, bubble surface tension and GDL design are also important for effective anode gas management.

\subsubsection{Volumetric Void Fraction}

The volumetric void fraction $(\alpha)$ is one of the key physical parameters, used to characterize the two-phase flows in various engineering applications. It is defined as the fraction of the volume of voids (gas phase) over the entire volume [23]:

$$
\alpha=\frac{V_{g}}{V_{l}+V_{g}}
$$

where $V_{g}$ is the volume of the channel, occupied by the gas phase and $V_{l}$ is that of the liquid phase. Void fraction is also used to determine other important two-phase flow characteristics such as two-phase density and viscosity, slip ratio (which is defined as the relative average velocity between the two phases) and pressure drop [23].

It is important to note that, in the bubbly flow regime (small operating current densities), the void fraction is relatively small (near zero) whereas in slug/plug flow regime (high operating current densities), the void fraction is closer to unity [23].

\subsubsection{Surface Tension}

The liquid-vapor surface tension, $\sigma$, has the units of force per meter $(\mathrm{N} / \mathrm{m})$ and thus, can be interpreted as the contracting force between the two phases, per unit length around the perimeter. This phenomenon is dimensionally equivalent to energy per unit area $\left(\mathrm{J} / \mathrm{m}^{2}\right)$ and is a measurement of the cohesive energy or excess free energy present at the interface between the two phases [23]:

$$
\sigma=\left(\frac{\partial E}{\partial A}\right)_{T, V, N}
$$


where $E$ is the Helmholtz free energy of the system, $A$ is the area of the interface, $T$ is temperature, $V$ is the volume, and $N$ is the number of molecules. Surface tension plays an important role when dealing with two-phase flow regimes in small channels (such as DMFC fuel channels). High surface tension often causes a strong adhesion between the gas bubbles and channel walls and thus, enhances the resistance against the flow stream.

\subsubsection{Two-Phase Pressure Drop Modelling}

In most engineering applications, the presence of two-phase flow adds many complications to the calculation of pressure drop and flow distributions. The two-phase flow pressure drop is a major design variable, governing the pumping power required to transport methanol solution inside the DMFC unit. It also influences the flow distribution within the fuel channels. There are two major modelling strategies for estimating the two-phase pressure drop:

Homogenous Flow Modelling: In this type of approach, both gas and liquid phases are assumed to be mixed homogenously, to form a pseudo-fluid that obeys the conventional design equations for single phase fluids, considering the average properties of the liquid and gas phases. One important assumption in homogenous flow modelling is that both gas and liquid phases travel at the same speed $[23,24]$.

Separated Flow Modelling: In this type of approach, the two phases are artificially separated into two streams with different velocities. The frictional component of the overall two-phase pressure is then calculated from that of either gas or liquid phases, using a pressure multiplier $[23,24]$.

The homogenous flow modelling approach is much simpler than the latter however, it is proven to be inaccurate when the void fraction is high (slug/plug flow regime). This is due to the fact that unlike the bubbly flow regime, in the slug/plug flow regime, the two phases are not thoroughly mixed and thus, the phase velocities are significantly different [23]. 


\section{Chapter 2}

\section{Literature Review}

As mentioned in the Chapter 1, the performance of the DMFC is strongly affected by $\mathrm{CO}$ poisoning of the anode catalyst layer, $\mathrm{CO}_{2}$ at the anode compartment and methanol crossover. This chapter is divided into two sections. The first section, provides an overview on two-phase flow studies in general engineering applications and in DMFCs. The second section, provides a literature review on methanol crossover in DMFCs and the use of a circulating electrolyte in fuel cells.

\section{$2.1 \quad$ Two-Phase Flow Modelling}

Two-phase flow models have traditionally been divided into two categories: homogeneous flow models and separated flow models. Both the homogeneous and separated flow models have been developed extensively through several two-phase flow studies $[21,24]$. A brief literature survey of each modelling approach is presented below:

\subsubsection{Homogeneous Flow Models}

These models assume that the liquid and gas phases are traveling at the same velocity and the mixture is treated as a single phase flow. To use homogeneous models, a two-phase Reynolds number is calculated based on averaged properties:

$$
R e_{a v g}=\frac{\rho_{\text {avg }} V_{s} d_{h}}{\mu_{\text {avg }}}
$$


where $\rho_{a v g}$ is the average mixture density, $V_{s}$ is the mixture velocity, $d_{h}$ is the channel hydraulic diameter and $\mu_{a v g}$ is the average mixture viscosity. Using the average Reynolds number, a friction factor is calculated from the single phase equations [24].

The key to homogeneous two-phase models is the choice of average properties. Since both the liquid and gas phases are flowing together in the channel, the density of the mixture in any channel section is governed by a mass average [24]:

$$
\frac{1}{\rho_{\text {avg }}}=\frac{x}{\rho_{g}}+\frac{1-x}{\rho_{l}}
$$

where $x$ is the mixture quality, $\rho_{g}$ is the gas phase density and $\rho_{l}$ is the liquid phase density.

The choice of average viscosity $\left(\mu_{\text {avg }}\right)$ is a little less transparent. Generally, the concept of average viscosity is described as the "equivalent damping element" in a two-phase flow system. It highly depends on the arrangement of individual phases (series/parallel) inside the channel. This is illustrated in Figure 2.1 [24], where the arrangement of parallel and series dampers are shown in an additive combination and reciprocal additive combination, respectively. The phase viscosities can be weighted by mass (same as average mixture density) or by volume [24].

McAdams et al. $(1942)[24,25]$ used a series combination of the two-phase viscosities, weighted by mass to calculate the average viscosity:

$$
\frac{1}{\mu_{a v g}}=\frac{x}{\mu_{g}}+\frac{1-x}{\mu_{l}}
$$

where $\mu_{g}$ is the gas phase viscosity and $\mu_{l}$ is the liquid phase viscosity. Dukler et al. (1964) [24] developed a model that is a parallel combination of the phase viscosities, but weighting their contributions by volume:

$$
\mu_{\text {avg }}=\alpha \mu_{g}+(1-\alpha) \mu_{l}
$$

Where $\alpha$ is the void fraction. Cicchitti et al. $(1960)[24,25]$ formulated the mixture viscosity based on a parallel combination with mass weighting: 


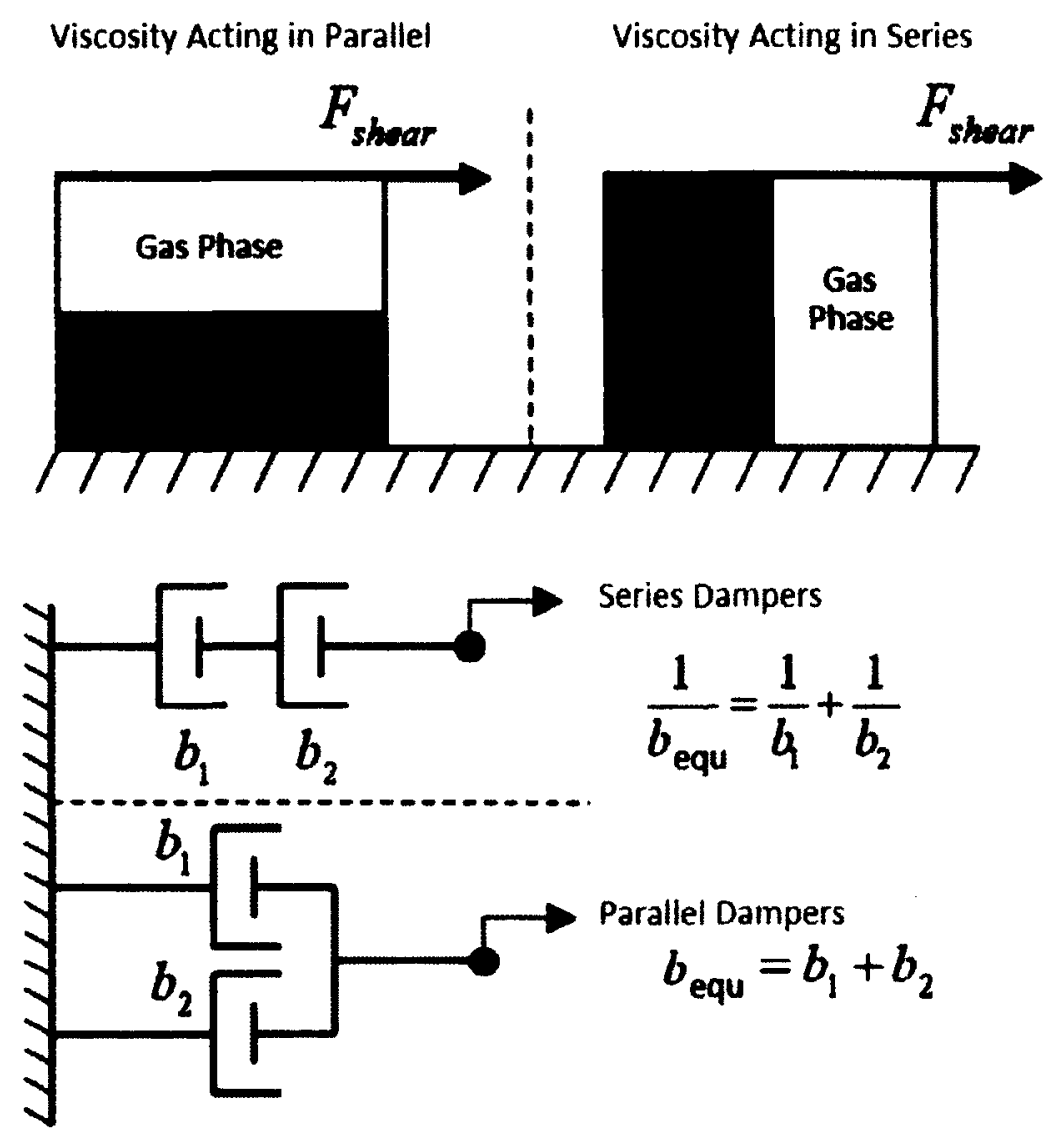

Figure 2.1: Viscosity-damper arrangements (Field et al.)

$$
\mu_{\text {avg }}=x \mu_{g}+(1-x) \mu_{l}
$$

Following this framework, Bittle and Weis (2002) [24] put forth a new model by combining the viscosities in series and weighting them by void fraction:

$$
\frac{1}{\mu_{\text {avg }}}=\frac{\alpha}{\mu_{g}}+\frac{1-\alpha}{\mu_{l}}
$$

\subsubsection{Separated Flow Models}

Not all types of two-phase flow regimes can be addressed with a homogeneous model. In majority of real life applications, the two phases travel with different velocities and have different properties. In order to better address these types of flow regimes, separated flow models have been developed. The idea of different phase 
velocities is extremely important when phase densities are reasonably different and a gravitational potential field is present. Given the density difference and the effects of buoyancy, the lighter phase tends to induce a drift velocity to the heavier phase.

The separated flow model is formulated with a two-phase multiplier $\left(\phi^{2}\right)$. In this type of modelling approach, it is assumed that, only liquid or gas phase exists inside the channel. The gas or liquid phase pressure gradient is calculated based on the single phase equations. The resulting single phase pressure gradient is then multiplied by the corresponding two-phase multiplier (correction factor), to yield the two-phase pressure gradient.

By comparing multiple sets of experimental pressure drop data obtained from various sources, Lockhart and Martinelli $(1949)[24,26]$ realized that, the ratio of single phase pressure gradients follows a certain pattern:

$$
X^{2}=\frac{\left(\frac{\Delta P}{\Delta L}\right)_{l}}{\left(\frac{\Delta P}{\Delta L}\right)_{g}}
$$

where $X$ is the Lockhart-Martinelli parameter and $\left(\frac{\Delta P}{\Delta L}\right)_{l}$ and $\left(\frac{\Delta P}{\Delta L}\right)_{g}$ are the liquid and gas phase pressure gradients, respectively. Using various experimental data for both laminar (viscous) and turbulent flow regimes, Chisholm (1967) [23] developed a theoretical basis for why $X$ would correlate pressure drop and void fraction, and recommended a simplified equation of:

$$
\phi_{l}^{2}=1+\frac{C}{X}+\frac{1}{X^{2}}
$$

where $\phi_{l}^{2}$ is the liquid phase pressure multiplier (correction factor). Based on Chisholm's analogy, $C$ is considered as an interaction parameter between the liquid and gas phases. Numerous studies have been performed for determining $C$ based on flow propertics.

Mishima and Hibiki (1996) $[24,27]$ were among the first researchers to develop an empirical correlation for $C$ based on channel hydraulic diameter $\left(d_{h}\right)$. They tested air-water flow in 1 to $4 \mathrm{~mm}$ diameter tubes, and developed the following equation: 


$$
C=21\left(1-e^{-0.319 d_{h}}\right)
$$

where $d_{h}$ is measured in millimeters. Equation 2.9 however fails to take into account all the flow properties, except the channel hydraulic diameter $\left(d_{h}\right)$. English and Kandlikar (2005) $[24,28]$ measured the two-phase pressure drop in a square channel, with a hydraulic diameter of $1.018 \mathrm{~mm}$ and fluids with various surface tension values. They correlated the pressure drop measurements by modifying Mishima and Hibiki's correlation for $C$ to be:

$$
C=5\left(1-e^{-0.319 d_{h}}\right)
$$

Another effort to correlate $C$ for smaller channels, was done by Lee and Lee (2001) $[24,27]$. They tested the flow of air and water through rectangular channels, with various hydraulic diameters ranging from 0.78 to $6.7 \mathrm{~mm}$. Following the dimensional analysis developed by Suo and Griffith (1964) $[24,29]$, they developed a unique methodology for calculating parameter $C$ :

$$
C=A \lambda^{q} \psi^{r} R e_{l o}^{s}
$$

and:

$$
\begin{gathered}
\lambda=\frac{\mu_{l}^{2}}{\rho_{l} \sigma d_{h}} \\
\psi=\frac{\mu_{l} V_{s}}{\sigma} \\
R e_{l o}=\frac{\rho_{l} V_{s} d_{h}}{\mu_{l}}
\end{gathered}
$$

where the dimensionless number $\lambda$ is constant for a given fluid and channel diameter, being only a function of physical and geometrical parameters. The term $\psi$ represents the ratio of the viscous to surface tension effects, given in terms of the characteristic velocity, $V_{s}$ (liquid phase velocity). The parameter $R e_{l o}$ is the hypothetical Reynolds number, assuming the entire flow to be in liquid phase. The constants $A$, 
$q, r$, and $s$ are determined by regressing the measured pressure drop data for various flow regimes.

Lee and Mudawar (2005) $[24,30]$ measured the pressure drop across the microchannel evaporators of small hydraulic diameter. By looking at large database of experimental data, they developed a correlation for $C$ based on the dimensionless parameters, $R e_{l o}$ and $W e_{l o}$ for laminar and turbulent flow regimes:

$$
\begin{aligned}
& C_{\text {laminar }}=2.16 R e_{l o}^{0.047} W e_{l o}^{0.60} \\
& C_{\text {turbulent }}=1.45 R e_{l o}^{0.25} W e_{l o}^{0.23}
\end{aligned}
$$

where the $W e_{\text {lo }}$ is the hypothetical Weber number, assuming the entire flow to be in liquid phase. It represents the ratio of inertial forces in a flow to surface tension forces:

$$
W e_{l o}=\frac{\rho_{l} V_{s}^{2} L}{\sigma}
$$

\subsection{DMFC Hydrodynamic Studies}

Recent academic literature was surveyed to find applicable work on the two-phase flow modelling and gas management at the anode compartment of direct methanol fuel cells. Many studies in this area, have focused on exploring the two-phase flow and pressure drop phenomena in cathode flow channels of hydrogen fuel cells due to the issue of water management.

On the other hand, majority of the hydrodynamic studies on DMFCs only involve the transport of species through the gas diffusion layer (GDL) and does not explore the two-phase flow and pressure drop phenomena inside the anode fuel channels. In general, two types of hydrodynamic studies have been identified in the literature with respect to DMFC anode compartment:

1. $\mathrm{CO}_{2}$ visualization studies of anode compartment; 
2. Two-phase flow and CFD analysis of anode fuel channels based on the "homogeneous flow modelling" approach;

\subsubsection{Carbon Dioxide Visualization Studies in DMFCs}

The $\mathrm{CO}_{2}$ bubble behavior within the anode fuel channels has attracted many researchers in recent years. Bewer et al. [31] studied the $\mathrm{CO}_{2}$ bubble behavior inside the DMFC anode flow channels, using the decomposition of hydrogen peroxide solution $\left(\mathrm{H}_{2} \mathrm{O}_{2}\right)$. They discovered that, in large-size DMFCs, the flow field with grid structures provided a better bubble transport effect.

Yang et al. [32] performed a visualization study on the $\mathrm{CO}_{2}$ bubble behavior under different fuel cell operating conditions such as, current density and methanol flow rate. They used an in-house fabricated transparent DMFC, to experimentally investigate the pressure drop and two-phase flow in the anode compartment. They found that at first, the pressure drop increased with increasing current density however, after the current density reached a certain value, the trends of pressure drop were reversed.

Liao et al. [33] also carried out a visualization study on the dynamics of $\mathrm{CO}_{2}$ bubbles in anode channels of a DMFC. In their study, they observed that the processes of emergence, growth, coalescence, detachment, and sweeping of the gas bubbles always occurred in a periodic fashion.

Li et al. [20] studied the effects of anode flow field design on $\mathrm{CO}_{2}$ bubble behavior in micro-DMFCs. They concluded that, using a flow field pattern with gradual change (increase) in width (cross-section) along the fuel channel length, could substantially improve the performance.

\subsubsection{Two-Phase Flow Modelling in DMFCs}

In addition to experimental studies, some model-based mathematical simulations on the two-phase flow characteristics inside the DMFC anode fuel channels are also proposed in the literature.

Argyropoulos et al. [34] developed a two-phase flow model for predicting the pressure drop in a DMFC unit with pin-flow channel design. They assumed that the $\mathrm{CO}_{2}$ 
gas is completely dissolved in the methanol solution and used homogeneous modelling approach to estimate the pressure drop. They found that, the pressure drop across the anode compartment was a non-linear function of inlet methanol flow rate, and did not vary with current density.

Yang et al. [32] explored the pressure drop across a DMFC anode with single serpentine channel design. They demonstrated that, channel orientation and gravitational effects played an important role in determining the pressure drop. It is important to note that, in the work of both Argyropoulos et al. and Yang et al., capillary forces were neglected.

Maharudrayya et al. [35] investigated the flow distribution and pressure losses in a DMFC anode flow field with parallel serpentine channel configuration, using a combination of CFD simulation and experiments. They assumed laminar flow in the channel, and developed a three regime correlation for the excess bend loss coefficient, as a function of Reynolds number, aspect ratios, curvature ratios and spacer lengths between the channels.

Kim et al. [36] used three-dimensional CFD simulation modelling to optimize the flow field design of a DMFC bipolar plate for improving the gas management at the anode. They applied the homogeneous modelling approach to model the mass and momentum transfer of both gas and liquid phases inside the anode channels. Different channel configurations were simulated and the velocity and pressure distributions were examined for each case. They found that, in general, serpentine channel design provided more uniform velocity distribution and better performance.

Wang et al. [37] developed a multiphase mixture model with homogeneous flow assumption to study the two-phase flow behavior in the anode flow channel of a DMFC. They treated the fuel channel as a porous media with the pore size equal to the channel hydraulic diameter, and investigated the effects of various operating and structural parameters, such as: methanol concentration, anode flow rate, porosities of both anode and cathode electrodes and the rate of methanol crossover, on the cell performance. 


\subsection{Methanol Crossover Studies in DMFCs}

Another important challenge in the area of direct methanol fuel cells is to understand and prevent methanol crossover. Many studies have been performed in this area and different strategies have been suggested in the literature to inhibit methanol molecules from traveling within the membrane and reaching the cathode catalyst layer.

In the majority of the research work found in the literature, Nafion ${ }^{\circledR}$ membranes are used as solid polymer electrolyte (SPE) in DMFCs. Direct investigation of methanol transfer through the membrane is very difficult and thus, most studies in this area have focused on the influence of methanol crossover on the fuel cell performance [38].

Kauranen and Skou [39] developed an experimental method for measuring the permeability of methanol in Nafion ${ }^{\circledR}$ membranes. Using the time responses of anodic peak currents on two working electrodes at $60^{\circ} \mathrm{C}$, they were able to estimate the permeability of methanol in a Nafion ${ }^{\circledR} 117$ membrane $\left(4.9 \times 10^{-6} \frac{\mathrm{cm}}{\mathrm{s}}\right)$.

Narayanan et al. [19] measured the methanol crossover rate by estimating the $\mathrm{CO}_{2}$ content of the cathode exit stream and found an increase in crossover rate with temperature in Nafion ${ }^{\circledR} 117$ membrane. In addition, they studied the dependence of the crossover rate on the cell current density and realized that as current density increased, the crossover rate diminished. They attributed this effect to an increased utilization of methanol molecules at high current densities.

Jung et al. [18] investigated the influence of the membrane thickness on crossover rate using three kinds of Nafion ${ }^{\circledR}$ membranes, 117, 115 and 112 at constant temperature. Using gas chromatography, they measured the methanol concentration in the drain water, exiting the cathode and reported that, the concentration of methanol in the drain water was three times higher for the fuel cell with Nafion ${ }^{\circledR} 112$ membrane, with respect to the fuel cell with Nafion ${ }^{\circledR} 117$ membrane.

\subsubsection{Preventative Strategies}

In order to reduce methanol crossover and its negative effects, some strategies have been proposed in the literature. As mentioned in the previous chapter, one of the 
consequences of methanol crossover in DMFCs is the contamination of the cathode catalyst with methanol molecules. An alternative way to reduce such impact is to apply methanol-tolerant cathode catalysts. Gao et al. [40] developed a $\mathrm{Pt} / \mathrm{CoSe}_{2}$ nano-belt cathode catalyst for DMFCs by in situ loading of Pt nano-particles on $\mathrm{CoSe}_{2} /$ diethylenetriamine nano-belts. They found that, the resulting catalysts exhibited high activity in the oxygen reduction reaction and were highly methanol tolerant.

Other strategies to decrease the methanol crossover rate within DMFCs involve developing new membrane technologies that are highly impermeable to methanol molecules. $\mathrm{Pu}$ et al. [41] developed a composite electrolyte where a methanol impermeable Palladium film with high proton conductivity was placed between two Nafion ${ }^{\circledR} 115$ membranes. The results showed that the metal hybrid film inside the two membranes could effectively reduce methanol crossover while improving the proton conductivity.

In addition, some researchers have tried to find alternative membrane materials that have zero methanol permeability. Kuver et al. [42] used differential electrochemical mass spectrometry to study the methanol crossover in substituted and cross-linked POP membranes (sulphonate-substituted polyoxiphenylenes). Comparing their results with those obtained with different commercial membranes such as Nafion ${ }^{\circledR}$ 117 , they realized that, POP membranes were extremely superior, with respect to methanol impermeability, than conventional Nafion 117 membranes.

Despite of the successful outcome in minimizing the issue of methanol crossover, the above strategies have limited potential for commercialization, due to expensive material/manufacturing costs and short term reliability. In 2001, Kordesch et al. $[43,44]$ built a DMFC prototype that employed a "circulating electrolyte" between its anode and cathode compartments. In their study, they concluded that the circulating electrolyte not only removed all the crossed-over methanol, but also washed away all the reaction by-products that passed through the Nafion ${ }^{\circledR}$ membrane. Other advantages of their design included: efficient thermal management, constant hydration of the membranes and rapid fuel cell startup and shutdown, especially at high current densities. 


\subsubsection{Direct Methanol Fuel Cell with Flowing Electrolyte}

As can be seen in Figure 2.2, an acidic flowing electrolyte is passed through a micro-porous material, placed between the two DMFC anode and cathode half MEAs. In this design, all the crossed-over methanol is efficiently removed from the cell by simple convection and since the electrolyte is acidic, it allows for efficient transport of protons to the cathode side. It is important to note that, a good electrolyte for this application should have certain characteristics such as high proton conductivity, low methanol permeation and low electron conductivity $[43,44]$.

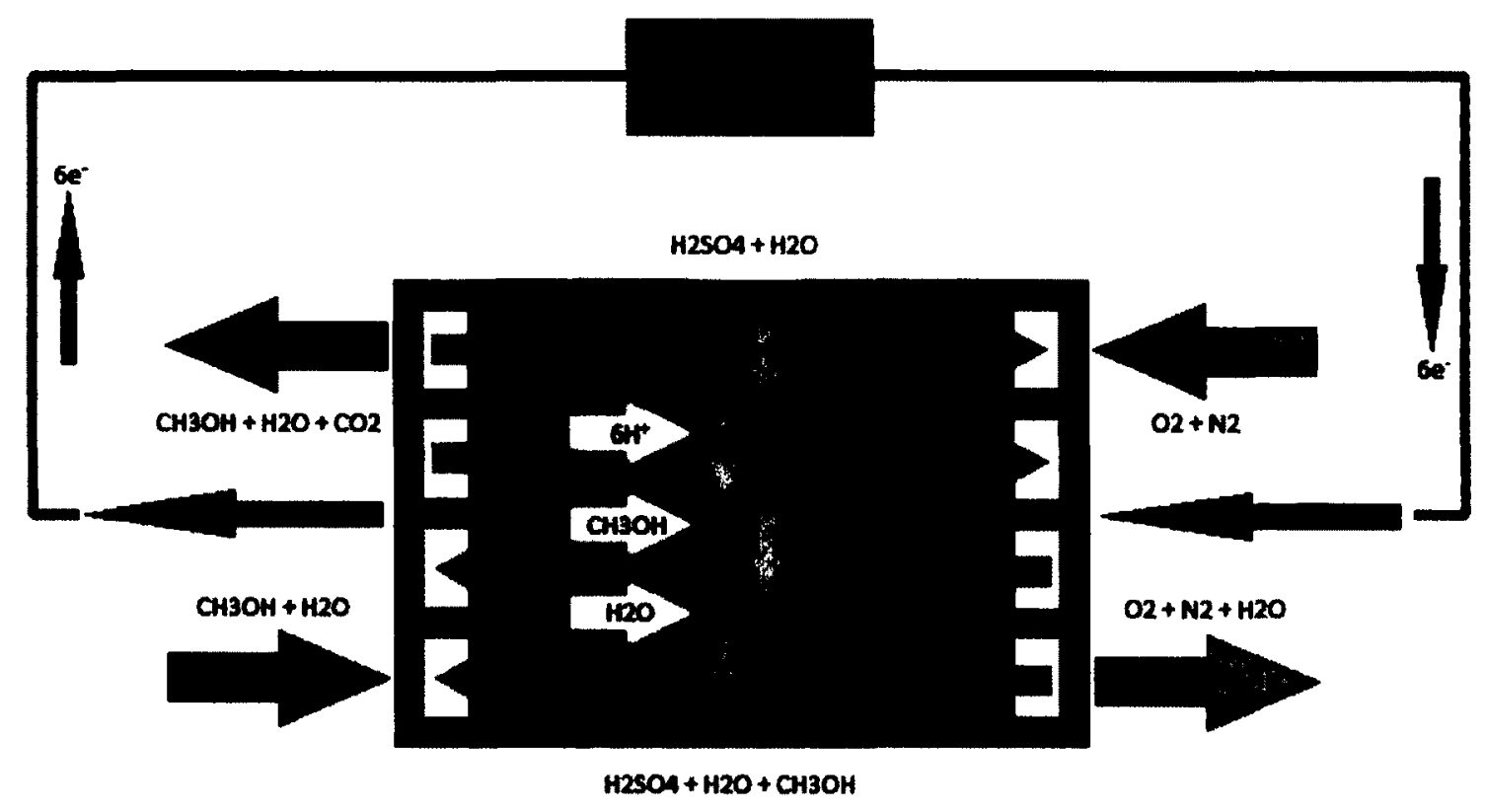

Figure 2.2: Schematic of a FE-DMFC unit

Another study in this area was carried out by Sabet-Sharghi et al. [45] They designed a single cell flowing electrolyte direct methanol fuel cell (FE-DMFC) and tested its performance at various operating conditions. Two types of half membrane electrode assemblies (MEAs) were fabricated for testing. One with Nafion ${ }^{\circledR} 112$ and the other with Nafion ${ }^{\circledR} 117$. They demonstrated that the fuel cell with the thinner membrane (Nafion ${ }^{\circledR} 112$ ) had better performance as long as a liquid electrolyte was circulated through the system. They used diluted sulphuric acid as the flowing electrolyte and concluded that the optimum methanol removal could be achieved by 
increasing the electrolyte flow rate and also by decreasing the flowing electrolyte (FE) channel thickness.

Despite of its importance, no studies have been conducted on the subject of "FEDMFC stacks". In order to commercialize the concept of direct methanol fuel cells with flowing electrolyte technology, the following issues must be addressed: stack hydrodynamics, thermal management, stack startup/shutdown and the effects of the flowing electrolyte.

\subsection{Thesis Objectives}

To improve the overall performance of direct methanol fuel cells and to use them commercially in the area of small-scale portable power production, the anode gas management and methanol crossover problems must be properly addressed.

Based on the provided literature survey, there is a dearth of information with respect to DMFC $\mathrm{CO}_{2}$ management at the anode compartment. Most researchers have tried to model the two-phase flow regime inside the anode fuel channels, by using a "homogenous flow modelling" approach. As mentioned in Chapter 1, this type of modelling approach is only valid when dealing with "bubbly flow" regime which takes place only at small current densities (when the $\mathrm{CO}_{2}$ generation rate is low). However, as the current density increases, the flow patterns change and turn into "slug/plug flow". Hence, to better understand the two-phase flow characteristics inside the DMFC anode compartment, a more elaborate modelling technique such as "separated flow modelling" approach, should be used.

In addition to gas management problem, methanol crossover is another significant issue in DMFCs. Many strategies to reduce methanol crossover have been suggested in the literature, including the use of a circulating electrolyte. Primary tests on single cell FE-DMFCs show promising results; however, more testing should be carried out on stack level to investigate the stack performance and scale-up challenges.

In the present work, the issues of DMFC gas management and methanol crossover have been investigated. The first part of this thesis involves the development of a steady state quasi two-dimensional numerical model to predict the two-phase flow 
behavior within the DMFC anode compartment. Various types of flow modelling approaches have been used to estimate the pressure drop and the results have been compared against the experimental data. The second part of this work involves the fabrication and testing of a five-cell FE-DMFC stack with parallel serpentine channel design. The effects of various operating parameters on the cell performance have been investigated, experimentally.

The research objectives of this thesis are as follows:

1. Create a quasi two-dimensional, steady state, hydrodynamic model of a single cell DMFC anode compartment, and compare its results against experimental data;

2. Compare different types of two-phase flow modelling approaches and various void fraction correlations to find the best combination for DMFC application;

3. Develop a model to predict the two-phase flow and pressure distributions within DMFC stack anode manifolds and compare the results against experimental data and;

4. Construct a five-cell FE-DMFC stack and test its performance at various operating conditions to find the maximum power output. 


\section{Chapter 3}

\section{DMFC Anode Hydrodynamic Modelling (Single Cell)}

Using conservation of mass and momentum principles, combined with multiphase flow equations, a two-phase flow model was developed to predict the hydrodynamic behavior of the DMFC anode compartment at various operating conditions. This chapter has two sections. In the first part, a thorough description of the modelling assumptions and methodology is presented and in the second part, the modelling results with various pressure and void fraction correlations are compared against experimental data.

\subsection{Modelling Approach}

\subsubsection{Assumptions}

The presented model in this work is based on a flow bed design, developed at Carleton University [46]. As shown in Figure 3.1, the design consists of a main flow bed with seven parallel serpentine channels, and two circular inlet/outlet sections. The channels all have square cross-sections $\left(1.5 \times 1.5 \mathrm{~mm}^{2}\right)$ and the cell total reaction area is $25 \mathrm{~cm}^{2}$. For further information about the physical, mechanical and electrical properties of the design, refer to Appendix A.

The following assumptions were considered:

1. The fuel cell operates at a steady state condition; 
2. The current distribution over the reaction area is assumed to be uniform. Since the methanol fuel enters the DMFC in liquid form, and its oxidation rate is relatively slow, excessive methanol is available on the catalyst layer at all times during operation and thus, the current distribution is not a problem for the DMFC;

3. The temperature distribution in the anode compartment is assumed to be constant. Since the hydraulic diameter of the channel and methanol solution flow rate are relatively small, the temperature gradient between the anode inlet and outlet is negligible;

4. The temperature of water is maintained below the boiling point and thus, water remains in the liquid phase;

5. The vaporization of methanol within the anode compartment is relatively small and thus, it is assumed that methanol remains in the liquid phase;

6. Carbon dioxide obeys the ideal gas law;

7. Carbon dioxide does not dissolve in water or methanol and remains in the gaseous phase;

8. All the generated carbon dioxide at the anode catalyst layer diffuse back into the fuel channel;

9. The reactants/products are consumed/formed as calculated according to Faraday's law;

10. The concentration diffusion and electro-osmotic drag are the only two mechanisms responsible for the transport of methanol and water molecules through the membrane;

11. Membranes are fully hydrated;

12. Methanol and water concentration profiles are considered linear across the gas diffusion layer (GDL) and membrane and;

13. Methanol molecules are fully consumed at the cathode catalyst layer. 


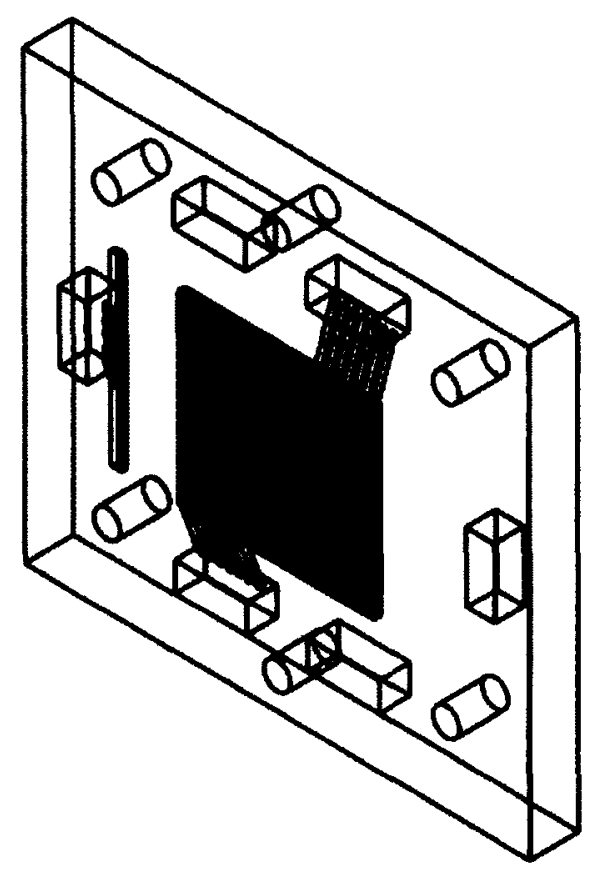

Figure 3.1: Schematic of the flow bed design

\subsubsection{Control Volume Setup}

Three-dimensional views of a small segment in the fuel channel and the corresponding anode backing layer are shown in Figures 3.2 and 3.3, respectively, where the $x$-axis direction corresponds to the channel length and the $y$-axis corresponds to channel thickness. All the terms used in Figures 3.2 and 3.3 are explained in further detail in the following sections. It is also important to note that the anode backing layer in these figures, is the same as the GDL.

\subsection{Mass Flow Rate and Concentration}

Considering the assumptions in Section 3.1.1, the mass conservation and species transport equations are developed for methanol, water and carbon dioxide, respectively. 


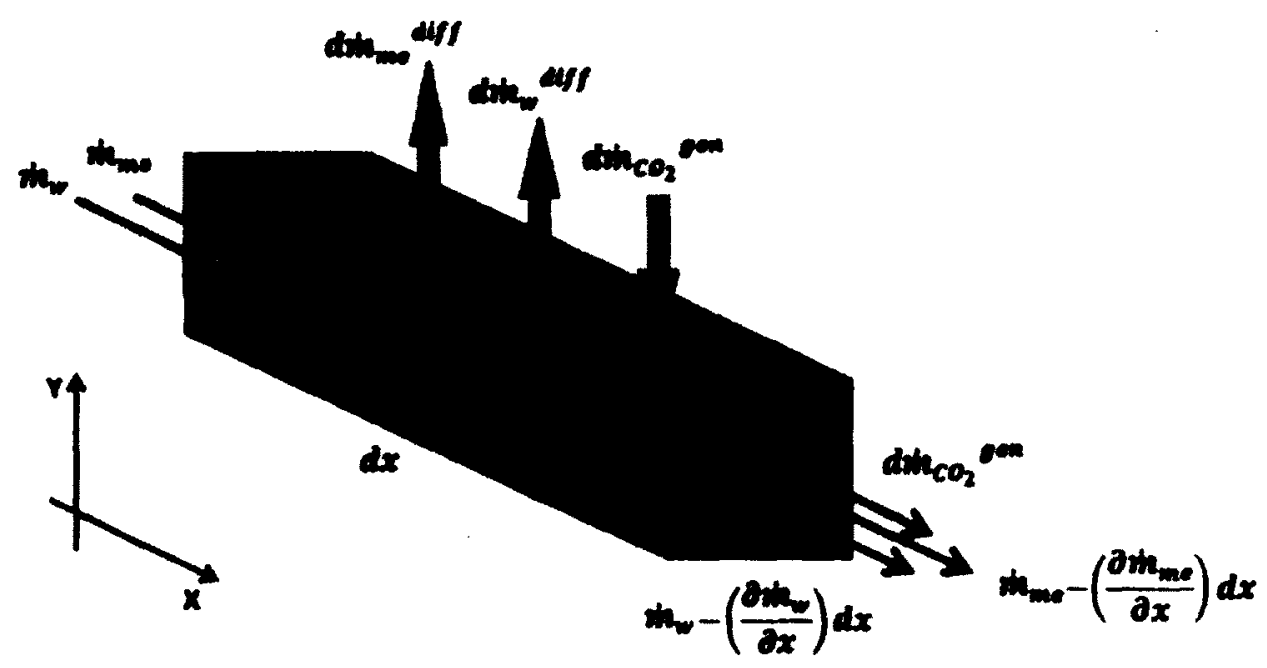

Figure 3.2: Anode fuel channel control volume

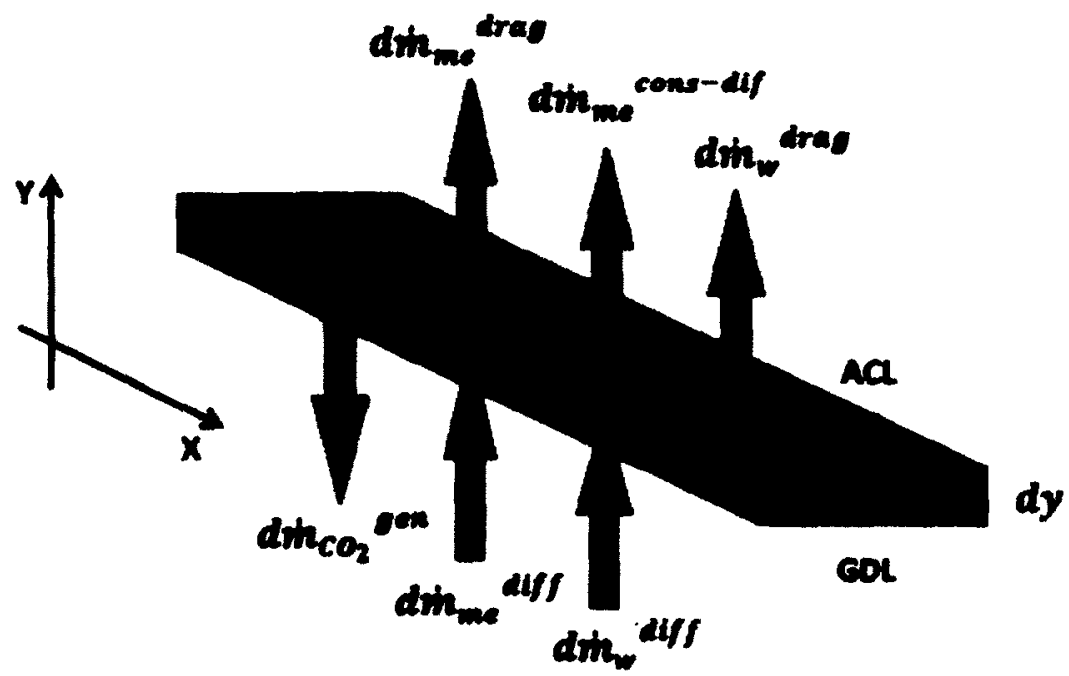

Figure 3.3: Gas diffusion layer control volume

\subsubsection{Methanol}

As the methanol molecules travel inside the fuel channel (Figure 3.2), a small portion diffuses through the anode backing layer $(A B L)$ to reach the anode catalyst layer $(A C L)$, where they get partially oxidized and the remainder crosses-over through the membrane. The following mass conservation and species transport equations can 
be used to describe the transport of methanol inside the DMFC anode compartment (underscript me denotes methanol):

$$
\dot{m}_{m e}=\dot{m}_{m e}-\left(\frac{\partial \dot{m}_{m e}}{\partial x}\right) d x+d \dot{m}_{m e}^{d i f}
$$

and thus:

$$
d \dot{m}_{m e}^{d i f}=\left(\frac{\partial \dot{m}_{m e}}{\partial x}\right) d x
$$

where $d \dot{m}_{m e}^{\text {dif }}$ is the mass flow rate of methanol which diffuses through the GDL. As shown in Figure 3.3, the anode catalyst layer involves:

$$
d \dot{m}_{m e}^{d i f}=d \dot{m}_{m e}^{c o n s}+d \dot{m}_{m e}^{c r o s s o v e r}
$$

where $d \dot{m}_{m e}^{\text {cons }}$ is the methanol consumption rate at the catalyst layer and according to Faraday's law it is equal to:

$$
d \dot{m}_{m e}^{c o n s}=\left(\frac{d i^{*}}{6 F}\right) M_{m e}
$$

where $d i^{*}$ is the incremental electric current generated during the oxidation reaction of methanol, and $M_{m e}$ is the molecular weight of methanol. The above formula can be written in terms of the cell current density by considering a correction factor $(z)$ for reaction area:

$$
d \dot{m}_{m e}^{\text {cons }}=\left[\frac{z j(W d x)}{6 F}\right] M_{m e}
$$

where $W$ is the channel width and $d \dot{m}_{m e}^{\text {crossover }}$ is the mass flow rate of methanol that crosses-over through the membrane. Two transport mechanisms are responsible for methanol crossover:

$$
d \dot{m}_{m e}^{\text {crossover }}=d \dot{m}_{m e}^{\text {cons-dif }}+d \dot{m}_{m e}^{d r a g}
$$

where $d \dot{m}_{m e}^{\text {cons-dif }}$ is the methanol mass flow rate due to concentration diffusion and $d \dot{m}_{m e}^{d r a g}$ is the methanol mass flow rate due to electro-osmotic drag. According 
to Fick's first law [47], $d \dot{m}_{m e}^{\text {cons-dif }}$ is proportional to the concentration gradient of methanol across the membrane, as follows:

$$
d \dot{m}_{m e}^{c o n s-d i f}=D_{m e}^{m e m}\left(\frac{\partial C_{m e}^{m e m}}{\partial y}\right)(W d x) M_{m e}
$$

where $D_{m e}^{m e m}$ is the methanol diffusion coefficient, and $\left(\frac{\partial C_{m e}^{m e m}}{\partial y}\right)$ is the concentration gradient of methanol across the membrane.

In this work, a Nafion ${ }^{\circledR} 115$ membrane was considered for modelling. This was due to the fact that Nafion ${ }^{\circledR} 115$ has similar electrochemical properties to that of Nafion ${ }^{\circledR}$ 117 but has smaller thickness and thus, better ohmic polarization characteristics.

Assuming constant methanol concentration within the anode catalyst layer, and zero methanol concentration at the cathode catalyst layer $(C C L)$ and since all the crossed-over methanol will be consumed at the $C C L$ ), the above equation can be simplified to:

$$
d \dot{m}_{m e}^{\text {cons-dif }}=D_{m e}^{m e m}\left(\frac{C_{m e}^{A C L}}{\delta_{m e m}}\right)(W d x) M_{m e}
$$

where $C_{m e}^{A C L}$ is the methanol concentration at the anode catalyst layer and $\delta_{m e m}$ is the membrane thickness. According to Scott et al. [48], the methanol diffusion coefficient through thick membranes can be described with the following correlation:

$$
D_{m e}^{m e m}=\varepsilon^{1.5} \times 4.9 \times 10^{-8} \times \exp \left[2436\left(\frac{1}{333}-\frac{1}{T}\right)\right]
$$

where $\varepsilon$ is the membrane porosity and $T$ is the temperature. On the other hand, $d \dot{m}_{m e}^{d r a g}$ is equal to:

$$
d \dot{m}_{m e}^{d r a g}=\left(\chi n_{d}\right)\left[\frac{z j(W d x)}{F}\right] M_{m e}
$$

where $\chi$ is methanol molar fraction in the liquid phase (inside the membrane) and $n_{d}$ is the electro-osmotic drag coefficient of water:

$$
\chi=\frac{C_{m e}^{A C L}}{C_{m e}^{A C L}+C_{w}^{A C L}}
$$


where $C_{w}^{A C L}$ is the water concentration at the $A C L$. According to Shaffer et al. [49], the electro-osmotic drag coefficient of water within the Nafion ${ }^{\circledR}$ membrane can be described with the following correlation:

$$
n_{d}=\left[\frac{\lambda^{*}-14}{8}\right]\left(n_{d, r e f}-1\right)+1
$$

where $\lambda^{*}$ is the membrane water content. For a fully hydrated membrane, $\lambda^{*}$ is equal to 22 and:

$$
n_{d, r e f}=1.6767+0.0155(T-273)+8.9074 \times 10^{-5}(T-273)^{2}
$$

By combining the above equations we have:

$$
\left(\frac{\partial \dot{m}_{m e}}{\partial x}\right) d x=\left[\frac{z j}{6 F}+D_{m e}^{m e m}\left(\frac{C_{m e}^{A C L}}{\delta_{m e m}}\right)+\left(\frac{C_{m e}^{A C L}}{C_{m e}^{A C L}+C_{w}^{A C L}}\right) n_{d}\left(\frac{z j}{F}\right)\right](W d x) M_{m e}
$$

The left-hand side in Equation 3.14, represents the diffusion of methanol molecules through the $(A B L)$. Using Fick's first law [47] we have:

$$
\left(\frac{\partial \dot{m}_{m e}}{\partial x}\right) d x=D_{m e}^{A B L}\left(\frac{\partial C_{m e}^{A B L}}{\partial y}\right)(W d x) M_{m e}
$$

where $D_{m e}^{A B L}$ and $\left(\frac{\partial C_{m e}^{A B L}}{\partial y}\right)$ are the diffusion coefficient and concentration gradient of methanol across the anode backing layer, respectively. The above equation can be rewritten as:

$$
\left(\frac{\partial \dot{m}_{m e}}{\partial x}\right) d x=D_{m e}^{A B L}\left[\frac{C_{m e}^{C h}-C_{m e}^{A C L}}{\delta_{A B L}}\right](W d x) M_{m e}
$$

where $C_{m e}^{C h}$ is methanol concentration in the fuel channel and $\delta_{A B L}$ is the anode backing layer thickness. In addition, according to Colpan et al. [50] the methanol diffusion coefficient at the anode backing layer can be described by the following formula:

$$
D_{m e}^{A B L}=\varepsilon^{1.5} \times 2.8 \times 10^{-7} \times \exp \left[2436\left(\frac{1}{333}-\frac{1}{T}\right)\right]
$$


By combining Equations 3.14 and 3.16, and by knowing the water concentration at the anode catalyst layer (which can be found by solving water transport equations), the methanol concentration at the anode catalyst layer can be calculated:

$$
D_{m e}^{A B L}\left(\frac{C_{m e}^{C h}-C_{m e}^{A C L}}{\delta_{A B L}}\right)-\frac{z j}{6 F}=D_{m e}^{m e m}\left(\frac{C_{m e}^{A C L}}{\delta_{m e m}}\right)+\left(\frac{C_{m e}^{A C L}}{C_{m e}^{A C L}+C_{w}^{A C L}}\right) n_{d}\left(\frac{z j}{F}\right)
$$

Once the methanol and water concentrations within the $A C L$ are found, the mass flow rate variations of methanol within the fuel channel can be calculated by integrating Equation 3.14:

$$
\dot{m}_{m e}^{C h}=\dot{m}_{m e}^{\text {inlet }}-\left[\frac{z j}{6 F}+D_{m e}^{m e m}\left(\frac{C_{m e}^{A C L}}{\delta_{m e m}}\right)+\left(\frac{C_{m e}^{A C L}}{C_{m e}^{A C L}+C_{w}^{A C L}}\right) n_{d}\left(\frac{z j}{F}\right)\right]\left(W M_{m e}\right) x
$$

where $\dot{m}_{m e}^{\text {inlet }}$ is the inlet mass flow rate of methanol inside the fuel channel. If the methanol inlet concentration $C_{m e}^{\text {inlet }}$ and the overall volume flow rate $Q$ are known, the inlet mass flow rate of methanol can be calculated, as follows:

$$
\dot{m}_{m e}^{\text {inlet }}=Q C_{m e}^{\text {inlet }} M_{m e}
$$

\subsubsection{Water}

In a similar manner to methanol and as shown in Figure 3.2, the water molecules travel inside the fuel channel and some amount diffuses through the $A B L$ to reach the catalyst layer. In the $A C L$, a small portion participates in the oxidation reaction and the remaining amount of water, passes through the membrane via electro-osmotic drag mechanism. The following mass transfer and species transport equations describe the mass flow rate and concentration variations of water molecules inside the anode compartment (underscript $w$ denotes water).

$$
\dot{m}_{w}=\dot{m}_{w}-\left(\frac{\partial \dot{m}_{w}}{\partial x}\right) d x+d \dot{m}_{w}^{d i f}
$$

and thus:

$$
d \dot{m}_{w}^{d i f}=\left(\frac{\partial \dot{m}_{w}}{\partial x}\right) d x
$$


where $d \dot{m}_{w}^{\text {dif }}$ is the mass flow rate of water which diffuses through the GDL. As shown in Figure 3.3, the anode catalyst layer involves:

$$
d \dot{m}_{w}^{d i f}=d \dot{m}_{w}^{\text {cons }}+d \dot{m}_{w}^{\text {crossover }}
$$

where $d \dot{m}_{m e}^{\text {cons }}$ is the water consumption rate at the anode catalyst layer and $d \dot{m}_{w}^{\text {crossover }}$ is the water mass flow rate through the membrane. Similar to methanol, the water consumption rate can be calculated according to Faraday's law, as follows:

$$
d \dot{m}_{w}^{c o n s}=\left[\frac{z j(W d x)}{6 F}\right] M_{w}
$$

where $M_{w}$ is water molecular weight. It can be shown that when the Nafion ${ }^{\circledR}$ membrane is fully hydrated, the electro-osmotic drag is the main mechanism responsible for the transport of water molecules through the membrane. The mass flow rate of water within the membrane $\left(d \dot{m}_{w}^{d r a g}\right)$ is equal to:

$$
d \dot{m}_{w}^{d r a g}=n_{d} \frac{z j(W d x)}{F} M_{w}
$$

The mass flow rate of water inside the anode fuel channel can be calculated by combining the above equations:

$$
\left(\frac{\partial \dot{m}_{w}}{\partial x}\right) d x=\left(n_{d}+\frac{1}{6}\right)\left[\frac{z j(W d x)}{F}\right] M_{w}
$$

Integrating Equation 3.26 yields:

$$
\dot{m}_{w}^{C h}=\dot{m}_{w}^{\text {inlet }}-\left[\left(n_{d}+\frac{1}{6}\right)\left(\frac{z j}{F}\right)\right]\left(W M_{w}\right) x
$$

where $\dot{m}_{w}^{\text {inlet }}$ is the water inlet mass flow rate inside the fuel channel. If the inlet concentration of methanol $C_{m e}^{\text {inlet }}$ and the overall volume flow rate $Q$ are known, the water inlet mass flow rate can be calculated, as follows:

$$
\dot{m}_{w}^{\text {inlet }}=Q \rho_{w}\left(1-\frac{C_{m e}^{\text {inlet }} M_{m e}}{\rho_{m e}}\right)
$$


where $\rho_{w}$ and $\rho_{m e}$ are the densities of water and methanol, respectively. As mentioned earlier, in order to determine the concentration of methanol inside the anode catalyst layer (equation 3.18), the water concentration in $A C L$ must be known. This can be achieved by solving the water transport equation across the $A B L$. Assuming the membrane is fully hydrated, the concentration gradient of water between the $A C L$ and the membrane is zero.

The left-hand side of Equation 3.26 represents the diffusion of water molecules through the $A B L$. Using Fick's first law [47], it can be shown that:

$$
\left(\frac{\partial \dot{m}_{w}}{\partial x}\right) d x=D_{w}^{A B L}\left(\frac{\partial C_{w}^{A B L}}{\partial y}\right)(W d x) M_{w}
$$

where $D_{w}^{A B L}$ and $\left(\frac{\partial C_{w}^{A B L}}{\partial y}\right)$ are the diffusion coefficient and concentration gradient of water across the anode backing layer, respectively. The above equation can be rewritten as:

$$
\left(\frac{\partial \dot{m}_{w}}{\partial x}\right) d x=D_{w}^{A B L}\left[\frac{C_{w}^{C h}-C_{w}^{A C L}}{\delta_{A B L}}\right](W d x) M_{w}
$$

where $C_{w}^{C h}$ is the water concentration in the fuel channel. It should be noted that, the diffusion coefficient of water is similar to that of methanol and thus, the same correlation can be used. By equating Equations 3.26 and 3.30, the water concentration inside the $A C L$ is found:

$$
C_{w}^{A C L}=C_{w}^{C h}-\left[\frac{\left(n_{d}+\frac{1}{6}\right) j}{D_{w}^{A B L} F}\right] \delta_{A B L}
$$

The water and methanol concentrations inside the fuel channel, can be related by the following equation:

$$
C_{w}^{C h}=\left(\frac{1}{M_{w}}-\frac{M_{m e}}{M_{w}} \frac{C_{m e}^{C h}}{\rho_{m e}}\right) \rho_{w}
$$




\subsubsection{Carbon Dioxide}

When methanol molecules get oxidized at the $A C L, C_{2}$ gas is generated. In this model, it is assumed that all the carbon dioxide will diffuse back into the fuel channel (Figures 3.2 and 3.3). According to Faraday's law, carbon dioxide generation rate is proportional to electric current as follows:

$$
d \dot{m}_{C O_{2}}^{g e n}=\left(\frac{d i^{*}}{6 F}\right) M_{C O_{2}}
$$

where $d \dot{m}_{\mathrm{CO}_{2}}^{g e n}$ is the carbon dioxide generation rate at the anode catalyst layer and $\mathrm{M}_{\mathrm{CO}_{2}}$ is carbon dioxide molecular weight. Considering the correction factor for area, the above formula can be rewritten as:

$$
d \dot{m}_{C O_{2}}^{g e n}=\left[\frac{z j(W d x)}{6 F}\right] M_{C O_{2}}
$$

Integrating Equation 3.34 yields:

$$
\dot{m}_{C O_{2}}^{g e n}=\left(\frac{z j}{6 F}\right) W M_{\mathrm{CO}_{2}} x
$$

The liquid phase mass flow rate $\left(\dot{m}_{l}\right)$ inside the anode fuel channel is written as:

$$
\dot{m}_{l}=\dot{m}_{m e}^{C h}+\dot{m}_{w}^{C h}
$$

In addition, the mass flow rate of the gaseous phase $\left(\dot{m}_{g}\right)$ within the anode fuel channel is represented as:

$$
\dot{m}_{g}=\dot{m}_{C O_{2}}^{g e n}
$$

and:

$$
G=\frac{\dot{m}_{l}+\dot{m}_{g}}{A_{\text {cross }}}
$$

where $G$ is the total mass flux inside the anode fuel channel and $A_{\text {cross }}$ is the channel cross-sectional area. 


\subsection{Density and Viscosity}

In order to properly model the two-phase flow within the anode fuel channel, the density and viscosity of each phase have to be predicted with high accuracy. Both density and viscosity are highly affected by temperature, pressure and species characteristics. In this section, corresponding correlations for estimating the density and viscosity of water, methanol and carbon dioxide are presented.

\subsubsection{Density}

In order to calculate the liquid phase density, it is essential to estimate the densities of methanol and water. Using the correlation developed by Hankinson and Thomson [51], the saturated liquid densities of methanol and water can be calculated as follows:

$$
\frac{V_{s a t}}{V^{*}}=V_{R}^{(0)}\left[1-\omega_{S R K} V_{R}^{(\delta)}\right]
$$

where $V_{s a t}$ is the saturated liquid molar volume, $V^{*}$ is the pure component characteristic volume, $\omega_{S R K}$ is the acentric factor and, $V_{R}^{(0)}$ and $V_{R}^{(\delta)}$ are the correlation parameters. The following equations are used to calculate the correlation parameters:

$$
\begin{gathered}
V_{R}^{(0)}=1+a\left(1-T_{r}\right)^{\frac{1}{3}}+b\left(1-T_{r}\right)^{\frac{2}{3}}+c\left(1-T_{r}\right)+d\left(1-T_{r}\right)^{\frac{4}{3}} \\
V_{R}^{(\delta)}=\frac{e+f T_{r}+g T_{r}^{2}+h T_{r}^{3}}{T_{r}-1.00001}
\end{gathered}
$$

where $T_{r}$ is the reduced temperature which can be calculated by normalizing the temperature with species critical temperature $\left(T_{c}\right)$ :

$$
T_{r}=\frac{T[K]}{T_{c}}
$$

Table 3.1 [51], shows the values of $V^{*}, \omega_{S R K}$ and $T_{c}$ for liquid methanol and water. In addition, values of the constants used in Equations 3.40 and 3.41 are presented in Table 3.2 [51]: 
Table 3.1: Density correlation values for liquid methanol and water

\begin{tabular}{|l|c|c|c|}
\hline Parameter & $V^{*}[L / m o l]$ & $\omega_{S R K}$ & $T_{c}[K]$ \\
\hline Methanol & 0.1198 & 0.5536 & 513.15 \\
\hline Water & 0.0436 & 0.3852 & 647.37 \\
\hline
\end{tabular}

Table 3.2: Table of constants

\begin{tabular}{|c|c|c|c|}
\hline $\mathrm{a}$ & -1.528160 & $\mathrm{e}$ & -0.2961230 \\
\hline $\mathrm{b}$ & +1.439070 & $\mathrm{f}$ & +0.3869140 \\
\hline $\mathrm{c}$ & -0.814460 & $\mathrm{~g}$ & -0.0427258 \\
\hline $\mathrm{d}$ & +0.190454 & $\mathrm{~h}$ & -0.0480645 \\
\hline
\end{tabular}

Once the term $V_{s a t}$ is found, densities of liquid methanol and water are calculated as follows:

$$
\begin{gathered}
\rho_{m e}=\frac{M_{m e} \times 1000}{V_{s a t}^{m e}} \\
\rho_{w}=\frac{M_{w} \times 1000}{V_{s a t}^{w}}
\end{gathered}
$$

Finally, the density of the liquid phase is calculated by the following formula:

$$
\rho_{l}=\rho_{w}+\left(1-\frac{\rho_{w}}{\rho_{m e}}\right) M_{m e} C_{m e}^{C h}
$$

Using ideal gas assumption for carbon dioxide, the gaseous phase density is calculated by the following equation:

$$
\rho_{g}=\frac{P_{g}^{A C L} M_{C O_{2}}}{R T}
$$

where $P_{g}^{A C L}$ is the pressure of carbon dioxide gas at the anode catalyst layer and $R$ is the universal gas constant. The above equation can be solved iteratively by assuming $P_{g}^{A C L}$ to be $1 \mathrm{~atm}$ for the first iteration. The solution process is continued until the convergence limit $\left(10^{-4}\right)$ is reached. 


\subsubsection{Viscosity}

Viscosity is another important parameter in describing the two-phase flow behavior. Similar to density, it is highly affected by temperature, pressure and species characteristics. The following correlations from White et al. [52] are used to calculate the viscosities of methanol, water and carbon dioxide.

For methanol, the following correlation is used:

$$
\frac{\mu_{m e}}{\mu_{m e}^{r e f}}=\exp \left[C\left(\frac{293}{T[K]}-1\right)\right]
$$

where $\mu_{m e}$ is the liquid methanol viscosity and $\mu_{m e}^{r e f}$ is the reference viscosity for methanol. The viscosity of water is calculated by the following formula:

$$
\ln \left(\frac{\mu_{w}}{\mu_{w}^{r e f}}\right)=-1.704-5.306 s+7.003 s^{2}
$$

and:

$$
s=\frac{273}{T[K]}
$$

where $\mu_{w}$ is the viscosity of water and $\mu_{w}^{r e f}$ is the water reference viscosity. Using Irving (1977) correlation for binary liquid mixtures [53], the liquid mixture viscosity is calculated as follows:

$$
\ln \mu_{l}=(1-\chi) \ln \mu_{w}+\chi \ln \mu_{m e}
$$

where $\mu_{l}$ is the liquid mixture viscosity and as mentioned earlier, $\chi$ is the methanol molar fraction. The viscosity of carbon dioxide or gaseous phase viscosity $\left(\mu_{g}\right)$, is calculated by the following formula:

$$
\begin{aligned}
\frac{\mu_{C O_{2}}}{\mu_{C O_{2}}^{r e f}} & =\left(\frac{T[K]}{293}\right)^{0.79} \\
\mu_{g} & =\mu_{C O_{2}}
\end{aligned}
$$


where $\mu_{\mathrm{CO}_{2}}$ is the viscosity of carbon dioxide and $\mu_{\mathrm{CO}_{2}}^{r e f}$ is the carbon dioxide reference viscosity. The corresponding parameter values used in Equations 3.47, 3.48 and 3.51 are shown in Table 3.3 [52]:

Table 3.3: Viscosity correlation values for methanol, water and carbon dioxide

\begin{tabular}{|l|c|c|}
\hline Parameter & $\mu^{\text {ref }}[\mathrm{kg} / \mathrm{m.s}]$ & $C$ \\
\hline Methanol & $5.980 \times 10^{-4}$ & 4.63 \\
\hline Water & $1.788 \times 10^{-3}$ & - \\
\hline Carbon dioxide & $1.480 \times 10^{-5}$ & - \\
\hline
\end{tabular}

\subsection{Volumetric Void Fraction}

As mentioned earlier, the volumetric void fraction $(\alpha)$ is an important parameter in describing the two-phase flow patterns in DMFCs. In the anode compartment of an operating DMFC, carbon dioxide gas is added to the methanol solution as it travels along the fuel channel. As described in Equation 3.35, the rate at which $\mathrm{CO}_{2}$ is introduced into the channel increases linearly with length. This means that the volumetric void fraction within the anode compartment grows with distance from the inlet.

In order to properly estimate the flow regime and pressure drop inside the anode compartment, void fraction variations have to be properly predicted. This is not trivial since, the void fraction is affected by various factors such as: channel geometry, GDL porosity, hydrophobic/hydrophilic characteristics of the anode backing layer and fuel cell operating conditions. In this section, the void fraction equations which are commonly used in "homogenous flow" and "separated flow" models are introduced.

\subsubsection{Homogenous Void Fraction}

When using the "homogenous flow modelling" approach, it is assumed that both liquid and gas phases travel at the same velocity. With some mathematical manipulation, the homogenous void fraction is obtained as follows [54]: 


$$
\alpha=\left[1+\left(\frac{1-x}{x}\right)\left(\frac{\rho_{g}}{\rho_{l}}\right)\right]^{-1}
$$

where $x$ is the mixture vapor quality and is calculated by the following equation:

$$
x=\frac{\dot{m}_{g}}{\dot{m}_{l}+\dot{m}_{g}}
$$

It should be noted that the homogenous void fraction is reasonably accurate for only a limited range of circumstances. The best agreement is for the "bubbly flow" case where the entrained phase (gaseous phase) travels at nearly the same velocity as the continuous phase (liquid phase). This condition is achieved only when the DMFC operates at extremely low current densities. For better estimation of $\alpha$ at higher current densities, where the flow pattern is changed to "slug/plug flow", the following correlations are used.

\subsubsection{Void Fraction Correlations for Separated Flow Regimes}

As mentioned earlier, in separated flow models, it is assumed that the liquid and gas phases are separated into two streams which flow through the channel with different velocities. Several empirical void fraction correlations for these types of flow regimes have been provided by Lockhart and Martinelli (1949), Baroczy (1963), and Wallis (1969) [55]. In most of these correlations, the void fraction, $\alpha$ is related to the Lockhart-Martinelli parameter $(X)$ and to mixture vapor quality $(x)$.

Butterworth (1975) [56] showed that, the Lockhart and Martinelli correlation for void fraction, as well as several other void fraction correlations, can be represented in the following generic form:

$$
\frac{1-\alpha}{\alpha}=A\left(\frac{1-x}{x}\right)^{p}\left(\frac{\rho_{g}}{\rho_{l}}\right)^{q}\left(\frac{\mu_{l}}{\mu_{g}}\right)^{r}
$$

where $A=0.28, p=0.64, q=0.36$ and $r=0.07$ for the Lockhart and Martinelli correlation, and $A=1.0, p=0.74, q=0.65$ and $r=0.13$ for the Baroczy correlation.

In another study, Zuber and Findlay (1965) [56] developed a correlation for void fraction by considering a "drift velocity" $\left(U_{g l}\right)$ between the gas and liquid phases. The 
drift velocity $\left(U_{g l}\right)$ represents the rate at which the gas phase is passing forwards or backwards through a moving unit plane, normal to the channel axis [23]. The plane is assumed to travel with the flow at the speed of $U_{g}+U_{l}$, where $U_{g}$ and $U_{l}$ are the superficial gas phase and liquid phase velocities, respectively. The following equation is developed for void fraction using the drift velocity approach:

$$
\alpha=\frac{U_{g}}{C_{o}\left(U_{g}+U_{l}\right)+U_{g l}}
$$

where $C_{o}$ is the distribution factor which highly depends on flow direction and Reynolds number. According to Wolk et al. [37], the distribution factor and the drift velocity for the slug flow through rectangular channels are given by:

$$
\begin{gathered}
C_{o}=1.35-0.35 \sqrt{\frac{\rho_{g}}{\rho_{l}}} \\
U_{g l}=(0.23+0.13 a) \sqrt{\frac{\left(\rho_{l}-\rho_{g}\right) W g}{\rho_{l}}}
\end{gathered}
$$

where $a$ is the channel cross-section aspect ratio (for a square cross-section, it is equal to one) and $g$ is the gravitational acceleration. In the DMFC anode compartment, the fuel channel cross-sectional area is relatively small $\left(1-2 \mathrm{~mm}^{2}\right)$. At this dimension range, surface tension forces become significant and thus, a more elaborate correlation is required to predict the void fraction distribution along the channel.

In order to address this issue, a void fraction correlation was developed by the CISE group (from CISE laboratories in Milan, Italy) [56]. Starting from homogenous void fraction equation, Premoli et al. (1971) [56] introduced the following void fraction correlation which considered surface tension influences:

$$
\alpha=\left[1+\left(\frac{1-x}{x}\right)\left(\frac{\rho_{g}}{\rho_{l}}\right) S\right]^{-1}
$$

and:

$$
S=1+E_{1} \sqrt{\frac{y}{1+y E_{2}}-y E_{2}}
$$


Where:

$$
\begin{gathered}
y=\left(\frac{\rho_{l}}{\rho_{g}}\right)\left(\frac{x}{1-x}\right) \\
E_{1}=1.578\left(\frac{G d_{h}}{\mu_{l}}\right)^{-0.19}\left(\frac{\rho_{l}}{\rho_{g}}\right)^{0.22} \\
E_{2}=0.0273\left(\frac{G^{2} d_{h}}{\sigma \rho_{l}}\right)\left(\frac{G d_{h}}{\mu_{l}}\right)^{-0.51}\left(\frac{\rho_{l}}{\rho_{g}}\right)^{0.08}
\end{gathered}
$$

where $S$ is the slip ratio and $\sigma$ is the surface tension. In this work, only the surface tension of water is considered for modelling, since methanol concentration is relatively low. The following equation is derived by curve fitting the water surface tension versus temperature data, obtained from the National Institute of Standards and Technology (NIST):

$$
\sigma=-0.0002(T[K]-273)+0.076
$$

\subsection{Two-Phase Pressure Drop}

Accurate prediction of the two-phase pressure drop in the DMFC anode compartment, is of paramount importance to the design and optimization of fuel channels, manifolds and pumping systems. In general, the total pressure drop of a two-phase flow consists of gravitational, acceleration, frictional and form components. In this section, each pressure drop component is explained in detail.

\subsubsection{Gravitational Pressure Drop}

The two-phase gravitational pressure drop is due to the force of gravity which is exerted on the bulk of the two-phase fluid. It can be calculated as follows:

$$
\Delta P_{\text {grav }}=\rho_{t p} g \Delta h
$$

where $\Delta P_{\text {grav }}$ is the gravitational component of the two-phase pressure drop, $\rho_{t p}$ is the two-phase mixture density and $\Delta h$ is the vertical elevation. The two-phase mixture density can be expressed by the following equation: 


$$
\rho_{t p}=\alpha \rho_{g}+(1-\alpha) \rho_{l}
$$

\subsubsection{Acceleration Pressure Drop}

In the DMFC anode compartment, the bulk density of the two-phase fluid varies along the fuel channel as methanol solution is consumed and carbon dioxide is generated. This variation in bulk density, creates an extra momentum within the two-phase fluid which is represented by the acceleration pressure drop.

The momentum variation is easily determined from the inlet and outlet conditions of the overall system, as follows:

$$
\Delta P_{a c c}=\left[\frac{x^{2} G^{2}}{\rho_{g} \alpha}+\frac{(1-x)^{2} G^{2}}{\rho_{l}(1-\alpha)}\right]_{\text {outlet }}-\left[\frac{x^{2} G^{2}}{\rho_{g} \alpha}+\frac{(1-x)^{2} G^{2}}{\rho_{l}(1-\alpha)}\right]_{\text {inlet }}
$$

where $\Delta P_{a c c}$ is the acceleration component of the two-phase pressure drop.

\subsubsection{Frictional Pressure Drop}

As fluid particles travel inside the fuel channels, a large portion of their kinetic energy is lost through friction with channel walls. This energy loss is presented in the form of frictional pressure drop. In the case of two-phase flow in the DMFC anode compartment, two types of modelling approaches can be applied.

The first approach is the "homogenous flow modelling". This approach consists of modelling the two-phase stream as a single phase flow with mixed properties. The frictional pressure drop is then calculated with single phase equations. The second approach is the "separated flow modelling". In this approach, the pressure gradient due to one phase is first calculated from the phase flow properties and the result is then, multiplied by a corresponding correction factor to yield the two-phase pressure gradient. In this work, the frictional pressure drop component is calculated by both methodologies and the results are compared against experimental data. 


\section{Homogeneous Flow Modelling Equations}

In this type of modelling approach, the frictional component of the two-phase pressure drop $\left(\Delta P_{f r i c}\right)$ is obtained by Weisbach (1850) [52] equation for single phase flows, as presented below:

$$
\Delta P_{\text {fric }}=\frac{1}{2} f \frac{L}{d_{h}} \frac{G^{2}}{\rho_{\text {avg }}}
$$

where $f$ is the Darcy friction factor and $L$ is the channel length. As mentioned earlier in Chapter 2, $\rho_{\text {avg }}$ is the average mixture density and is calculated by Equation 2.2. Since the flow inside the DMFC anode compartment is laminar, the Darcy friction factor is only dependent on average Reynolds number $\left(R e_{a v g}\right)$, as follows:

$$
f=\frac{4 C_{f}}{R e_{\text {avg }}}
$$

where $C_{f}$ is the friction constant which depends only on the channel geometry. For a channel with a rectangular cross-section, Shah and London (1978) [57] developed a correlation for calculating $C_{f}$ as a function of aspect ratio $(a)$, in the form of:

$$
C_{f}=96\left(1-1.3553 a+1.9467 a^{2}-1.7012 a^{3}+0.9564 a^{4}-0.2537 a^{5}\right)
$$

It is important to note that in order to calculate the average mixture viscosity $\left(\mu_{\text {avg }}\right)$, the correlation by Cicchitti et al. $[24,25]$ is used (Equation 2.5).

\section{Separated Flow Modelling Equations}

In this type of modelling approach, the frictional component of the two-phase pressure drop $\left(\Delta P_{\text {fric }}\right)$ is calculated as follows:

$$
\left(\frac{\Delta P_{\text {fric }}}{\Delta L}\right)_{t p}=\phi_{l}^{2}\left(\frac{\Delta P_{\text {fric }}}{\Delta L}\right)_{l}
$$

where $\left(\frac{\Delta P_{\text {fric }}}{\Delta L}\right)_{t p}$ and $\left(\frac{\Delta P_{\text {fric }}}{\Delta L}\right)_{l}$ are the frictional pressure gradients of the twophase mixture and liquid phase, respectively. The term $\phi_{l}^{2}$ is the two-phase multiplier, being derived from the following equation: 


$$
\phi_{l}^{2}=1+\frac{C}{X}+\frac{1}{X^{2}}
$$

The corresponding values for parameter $C$ in Equation 3.72 are presented in Table 3.4 [23]. As mentioned in Chapter 2, $X$ is the Lockhart-Martinelli parameter and is calculated as follows:

$$
X^{2}=\frac{\left(\frac{\Delta P_{\text {fric }}}{\Delta L}\right)_{l}}{\left(\frac{\Delta P_{\text {fric }}}{\Delta L}\right)_{g}}
$$

Since the flow stream inside the fuel channel is extremely slow, it can be considered to be laminar and thus, the above formula can be simplified to the following equation:

$$
X=\left(\frac{1-x}{x}\right)^{0.5}\left(\frac{\rho_{g}}{\rho_{l}}\right)^{0.5}\left(\frac{\mu_{l}}{\mu_{g}}\right)^{0.5}
$$

Table 3.4: List of correlation values for $C$

\begin{tabular}{|l|l|c|}
\hline Liquid & Gas & $C$ \\
\hline Turbulent & Turbulent & 20 \\
\hline Laminar & Turbulent & 12 \\
\hline Turbulent & Laminar & 10 \\
\hline Laminar & Laminar & 5 \\
\hline
\end{tabular}

It is important to note that, the liquid phase frictional pressure gradient $\left(\left(\frac{\Delta P_{\text {fric }}}{\Delta L}\right)_{l}\right)$ is calculated by the following equation:

$$
\left(\frac{\Delta P_{f r i c}}{\Delta L}\right)_{l}=\frac{2 C_{f} \mu_{l} G(1-x)}{\rho_{l} d_{h}^{2}}
$$

\subsubsection{Form Pressure Drop}

The form pressure drop occurs when the fluid particles lose their kinetic energy as they travel through bends, sudden enlargements or contractions, orifices and valves. 
This type of pressure drop is one of the least-studied aspects in two-phase pressure drop modelling [23].

As shown in Figure 3.1, a parallel serpentine design was considered for fuel channels. Maharudrayya et al. [35] investigated the single phase laminar flow through serpentine channels and developed a three regime correlation for form pressure factor $(K)$, based on the Reynolds number. The following set of equations are developed by substituting the corresponding fuel cell geometry values into Maharudrayya's three regime correlation:

$$
K= \begin{cases}0 & \text { if } 0<R e_{a v g}<100 \\ 0.75 R e_{\text {avg }}^{0.33} & \text { if } 100<R e_{a v g}<1000 \\ 5.51 & \text { if } 1000<R e_{\text {avg }}<2100\end{cases}
$$

where $K$ is the single phase form pressure factor for a $90^{\circ}$ bend. In another study, Chisholm (1968) [23] developed a correlation for two-phase form pressure factor for $90^{\circ}$ bends. He started with the Lockhart-Martinelli equation and used a similar approach to calculate the two-phase form pressure drop $\left(\Delta P_{\text {form }}\right)$. However, instead of using the two-phase multiplier, he developed a specific form pressure correction factor $\left(\phi_{f}^{2}\right)$ to account for bend losses.

$$
\begin{gathered}
\left(\frac{\Delta P_{\text {form }}}{\Delta L}\right)_{t p}=\phi_{f}^{2}\left(\frac{\Delta P_{\text {fric }}}{\Delta L}\right)_{l} \\
\phi_{f}^{2}=1+\frac{Z}{X}+\frac{1}{X^{2}}
\end{gathered}
$$

where $\left(\frac{\Delta P_{\text {form }}}{\Delta L}\right)_{t p}$ is the two-phase form pressure gradient, $X$ is the LockhartMartinelli parameter and $Z$ is the form pressure parameter which is calculated by the following formula:

$$
Z=\Psi\left(\frac{\rho_{g}}{\rho_{l}-\rho_{g}}\right)^{0.5}\left[\left(\frac{\rho_{g}}{\rho_{l}}\right)^{0.5}+\left(\frac{\rho_{l}}{\rho_{g}}\right)^{0.5}\right]
$$

Parameter $\Psi$ is calculated by the following equation: 


$$
\Psi=1+\frac{2.2}{K\left(2+\frac{R}{d_{h}}\right)}
$$

where $K$ is the single phase form pressure factor for a $90^{\circ}$ bend [47] and $R$ is the bend radius. Finally, the total two-phase pressure drop $\left(\Delta P_{\text {total }}\right)$ is obtained by adding gravitational, acceleration, frictional and form components.

$$
\Delta P_{\text {total }}=\Delta P_{\text {grav }}+\Delta P_{\text {acc }}+\Delta P_{\text {fric }}+\Delta P_{\text {form }}
$$

\subsection{Solution Procedure}

In order to obtain the flow and pressure variations within the anode compartment, the flow domain which is confined by the channel geometry is divided into $N_{p}$ number of nodes. Each nodal point is surrounded by a control volume to form a differential element.

The calculation process is started from the first node at the inlet. Initially, the mass conservation and species transport principles are applied in both $x$ and $y$ directions within the control volume to obtain the channel-wise differential mass flow rates, and thickness-wise concentration profiles for methanol, water and carbon dioxide.

As a quasi-two dimensional model, once the first nodal point is processed iteratively (in $y$ direction), the software advances forward to the adjacent node (in $x$ direction) and applies the same calculation scheme, until the outlet section is reached. In addition, the differential two-phase pressure drop at each nodal point (in $x$ direction) is calculated by solving the corresponding pressure drop equations.

\subsection{Experimental Setup}

In order to verify the modelling results, two sets of experimental data were considered. The first set was obtained by in-house testing of a single FE-DMFC unit with parallel serpentine flow bed design, at various operating conditions such as: current density, methanol solution flow rate and temperature. The second set of data was 
acquired from the work of Yang et al. [32] They tested a single DMFC unit with single serpentine flow bed design at various operating conditions.

For the in-house testing as illustrated in Figure 3.4, the pre-heated methanol solution is pumped through the anode compartment using a peristaltic pump (MASTERFlex C/L Pump). In order to avoid the accumulation of $\mathrm{CO}_{2}$ gas inside the anode fuel channels, methanol solution was directed through the cell from the lower left corner towards the outlet at the upper right corner (Figure 3.1). To measure the pressure drop between the inlet and outlet of the anode compartment, a differential pressure transducer (OMEGA - Model No: PX409-001DWU5V) was employed (Figure 3.5). The high and low pressure sides of the transducer were connected, respectively, to the pressure taps located at the inlet and outlet of the anode flow field. Using a data acquisition card (National Instruments - Model No: NI USB-6009), the transducer signal was transferred to a personal computer where the pressure drops were monitored. In order to regulate and control the fuel cell current and output voltage, a load controller (load bank) from Fideris Inc. was used. For further information with regards to the experimental equipment, please refer to Appendix B.

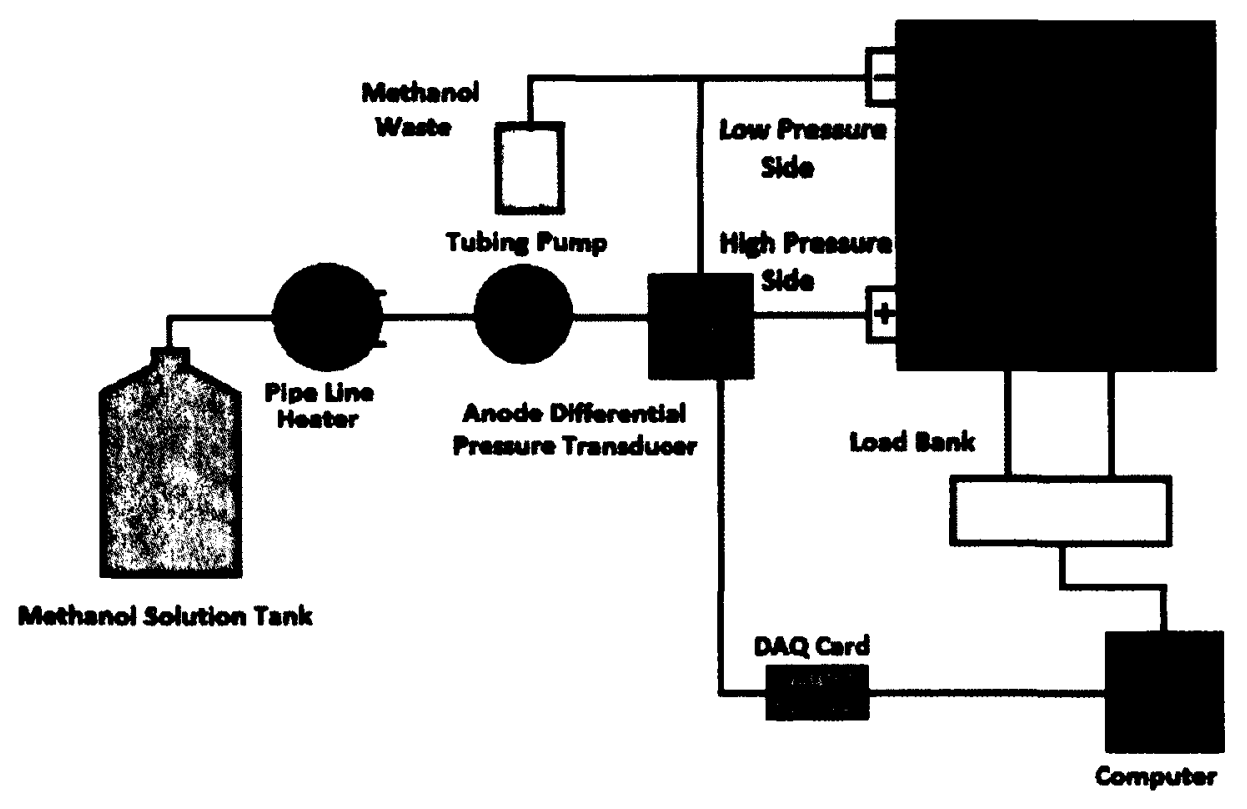

Figure 3.4: Schematic of the in-house FE-DMFC test loop 


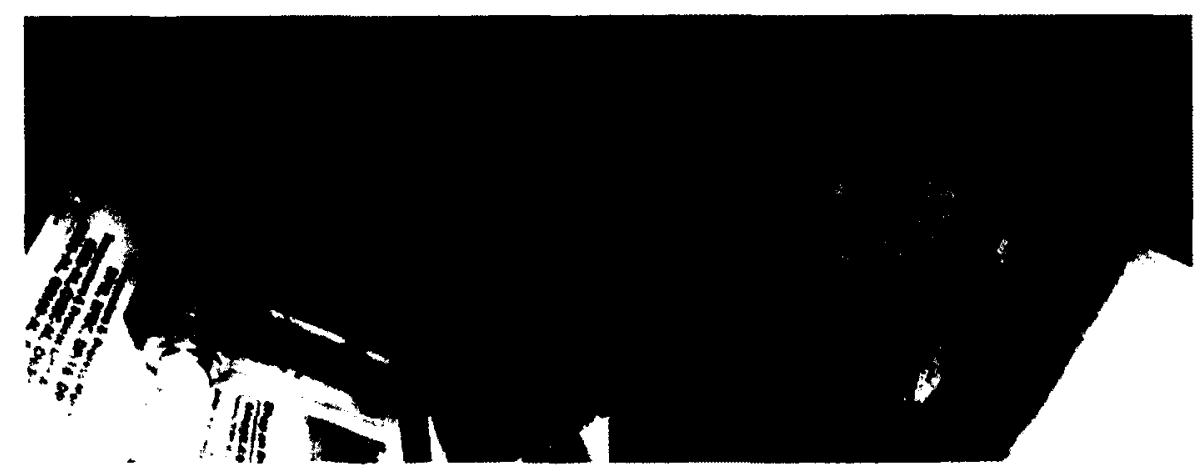

Figure 3.5: Views of differential pressure transducer (left) and DAQ card (right)

\subsubsection{Repeatability of Experimental Results}

For a typical test, the differential pressure transducer was set to collect data continuously at the rate of $1000 \mathrm{~Hz}$. Two types of measurement schemes were utilized: steady state and transient.

In the steady state scheme, the load bank was operated at constant current mode. In order to reach a steady state condition, every operation interval was set to last for one minute and during this time, the pressure variations were recorded. This process was repeated for three times at every operating condition, prior to increasing the current.

In the transient scheme, the load bank was initially set to operate at zero current (OCV condition). The current was then increased in $10 \mathrm{~mA}$ increments until it reached the upper bound. The overall sweep time was set to 2 minutes for all the experiments and for each testing process, data points were collected by recording three full sweeping cycles.

In order to verify the consistency of the in-house experimental pressure drop measurements, two unit cells were constructed and tested in two different days under similar conditions. In this work, the pressure drop curves are obtained by averaging all the corresponding measurement cycles. The error bars on the other hand, represent the corresponding standard deviation values for each data point. 


\subsection{Results and Discussions}

In this section, the hydrodynamic modelling results for a single DMFC are presented and discussed. The anode pressure drops were evaluated by applying different void fraction correlations at various fuel cell operating conditions. Both "homogenous" and "separated" flow modelling approaches were utilized.

\subsubsection{Overall Steady State Pressure Drop Variations}

The overall steady state two-phase pressure drop variations across the anode compartment were modeled using both "homogenous" and "separated" flow modelling approaches. For homogenous flow approach, the corresponding homogenous void fraction correlation was utilized; whereas for the separated flow approach, three different void fraction correlations were applied.

To verify the simulation results, five sets of experimental data from two different testing sets were used. The first set of experimental data were obtained by testing an in-house FE-DMFC unit with parallel serpentine flow bed design and channel crosssectional area of $1.5 \times 1.5 \mathrm{~mm}^{2}$ (for more details about the channel geometry and flow distribution plate, please refer to Appendix A). The second set of experimental data were obtained from the work of Yang et al. [32]. They reported the two-phase pressure drop variations across the anode compartment of a DMFC unit with single serpentine flow bed design and channel cross-sectional area of $1 \times 1 \mathrm{~mm}^{2}$.

For each set of experimental data, the corresponding geometrical parameters and operating conditions were modified in the model. By comparing the results with experimental data, the best two-phase pressure drop/void fraction combination was determined. Please refer to Table 3.5, for the list of acronyms used in the following graphs and their corresponding description.

\section{In-House Fuel Cell}

Figures 3.6, 3.7 and 3.8 show the overall two-phase pressure drop variations with respect to the operating current density across the in-house FE-DMFC unit at various methanol solution flow rates. In all cases, the corresponding experimental data are included for comparison. 
The fuel cell operating temperature was kept constant at $70^{\circ} \mathrm{C}$. Methanol and sulphuric acid concentrations were considered to be $2 \mathrm{M}$. Both air and flowing electrolyte were provided to the system at the rates of 400 and $7.5 \mathrm{ml} / \mathrm{min}$, respectively.

Table 3.5: List of acronyms used in pressure drop modelling

\begin{tabular}{|l|l|l|}
\hline Acronym & Pressure & Void Fraction \\
\hline H & Homogenous Model & Homogenous Model \\
\hline MD & Lockhart-Martinelli Model & Drift Flux Model \\
\hline MM & Lockhart-Martinelli Model & Lockhart-Martinelli Model \\
\hline MC & Lockhart-Martinelli Model & CISE Model \\
\hline
\end{tabular}

At zero current density (OCV condition), the flow within the anode fuel channel was single phase, i.e., no $\mathrm{CO}_{2}$ was generated. As the current density was increased, carbon dioxide gas was generated at the anode catalyst layer, which diffused backwards into the fuel channel to form a two-phase flow regime. As mentioned in Chapter 1, at low current densities, the flow regime within the fuel channel was "bubbly" and at higher current densities, the flow pattern became "slug/plug".

As shown in these figures, increasing the operating current density, led to a decrease in overall two-phase pressure drop, particularly at lower flow rates. This was due the fact that, since the fuel (methanol solution) was in liquid form, the gravitational component of the two pressure drop had the highest impact on the overall pressure drop value. By increasing the current density, the amount of carbon dioxide gas within the anode fuel channel was increased and thus, the overall two-phase density was reduced which in return, lowered the gravitational pressure drop.

It is important to note that by increasing the $\mathrm{CO}_{2}$ volume in the channel, the frictional and acceleration components of the two-phase pressure drop were also increased, however, their impact on the overall pressure drop was minute specially at low fuel flow rates. By increasing the flow rate on the other hand, as shown in theses 


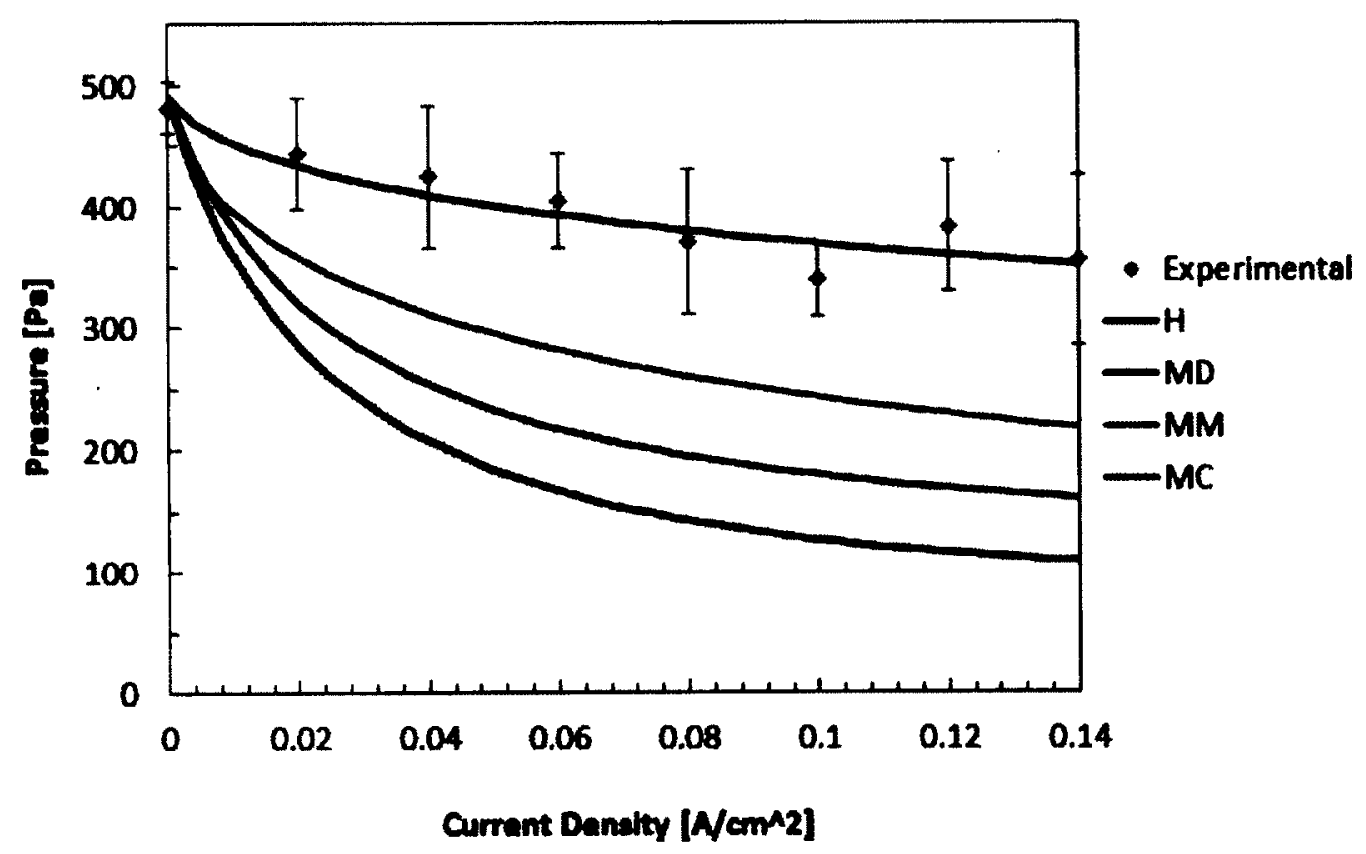

Figure 3.6: Pressure drop versus current density at $1 \mathrm{ml} / \mathrm{min}$ fuel flow rate

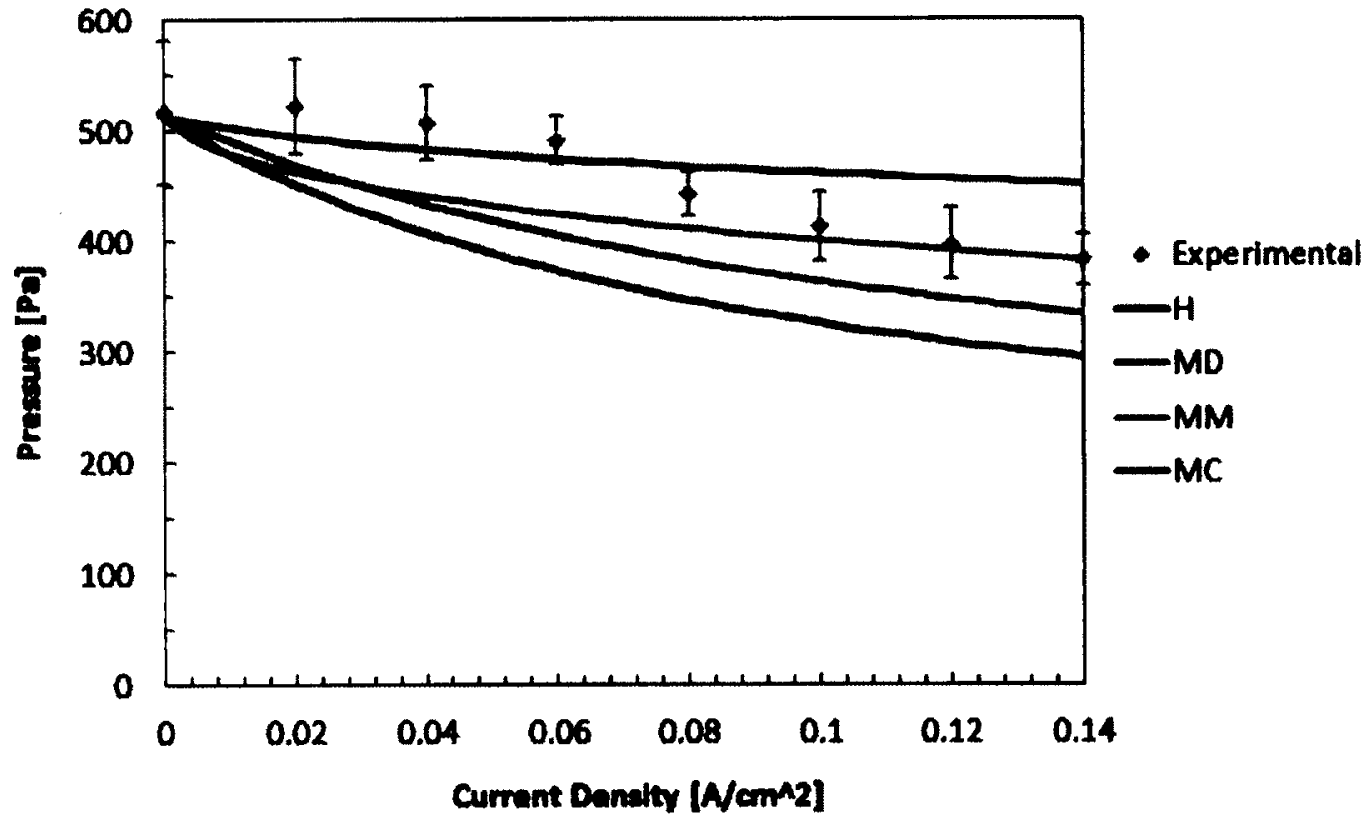

Figure 3.7: Pressure drop versus current density at $5 \mathrm{ml} / \mathrm{min}$ fuel flow rate 


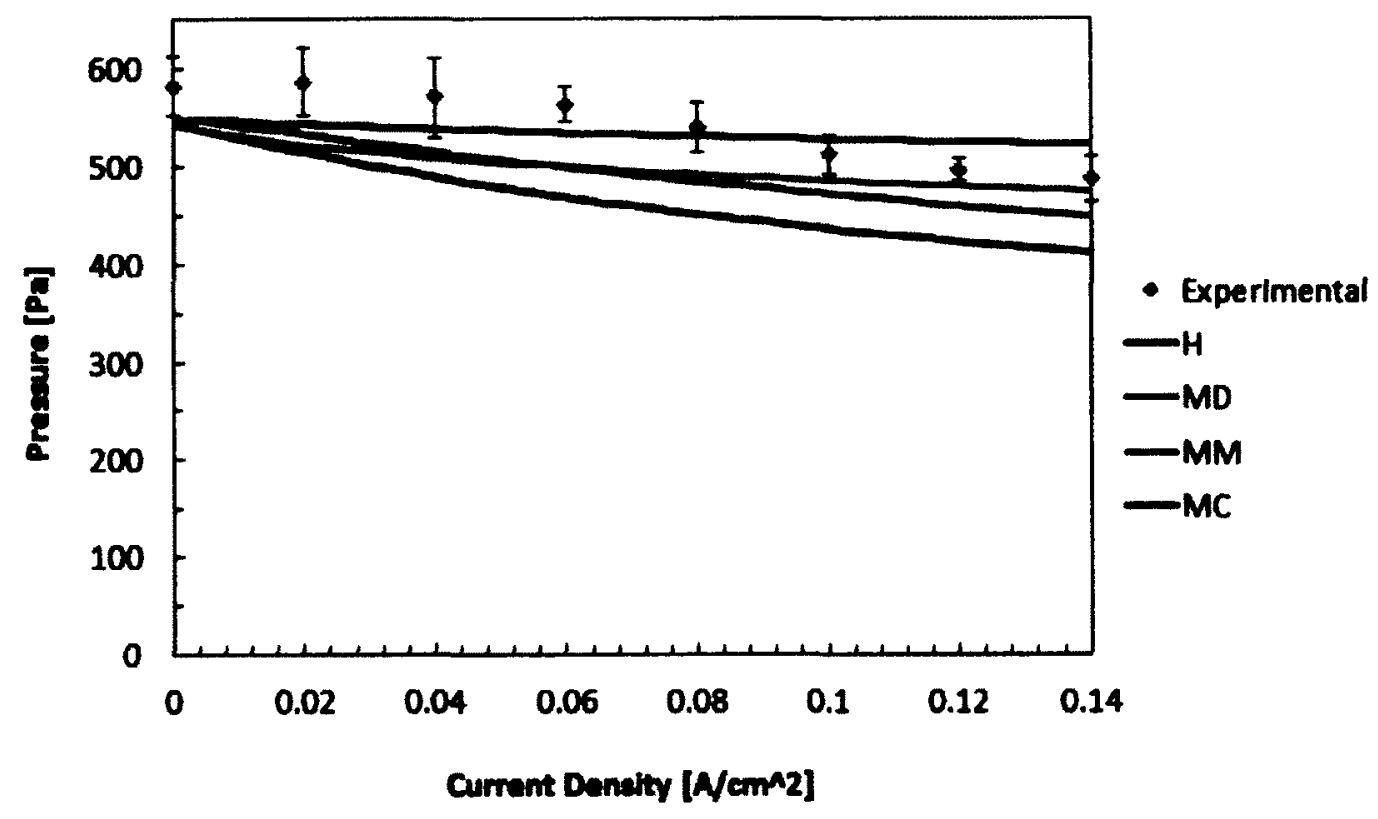

Figure 3.8: Pressure drop versus current density at $10 \mathrm{ml} / \mathrm{min}$ fuel flow rate

figures, the influence of the frictional and acceleration components were increased drastically. This was due to the fact that by increasing fuel flow rate, the friction between the wall and fluid domain as well as momentum exchange between the gas and liquid phases were increased.

By comparing the homogenous and separated flow modelling approaches and their corresponding void fraction correlations with experimental data, one can easily conclude that the homogenous flow modelling approach could not accurately predict the two-phase flow behavior. This was due to the fact that, in homogenous flow modelling approach, it was assumed that both gaseous and liquid phases travel at the same speed which was not necessarily the case, particularly at high current densities (slug/plug flow regime).

The overall pressure drop was also calculated using the separated flow modelling approach and with various void fraction correlations such as: Martinelli, Drift Flux and CISE. By comparing these correlations with experimental data, it was observed that the separated flow modelling approach combined with the CISE correlation for void fraction, provided the best two-phase pressure drop estimation across the fuel 
cell anode compartment. This was due to the fact that CISE correlation was the only void fraction correlation that took the surface tension effects into account.

In a typical DMFC, the channel thickness is relatively small and thus, the surface tension of the fuel (mainly water) plays an important role in determining the hydrodynamic behavior of the system.

As illustrated in Figures 3.6, 3.7 and 3.8, by increasing the fuel flow rate, the overall differences among various void fraction correlations were diminished. This was due to the fact that by increasing the fuel flow rate the relative liquid phase volume within the anode fuel channel was increased, which in return, resulted in significant reduction in void fraction and two-phase effects.

\section{Yang Fuel Cell}

Figures 3.9 and 3.10 show the overall two-phase pressure drop variations with respect to the operating current density across the DMFC unit, used in the work of Yang et al. [32].

Two methanol solution flow rates were considered for modelling and for each case, the corresponding experimental data were provided for comparison. The fuel cell operating temperature was maintained at $60^{\circ} \mathrm{C}$ and methanol concentration was considered to be $1 \mathrm{M}$.

As mentioned earlier, by increasing the fuel flow rate, the influences of dynamic components of the two-phase pressure drop were magnified. The overall pressure drop across the fucl cell anode compartment was estimated using both homogenous and separated flow modelling approaches. It is important to note that in separated flow modelling, the CISE correlation for void fraction was used. As expected, the best two-phase pressure drop estimation was attained by applying the separated flow modelling approach. 


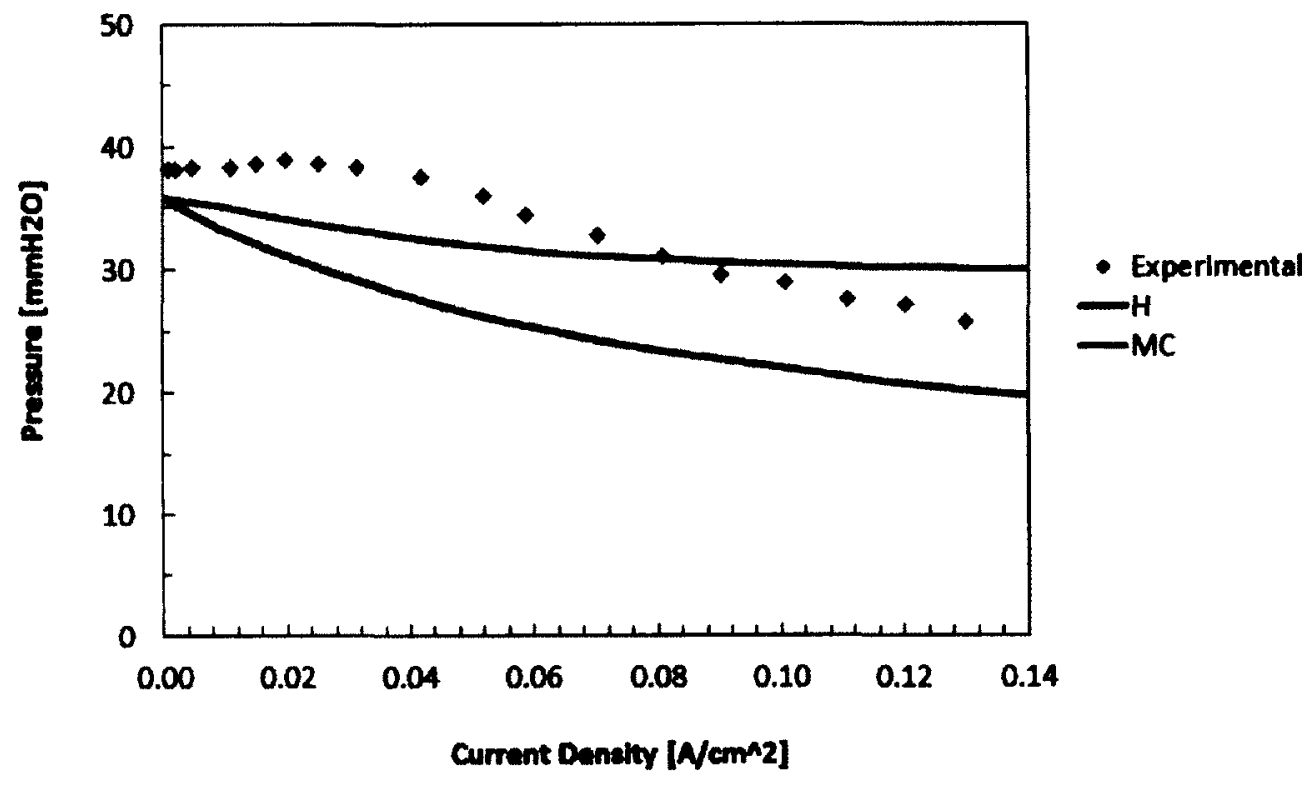

Figure 3.9: Pressure drop versus current density at $2 \mathrm{ml} / \mathrm{min}$ fuel flow rate

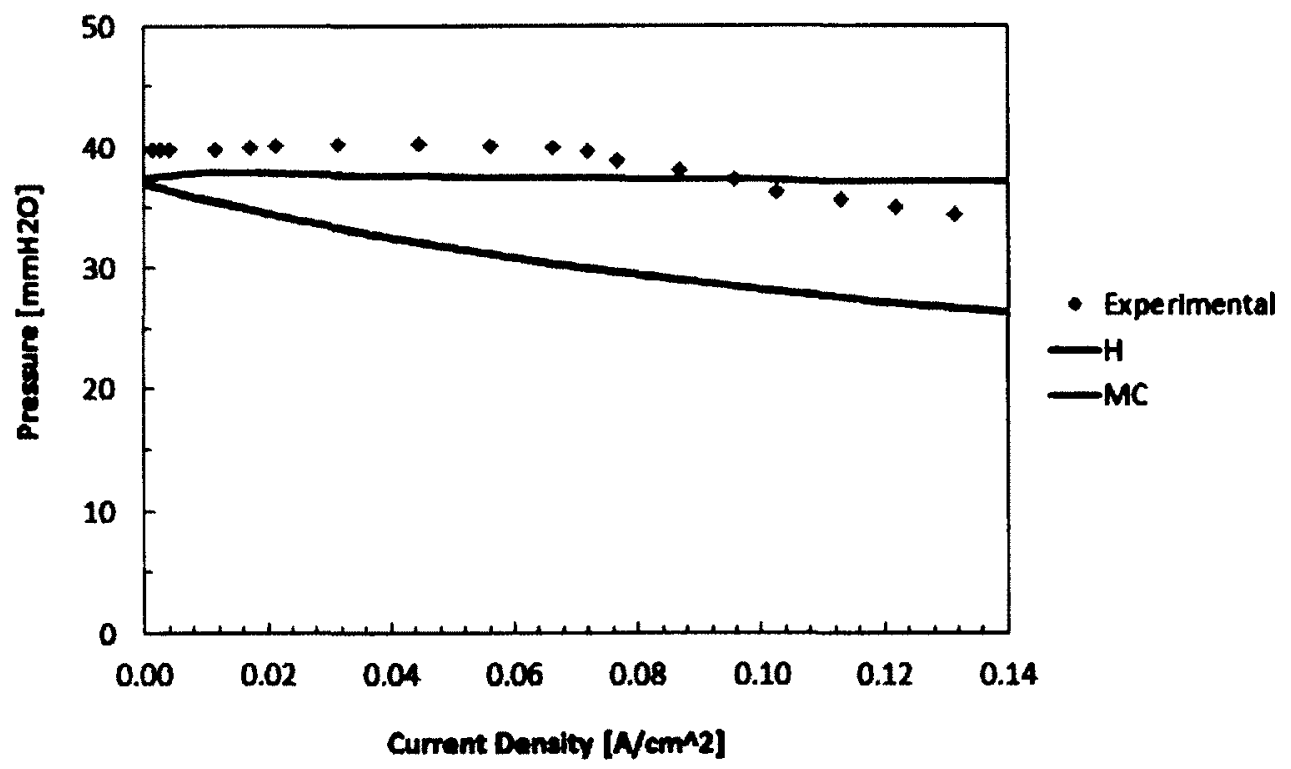

Figure 3.10: Pressure drop versus current density at $4 \mathrm{ml} / \mathrm{min}$ fuel flow rate

\subsubsection{Temperature Effects}

In this section, the temperature influence on the overall two-phase pressure drop variations across the anode compartment of the in-house FE-DMFC unit is explored. 
As mentioned in previous sections, the most accurate prediction of DMFC hydrodynamic behavior was obtained by applying the separated flow model for pressure as well as the CISE correlation for void fraction.

Figure 3.11 demonstrates the modelling results for the two-phase pressure drop variations with temperature. It was found that by increasing the fuel cell operating temperature, the pressure profile was slightly shifted downwards. This observation was also verified by experimentation as illustrated in Figure 3.11 .

For experimentation purposes, methanol and sulphuric acid concentrations were considered to be $2 \mathrm{M}$, and their respective flow rates were adjusted to 3 and 7.5 $\mathrm{ml} / \mathrm{min}$. In addition, air was provided to the system at the rate of $400 \mathrm{ml} / \mathrm{min}$.

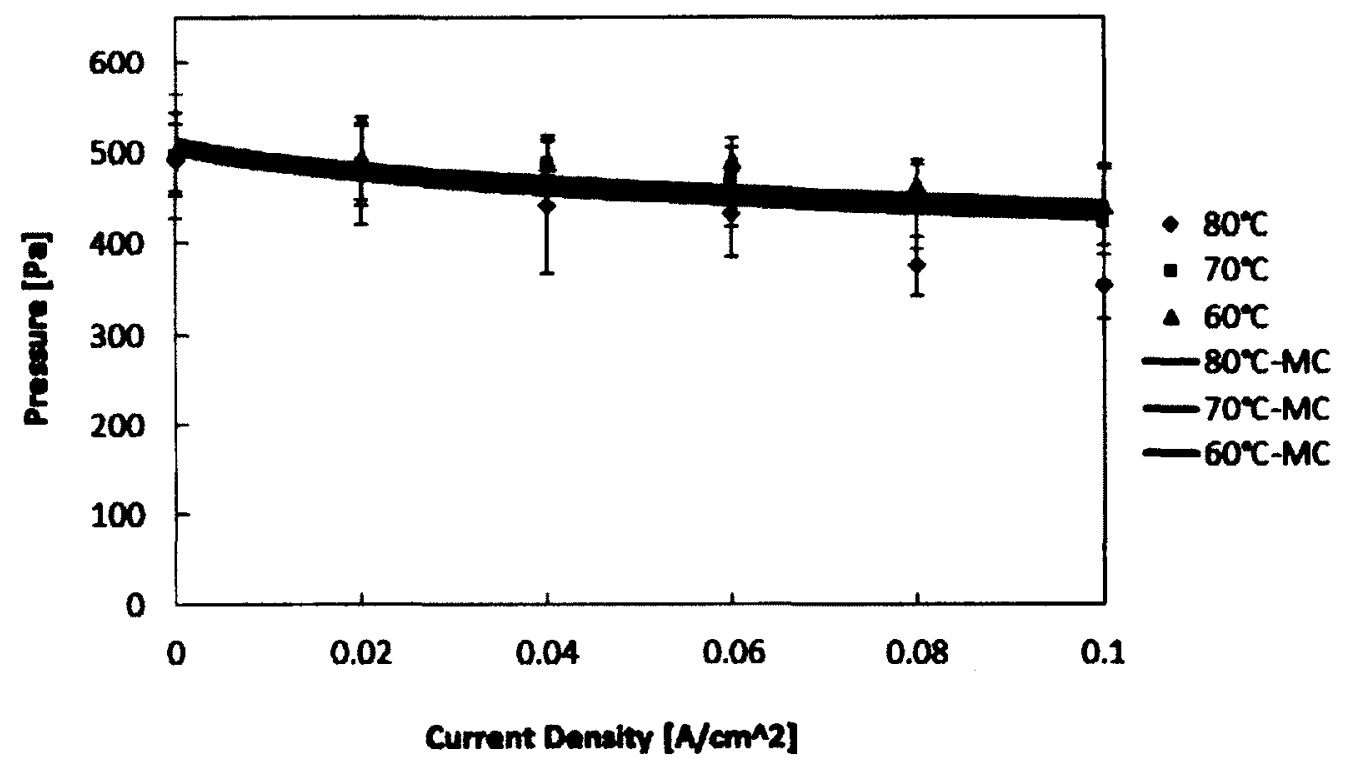

Figure 3.11: Pressure drop versus current density at various temperatures

By increasing the fuel cell operating temperature, the kinetic energy of the liquid fuel (methanol solution) was increased. This resulted in significant reduction in viscosity and thus, lowered the overall pressure across the anode compartment. 


\subsubsection{Overall Transient Pressure Drop Variations}

For better understanding of the in-house FE-DMFC hydrodynamic behavior, the transient pressure profile variations across the fuel cell anode compartment was obtained. As shown in Figure 3.12, the pressure variation with respect to the operating current density was found to be cyclic. This was due to the fact that the processes of emergence, growth and detachment of the $\mathrm{CO}_{2}$ bubbles always occurred in a periodic fashion. The frequency of this cycle was mainly dependant on fuel cell operating condition, fuel channel geometry, GDL hydrophobic/hydrophilic characteristics and the catalyst loading.

For experimentation purposes, methanol and sulphuric acid concentrations were considered to be $2 \mathrm{M}$. The fuel cell temperature was kept constant at $70^{\circ} \mathrm{C}$. Sulphuric acid flow rate was adjusted to $7.5 \mathrm{ml} / \mathrm{min}$, and air was provided to the system at the rate of $400 \mathrm{ml} / \mathrm{min}$.

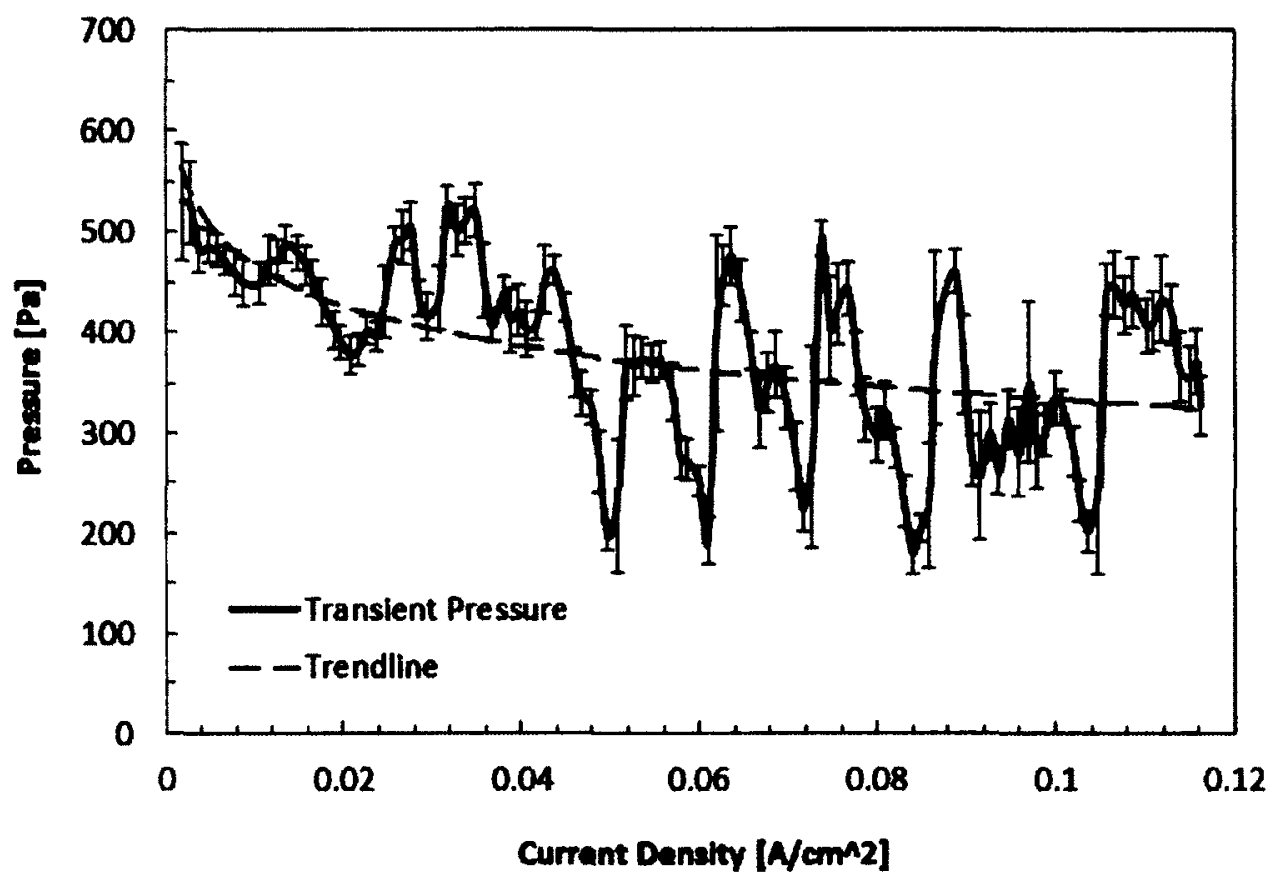

Figure 3.12: Transient pressure drop vs. current density at $1 \mathrm{ml} / \mathrm{min}$ fuel flow rate 
According to Figure 3.12, at low operating current densities, the emergence, growth and detachment of the $\mathrm{CO}_{2}$ bubbles occurred faster (with higher frequency) than that at high operating current densities. In fact, this phenomenon explained the reason behind the formation of different flow regimes inside the fuel channel.

At low operating current densities, $\mathrm{CO}_{2}$ production rate was low and the bubble formation/detachment occurred faster. This led to the dispersion of the gas phase inside the liquid domain, which created a "bubbly" flow regime. At high operating current densities on the other hand, gas generation rate was high and bubble formation/detachment took place at smaller rate. This provided more time for bubbles to expand, which in return created a "slug/plug" flow regime inside the fuel channels.

Using Fast Fourier Transform (FFT) analysis, the frequency spectrum of the pressure signal was obtained. This spectrum was then utilized to identify the constructing components of the pressure signal and detect any possible noise/interference that would influcur the musurement process. A brief description of the pressure signal Fast Fourier Transform analysis is presented in Appendix C.

\subsubsection{Anode Fuel Channel Hydrodynamics}

In previous sections, the hydrodynamic modelling results were compared against two sets of experimental data. The first set of experimental data were obtained by in-house testing of a FE-DMFC unit with a parallel serpentine flow bed design, and the second set were obtained from the work of Yang et al. [32], who measured the two-phase pressure drop across a DMFC unit with single serpentine flow bed design. Both fuel cells had a $25 \mathrm{~cm}^{2}$ reaction area.

Using the single cell hydrodynamic model (separated flow modelling for pressure and CISE correlation for void fraction), various hydrodynamic characteristics such as methanol concentration, void fraction and total pressure drop distributions along the fuel channels were modeled at various operating current densities. In the following sections, it was assumed that methanol solution concentration and flow rate were 2 $\mathrm{M}$ and $5 \mathrm{ml} / \mathrm{min}$. respectively. The fuel cell temperature was kept constant at $70^{\circ} \mathrm{C}$. 


\section{Methanol Concentration Variations}

Figure 3.13 demonstrates the simulation results for methanol concentration distributions along the fuel channel at operating current densities of $0.1,0.2$ and 0.3 $\mathrm{A} / \mathrm{cm}^{2}$. The methanol concentration profile in all graphs started form $2 \mathrm{M}$ (the inlet concentration), and dropped along the fuel channel towards the outlet. As the operating current density increased, the concentration profile diminished more rapidly. This was due to the fact that by elevating the operating current density, methanol consumption and carbon dioxide production rates enhanced which resulted in faster decline in methanol concentration along the fuel channel.

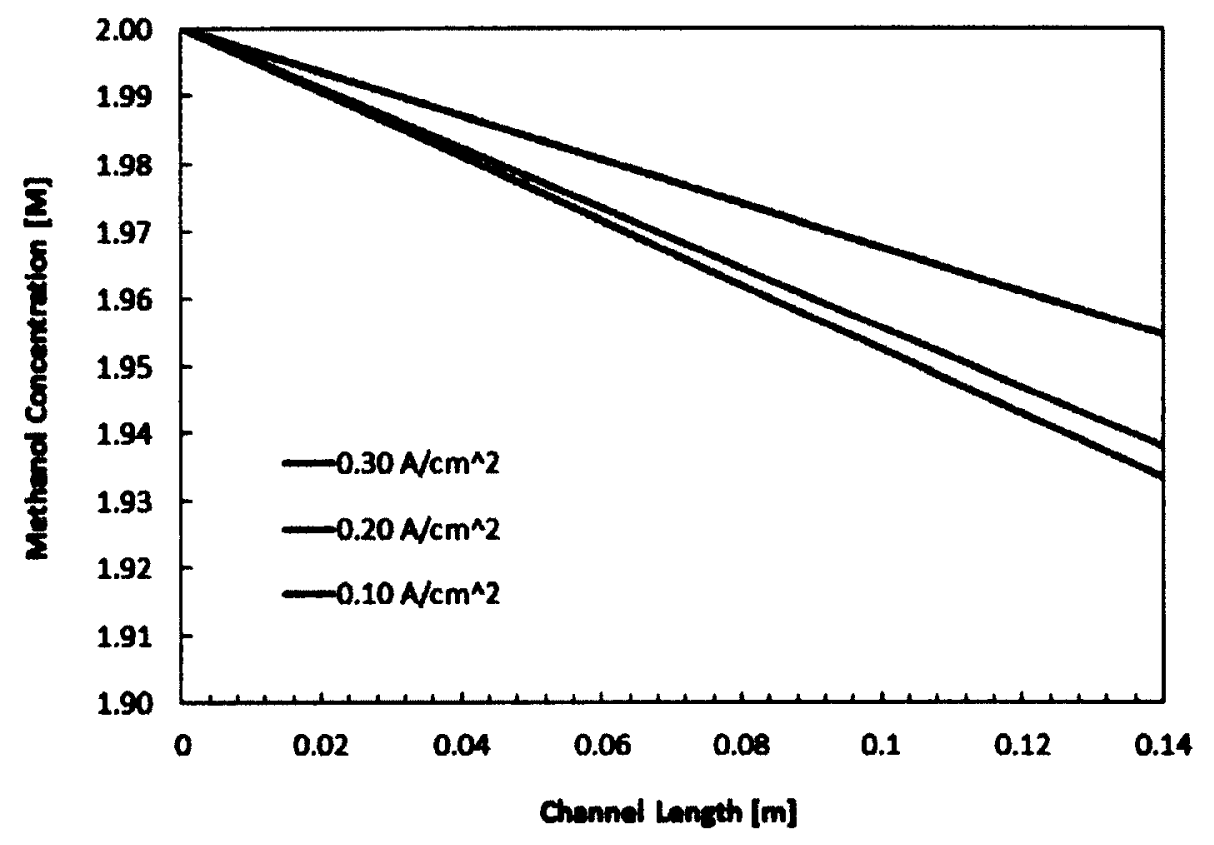

Figure 3.13: Methanol concentration variations along the fuel channel

It is also important to note that, methanol concentration did not vary significantly along the fuel channels even at high current densities. This was because during the cell operation, both methanol and water molecules were consumed/crossed-over at similar rates and thus, their ratio did not vary substantially. 


\section{Volumetric Void Fraction Variations}

The volumetric void fraction distributions at current densities of $0.1,0.2$ and 0.3 $\mathrm{A} / \mathrm{cm}^{2}$ are demonstrated in Figure 3.14.

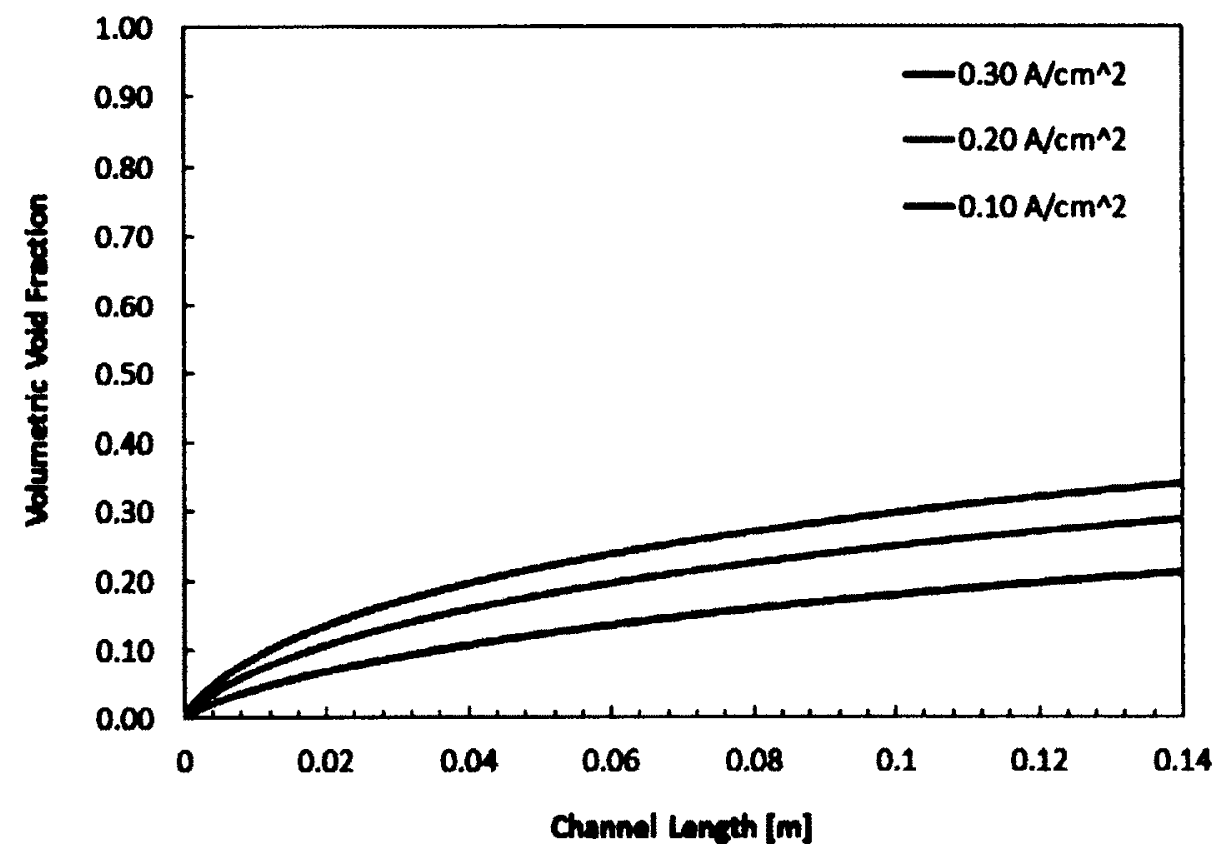

Figure 3.14: Volumetric void fraction variations along the fuel channel

When the methanol solution entered the fuel channel and traveled towards the outlet, methanol and water molecules diffused through the anode backing layer and reached the catalyst sites to produce protons, electrons and carbon dioxide gas. This carbon dioxide gas was then transferred back into the fuel channel and formed a two-phase flow regime.

The rate at which $\mathrm{CO}_{2}$ was introduced into the channel, increased continuously from the fuel cell inlet towards the outlet section. This increase in gaseous phase and reduction in liquid phase along the channel, caused the volumetric void fraction to increase.

As expected, by elevating the fuel cell operating current density, gas generation and liquid consumption rates at the anode compartment were increased and thus, higher volumetric void fractions were observed. 


\section{Pressure Variations}

The variations of the four components of the two-phase pressure drop along the fuel channel at the operating current density of $0.2 \mathrm{~A} / \mathrm{cm}^{2}$, are presented in Figure 3.15 .
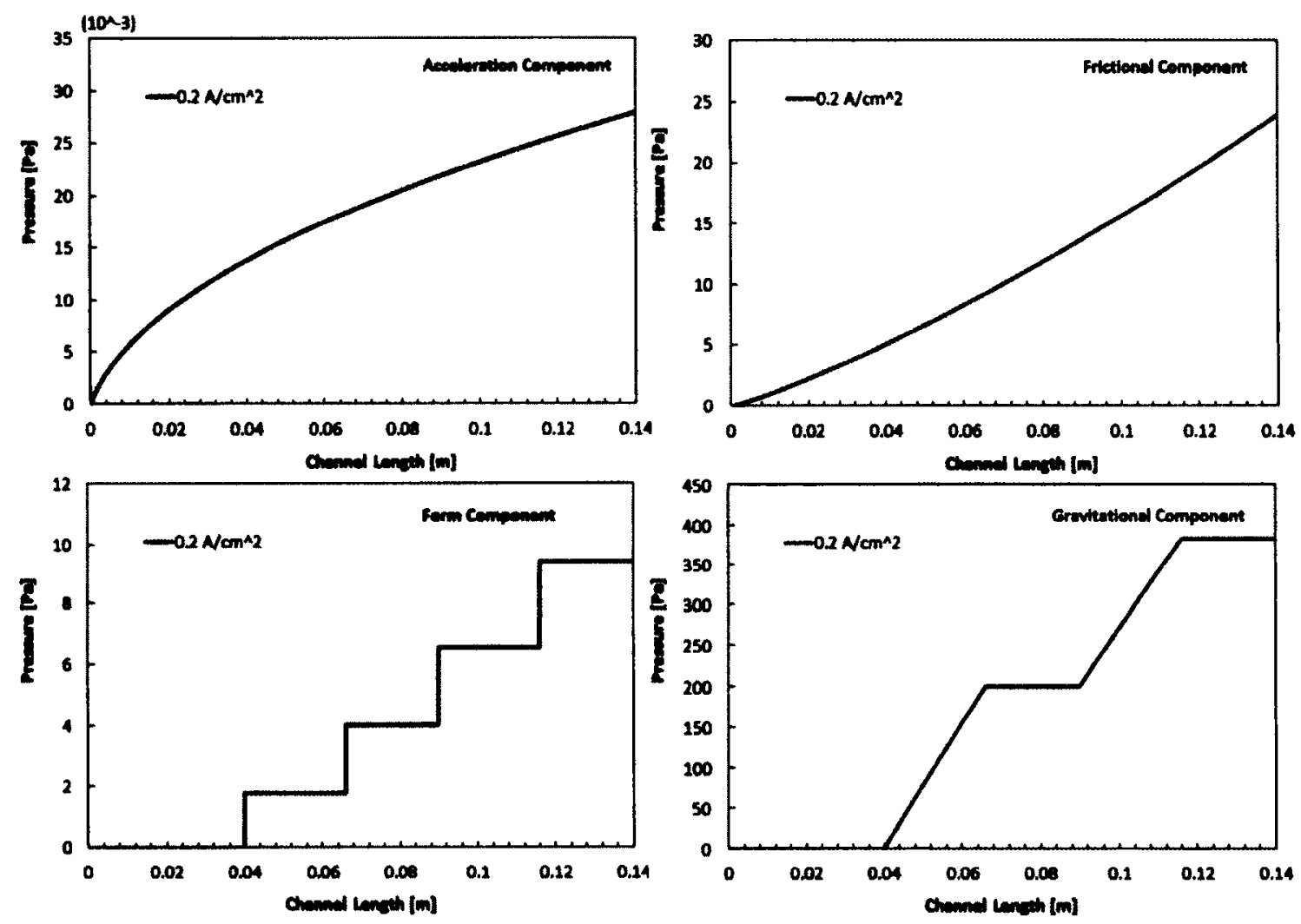

Figure 3.15: Two-phase pressure drop components along the fuel channel

As shown in Figure 3.15, the acceleration component of the two-phase pressure increased with channel length. This was due to the increase in gas volume along the fuel channel which enhanced the momentum exchange between the gas and liquid phases. Compared to other two-phase pressure drop components, the influence of the acceleration component was found to be negligible. This was attributed to the large density difference between the $\mathrm{CO}_{2}$ gas and liquid methanol solution.

Similarly, the frictional component of the two-phase pressure showed an increasing trend along the fuel channel. As methanol solution traveled within the anode 
compartment, the gas phase volume inside the fuel channel was increased. Since the channel cross-sectional area was relatively small, the rise in $\mathrm{CO}_{2}$ volume effectively enhanced the friction force between the two-phase fluid and the wall boundaries and thus increased the frictional component.

The variations in form component of the two-phase pressure are also presented in Figure 3.15. It can be seen that, the form pressure increased step-wise at every $90^{\circ}$ bend inside the anode compartment. It is interesting to note that, the value of each step systematically increased along the fuel channel. This was due to the elevation in $\mathrm{CO}_{2}$ gas volume along the anode compartment, which in return, enhanced the two-phase flow effects at the bends closer to the cell outlet.

As illustrated in Figure 3.15, the gravitational component of the two-phase pressure had the highest impact on the overall pressure drop across the DMFC anode compartment. At a fixed operating current density, the only parameter affecting the gravitational pressure was found to be the vertical displacement of the liquid methanol solution which occurred twice along the fuel pathway.

Figure 3.16 illustrates the total two-phase pressure distributions inside the fuel channel at operating current densities of $0.1,0.2$ and $0.3 \mathrm{~A} / \mathrm{cm}^{2}$.

The major increase in the overall two-phase pressure occurred along the two vertical sections of the fuel channel. This was due to the fact that, since the fuel was in liquid form, the gravitational component of the two-phase pressure dominated other pressure components.

By increasing the fuel cell operating current density, as shown in Figure 3.14, the gas production rate was elevated and thus, the overall two-phase fluid density along the fuel channel was reduced significantly. As a result, the gravitational component of the two-phase pressure diminished which in return, lowered the overall two-phase pressure drop. This behavior was also observed during the experimental testing.

It is also important to note that, by increasing the operating current density, the acceleration, frictional and form components of the two-phase pressure drop increased; 


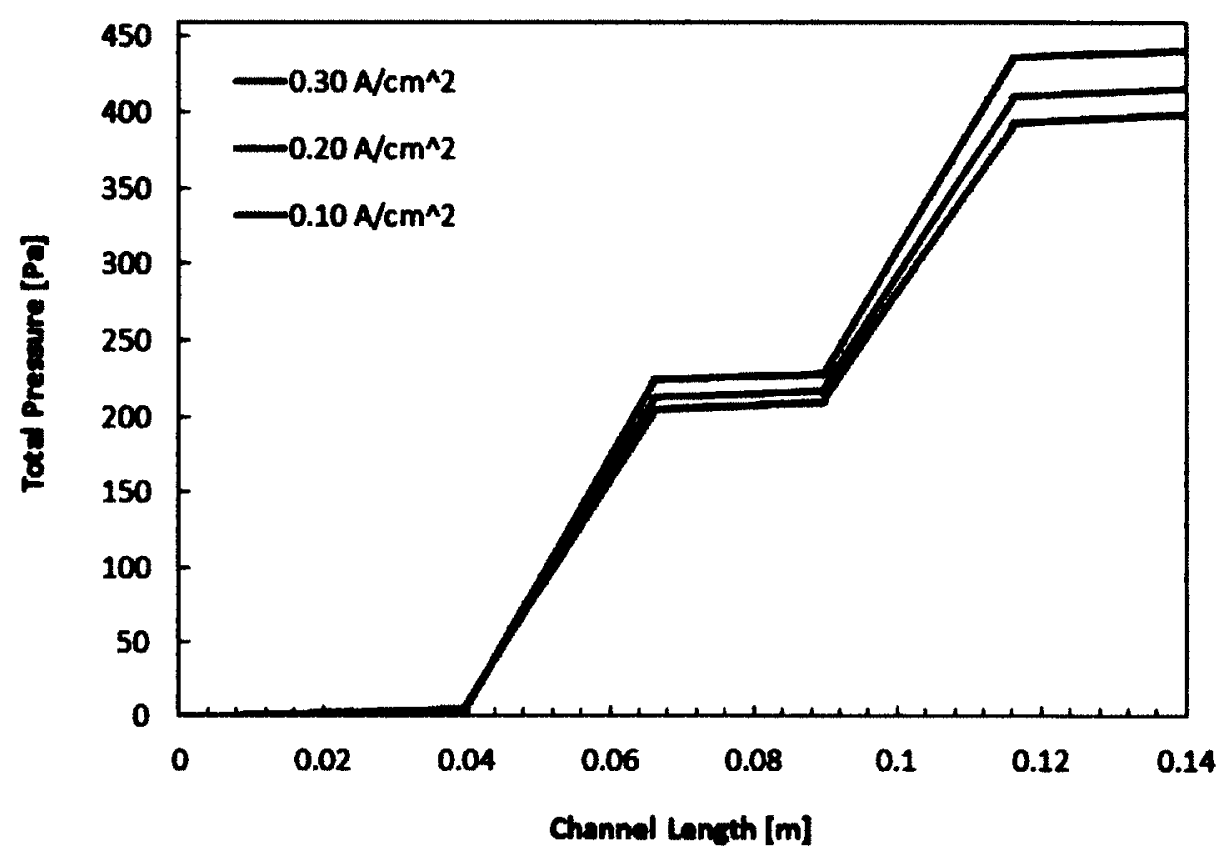

Figure 3.16: Total two-phase pressure variations along the fuel channel

however, their influence on the total two-phase pressure drop was not significant. 


\section{Chapter 4}

\section{DMFC Anode Hydrodynamic Modelling (Stack)}

As mentioned in Chapter 1 , in order to increase the power output of the direct methanol fuel cells, several unit cells are clustered together with either internal or external manifolds. One major problem encountered during the preliminary design stages of a typical DMFC stack, is the reactant flow distribution within the stack manifolds and fuel channels. In this chapter, a numerical model is proposed to evaluate the reactant flow and pressure distribution inside a DMFC stack. Ultimately, the modelling results are compared against experimental data.

\subsection{Background}

Manufacturing a fuel cell stack is often costly and requires intricate design. One major problem is the issue of flow distribution. As the stack size increases, reactant (fuel) flow distribution becomes extremely uneven causing some cells to receive excessive quantities of methanol solution while the others, lack the required amounts. As the fuel flow rate varies from one cell to another, the electrochemical reaction rate at the anode side of each individual cell changes, which causes a non-uniform power distribution inside the stack.

In order to avoid flow maldistribution within the DMFC stack anode compartment, the internal manifolds and fuel channels have to be properly constructed. However, due to high manufacturing costs, it is not viable to build several stack prototypes only for investigating flow and pressure distributions. Therefore, it is important 
to properly predict the circulation of fuel within the stack anode compartment at preliminary design stages.

In this work, a numerical hydrodynamic model is developed and utilized to examine the flow and pressure distributions within the anode compartment of a typical DMFC stack. As shown in Figure 4.1, the system has parallel serpentine fuel channel design and U-type reactant flow configuration.

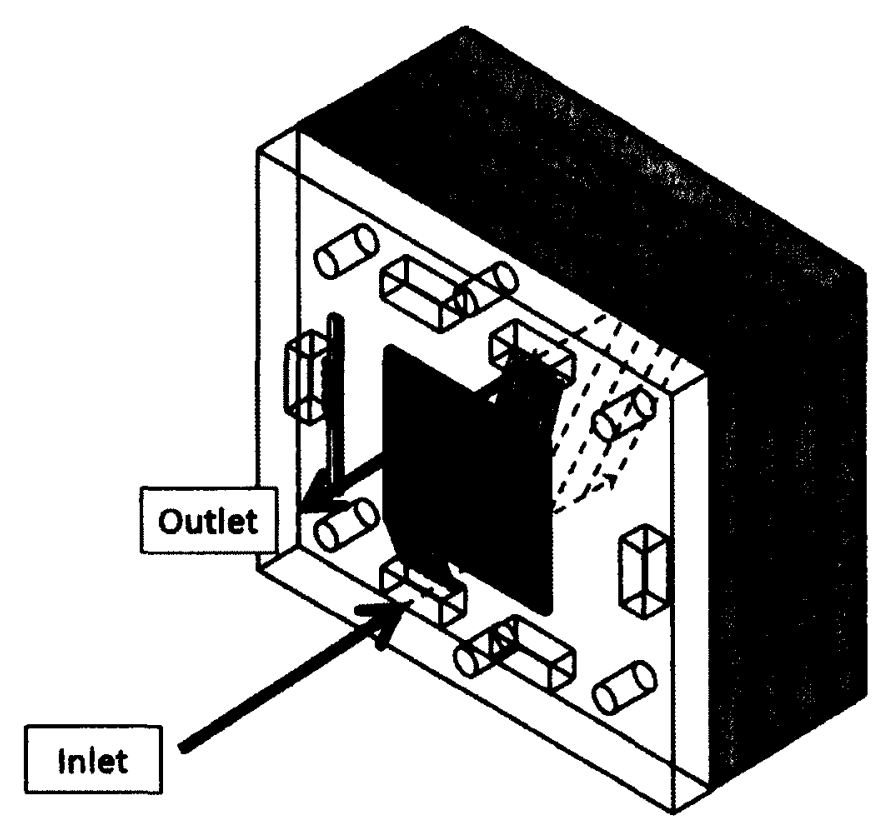

Figure 4.1: Schematic of stack fuel channels and manifold configuration

\subsection{Methodology}

This model originally assumes the principles of the "Hardy-Cross" method, but utilizes a better way for estimating the flow rate correction factors. The following assumptions were considered for stack modelling:

1. The stack operates at steady state condition;

2. The current distribution over the reaction area of each individual cell is assumed to be uniform; 
3. The stack operates at constant temperature;

4. The flow remains laminar inside the stack manifolds and fuel channels and;

5. The hydrodynamic performance of each unit cell in the DMFC stack, is modeled using the similar two-phase model, developed in the previous chapter (with all the corresponding assumptions).

\subsubsection{Hardy-Cross Algorithm}

This iterative method was first introduced by Hardy Cross (1936) [52]. It utilizes the conservation of mass and momentum principles to estimate the flow and pressure distributions within a network system.

In this method, an initial guess for flow rate is applied at each flow junction to satisfy the continuity. The flow rate values are then corrected by considering the fact that the summation of all the head losses around each loop in the network should add-up to zero (momentum conservation principle).

The following calculation scheme is applied for DMFC stack hydrodynamic modelling (Figure 4.2):

1. Every loop in the DMFC stack is identified and numbered;

2. An arbitrary flow direction (positive for clockwise and negative for counterclockwise) is assumed for every loop;

3. An initial guess value was assigned for the flow rate through each unit cell;

4. Using the same sign convention, head losses in each section are calculated;

5. The closure condition for each loop is checked by summing the head loss values in all segments in that loop;

6. The flow correction factors are calculated for each unit cell, to improve the head loss closure condition;

7. The process is repeated until all the head losses converged to a desired accuracy (convergence limit). 


\subsubsection{Modelling Equations}

A DMFC stack unit with U-type manifold design is considered for modelling, where the individual cells are numbered from 1 to $N$ in reverse order (Figure 4.2). The fuel enters and exits the system from the same side, through the $N^{\text {th }}$ cell.

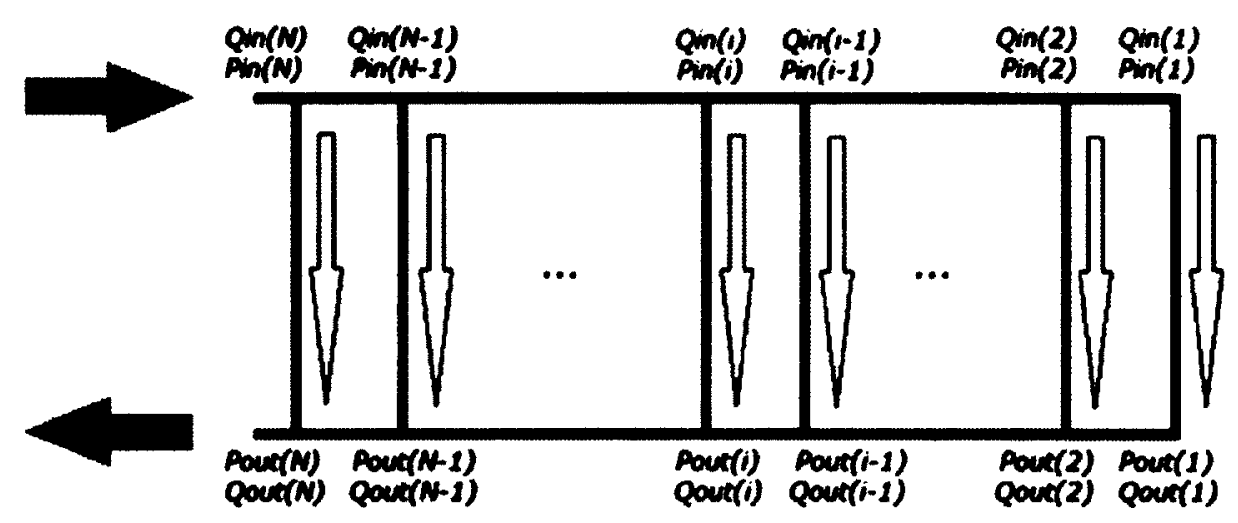

Figure 4.2: Stack pressure and flow rate variables

The cumulative methanol solution flow rate through the inlet manifold sections $\left(Q_{M-\text { in }}(i)\right)$ and the cumulative methanol solution flow rate through the outlet manifold sections $\left(Q_{M \text {-out }}(i)\right)$ in the DMFC stack are calculated by the following sets of equations, respectively:

$$
\begin{gathered}
Q_{M-\text { in }}(i)=\sum_{1}^{i} Q_{C}(i)=Q_{M-\text { in }}(i-1)+Q_{C}(i) \\
Q_{M-\text { out }}(i)=\sum_{1}^{i} Q_{C}(i)=Q_{M-\text { out }}(i-1)+Q_{C}(i)
\end{gathered}
$$

where the methanol solution flow rate through the channel area of the $i^{\text {th }}$ unit cell is denoted by $Q_{C}(i)$ and $i=2,3, N$. In addition, if the stack inlet flow rate is denoted by $Q_{\text {inlet }}$, one can write:

$$
Q_{M-i n}(N)=Q_{\text {inlet }}
$$


The pressure drops in both inlet and outlet manifold segments $\left(\Delta P_{M-i n}(i)\right)$ and $\left(\Delta P_{M-\text { out }}(i)\right)$ are calculated by the following sets of equations, respectively:

$$
\begin{gathered}
\Delta P_{M-\text { in }}(i)=P_{\text {in }}(i)+P_{\text {in }}(i-1) \\
\Delta P_{M-\text { out }}(i)=P_{\text {out }}(i-1)+P_{\text {out }}(i)
\end{gathered}
$$

where $P_{\text {in }}(i)$ and $P_{\text {out }}(i)$ are the pressure values inside the inlet and outlet manifold segments for the $i^{\text {th }}$ cell, respectively. Furthermore, the pressure drop across the fuel channel of each individual cell is denoted by $\Delta P_{C}(i)$, and is calculated by the following equation:

$$
\Delta P_{C}(i)=P_{\text {in }}(i)-P_{\text {out }}(i)
$$

As mentioned earlier, in order to solve this network flow problem, two conditions must be satisfied. The first condition is that, at any junction, the algebraic sum of flow rates into the junction must be equal to zero and the second condition implies that between any two junctions, the head loss is independent of the path taken. In other words, the overall pressure loss around any loop in the network must be equal to zero.

Inside the stack inlet manifold, the only existing fluid stream is the single phase methanol solution. As the fuel enters every individual cell in the stack, depending on the operating current density, carbon dioxide gas is generated and introduced into the fuel channels via the anode backing layer. All the generated carbon dioxide gas as well as the remaining methanol solution, are then accumulated inside the stack outlet manifold and form a two-phase flow stream towards the outlet.

In other words, there is a single phase flow inside the stack inlet manifold, which obeys the single phase hydrodynamic equations while the flow inside the stack outlet manifold is two-phase with more associated complexity. The following sections describe the pressure drop calculations within the stack inlet and outlet manifold segments. 


\section{Stack Inlet Manifold Pressure Drop Calculation}

The pressure drop within the stack inlet manifold has three components: acceleration, frictional and form. Using single phase flow equations, the following formula is developed for the overall pressure drop inside each inlet manifold segment:

$$
\Delta P_{M-i n}(i)=\frac{1}{2} \rho_{s o l}\left[\left(U_{\text {in }}(i)^{2}-U_{\text {in }}(i-1)^{2}\right)+f_{\text {in }}(i) \frac{l_{p}}{d_{h}} U_{\text {in }}(i)^{2}+K_{M} U_{\text {in }}(i)^{2}\right]
$$

and:

$$
\begin{gathered}
\rho_{s o l}=\rho_{w}+\left[M_{m e}\left(1-\left(\rho_{w} / \rho_{m e}\right)\right)\right]\left(C_{m e}^{\text {inlet }} \times 1000\right) \\
f_{i n}(i)=\frac{4 C_{f}}{R e_{s o l}(i)} \\
\operatorname{Re}_{s o l}(i)=\frac{\rho_{s o l} U_{i n}(i) d_{h}}{\mu_{l}}
\end{gathered}
$$

where $\rho_{s o l}$ is the methanol solution density inside the stack inlet manifold, $U_{\text {in }}(i)$ is the methanol solution velocity at the $i^{\text {th }}$ cell inside the stack inlet manifold, $f_{i n}(i)$ and $R e_{s o l}(i)$ are the $i^{t h}$ cell friction coefficients and Reynolds number and $l_{p}$ is the distance between the adjacent cells within the stack (stack pitch).

\section{Stack Outlet Manifold Pressure Drop Calculation}

When the manifold design is U-type, the flow directions inside the stack inlet and outlet manifold sections are opposite (Figure 1.4). As mentioned earlier, the generated $\mathrm{CO}_{2}$ gas and the remaining methanol solution are accumulated inside the outlet manifold to form a two-phase flow regime which travels towards the stack outlet. Applying a control volume at every outlet manifold segment, the gaseous quality is calculated as follows:

$$
x_{M-o u t}(i)=\frac{\sum_{1}^{i} \dot{m}_{g-\text { out }}(i)}{\sum_{1}^{i} \dot{m}_{g-\text { out }}(i)+\sum_{1}^{i} \dot{m}_{l-\text { out }}(i)}
$$

where $x_{M \text {-out }}(i)$ is the gaseous quality at every stack outlet manifold segment and $\dot{m}_{g-\text { out }}(i)$ and $\dot{m}_{l-\text { out }}(i)$ are the outlet gas phase and liquid phase mass flow rates for 
the $i^{\text {th }}$ coll. aspectively. In addition, the volumetric void fraction at every outlet

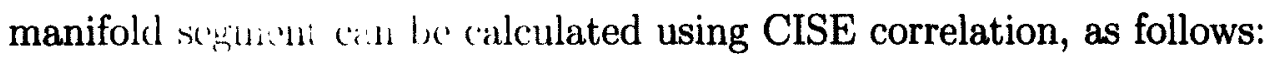

$$
a_{M-\text { out }}(i)=\left[1+\left(\frac{1-x_{M-\text { out }}(i)}{x_{M-\text { out }}(i)}\right)\left(\frac{\rho_{g-\text { out }}(i)}{\rho_{l-\text { out }}(i)}\right) S(i)\right]^{-1}
$$

and:

$$
S(i)=1+E_{1}(i) \sqrt{\frac{y(i)}{1+y(i) E_{2}(i)}-y(i) E_{2}(i)}
$$

where:

$$
\begin{gathered}
y(i)=\left(\frac{\rho_{l-\text { out }}(i)}{\rho_{\text {-out }}(i)}\right)\left(\frac{x_{M-\text { out }}(i)}{1-x_{M-\text { out }}(i)}\right) \\
E_{1}(i)=1.578\left(\frac{G_{\text {out }}(i) d_{h}}{\mu_{l-\text { out }}(i)}\right)^{-0.19}\left(\frac{\rho_{l-\text { out }}(i)}{\rho_{g-\text { out }}(i)}\right)^{0.22} \\
E_{2}(i)=\dot{v} .0273\left(\frac{G_{\text {out }}(i)^{2} d_{h}}{\sigma \rho_{l-\text { out }}(i)}\right)\left(\frac{G_{\text {out }}(i) d_{h}}{\mu_{l-\text { out }}(i)}\right)^{-0.51}\left(\frac{\rho_{l-\text { out }}(i)}{\rho_{g-\text { out }}(i)}\right)^{0.08}
\end{gathered}
$$

where $\alpha_{M-o u t}(i)$ is the volumetric void fraction at every outlet manifold segment, $G_{\text {out }}(i)$ is the rutal mitsis flux at every outlet manifold segment, $\mu_{l-o u t}(i)$ is the liquid phase viscusity at every outlet manifold segment, and $\rho_{\text {-out }}(i)$ and $\rho_{l \text {-out }}(i)$ are the outlet gascous $\mathrm{pl}$ ass' and liquid phase densities for the $i^{\text {th }}$ cell, respectively.

By knowing the quality and volumetric void fraction, the overall pressure drop inside the stack outlet manifold can be calculated. Similar to the inlet manifold section, the outlet manifold overall pressure drop is comprised of three components: acceleration, frictionai and form. These components are calculated by the corresponding two-phase pressure drop equations, introduced in Chapter 3.

\subsection{Solution Procedure}

Using the aforementioned technique for calculating the pressure drop values inside the stack minifoids anci coll channels, $N-1$ sets of equations are obtained for an $N$-cell DMFC stiks. in urder to solve the network, another equation is required 
to mathematically close the system. This extra equation is obtained by setting the outlet pressure to zero $\left(P_{\text {out }}(N)=0\right)$ which implies that the calculated pressure values within the stack unit are relative to atmospheric pressure.

The iteration process starts with an initial guess for the cell flow rates. One easy way to start is to assign an equal flow rate value to every cell inside the stack unit, which is obtained by dividing the inlet flow rate by the number of cells. Once the initial flow distribution within the stack unit is determined, and by setting the outlet pressure to zero, the pressure distribution within the outlet manifold is obtained by the corresponding pressure drop equations for the outlet.

For pressure distribution within the stack inlet manifold, similar to the analogy developed by Koh et al. [58], the last cell in the stack (cell 1) is selected as reference, and the inlet pressure for that cell is calculated. Once the inlet pressure for the reference cell is determined, the remaining pressure values within the stack inlet manifold, are obtained by applying the corresponding pressure drop equations for the inlet.

In order to correct the estimated flow rate values at each computational step, a set of correction factors are utilized. These parameters adjust the flow variations with pressure distribution inside the system, until a pre-defined convergence limit is reached. At first, the pressure drop across every individual cell inside the system is normalized, using the following equation:

$$
\eta(i)=\frac{P_{i n}(i)-P_{\text {out }}(i)}{\Delta P_{C}(\text { ref })}
$$

where $\eta(i)$ is the $i^{\text {th }}$ cell normalized pressure parameter and $\Delta P_{C}(r e f)$ is the reference cell (cell 1) pressure drop. Subsequently, the average and standard deviation of the pressure drop values for the individual unit cells inside the stack $\left(\Delta P_{\text {ave }}(i)\right.$ and $\left.\Delta P_{s t d}(i)\right)$, are calculated by the following equations:

$$
\Delta P_{\text {ave }}(i)=\frac{\sum_{1}^{i} \Delta P_{C}(i)}{i}
$$




$$
\Delta P_{s t d}(i)=\sqrt{\frac{\sum_{1}^{i}\left(\Delta P_{C}(i)-\Delta P_{a v e}(i)\right)^{2}}{i}}
$$

Finally, a flow rate correction parameter based on unit cell pressure drop, is obtained by combining Equations 4.17, 4.18 and 4.19, in the following manner:

$$
\Delta Q_{P}^{c o r}(i)=\eta(i) \frac{\Delta P_{\text {std }}(i)}{\Delta P_{\text {ave }}(i)} \frac{Q_{\text {inlet }}}{N}
$$

where $\Delta Q_{P}^{c o r}(i)$ is the flow rate correction factor based on pressure drop. The corrected inlet flow rate values for each individual cell are determined by the following equation:

$$
Q_{i n}^{c o r}(i)=Q_{i n}(i)-\Delta Q_{P}^{c o r}(i)
$$

where $Q_{i n}^{\text {cor }}(i)$ is the corrected inlet flow rate for the $i^{\text {th }}$ cell within the system. Another important closure condition for this iteration process is to satisfy the mass conservation inside the inlet manifold. Since the stack inlet flow rate $\left(Q_{\text {inlet }}\right)$ is set by the user, the following parameter $(\Delta Q)$ has to approach zero at each computational step to satisfy the continuity.

$$
\Delta Q=Q_{\text {inlet }}-\sum_{i=1}^{N} Q_{i n}^{c o r}(i)
$$

This can be achieved by applying another correction parameter to the flow, in the following manner:

$$
Q_{i n}^{c o r-n e w}(i)=Q_{i n}^{c o r}(i)+\frac{\Delta Q}{N}
$$

where $Q_{i n}^{\text {cor-new }}(i)$ is the new corrected inlet flow rate for the $i^{\text {th }}$ cell within the system. The iteration process is continued until the following condition is satisfied:

$$
\sum_{i=1}^{N}\left|Q_{i n}^{c o r-n e w}(i)-Q_{i n}(i)\right|^{2}<\xi
$$

where $\xi$ is the convergence limit and is set to $10^{-4}$. 


\subsection{Results and Discussions}

In this section, the hydrodynamic modelling results for a DMFC stack are presented and discussed. Similar to Chapter 3, the anode pressure drops were evaluated by applying different void fraction correlations at various fuel cell operating conditions. Both "homogenous" and "separated" flow modelling approaches were utilized.

The modelling results were compared against the corresponding experimental data for verification. All the experimental data were obtained by in-house testing of a five-cell FE-DMFC stack unit. The stack had a parallel serpentine flow bed design, a U-type manifold configuration and a $25 \mathrm{~cm}^{2}$ reaction area. The unit was tested at various operating conditions such as: current density and methanol solution flow rate.

As mentioned in Chapter 3 and similar to single cell hydrodynamic testing, a differential pressure transducer (OMEGA - Model No: PX409-001DWU5V) was employed to measure the pressure drop across the stack anode compartment. The high and low sides of the transducer were connected to stack inlet and outlet, respectively. For further information with regards to the experimental setup, please refer to Chapter 3 and Appendix B.

\subsubsection{Repeatability of Experimental Results}

Similar to single cell hydrodynamic testing, the differential pressure transducer was set to collect data continuously at the rate of $1000 \mathrm{~Hz}$. Both steady state and transient measurement schemes (as described in Chapter 3) were applied.

In order to ensure the repeatability of experimental pressure drop measurements, the five-cell FE-DMFC stack unit was tested in two different days under similar conditions. In this work, the pressure drop curves are obtained by averaging all the corresponding measurement cycles. The error bars on the other hand, represent the corresponding standard deviation values for each data point. 


\subsubsection{Stack Outlet Steady State Pressure Drop Variations}

In this section, the stack outlet steady state pressure drop variations at various operating current densities were modeled using the "homogenous" and "separated" flow modelling approaches along with their corresponding void fraction correlations. The modelling results were then compared with two sets of experimental data to obtain the best two-phase pressure drop/void fraction combination.

For experimentation purposes, methanol and sulphuric acid concentrations were considered to be $2 \mathrm{M}$. The stack temperature was kept constant at $70^{\circ} \mathrm{C}$. Sulphuric acid flow rate was adjusted to $7.5 \mathrm{ml} / \mathrm{min}$, and air was provided to the system at the rate of $2000 \mathrm{ml} / \mathrm{min}$.

As shown in Figures 4.3 and 4.4, by increasing the stack operating current density, the two-phase steady state pressure drop across the stack outlet was reduced. The decreasing trend in pressure drop was due to the fact that by increasing the operating current density, gas generation rates within fuel channels were increased, which in return, reduced the overall fluid density inside the system. This density reduction on the other hand caused the gravitational component of the two-phase pressure drop to decrease drastically. Since the fuel (methanol solution) was in liquid form, any change to gravitational component had the highest impact on the stack overall steady state two-phase pressure drop.

Furthermore, as illustrated in Figures 4.3 and 4.4, the separated flow modelling approach with various void fraction correlations provided the best prediction for stack outlet pressure drop. This was due to the fact that in this type of modelling approach, the gaseous phase and liquid phase superficial velocities were allowed to be different. This important feature, made the simulation more realistic.

Similar to the results obtained in Chapter 3, the CISE correlation for void fraction provided the best estimation for the two-phase pressure drop across the DMFC stack. This was due to the fact that, the pressure variations within the stack inlet and outlet manifolds and cell channels, were highly influenced by surface tension effects, particularly at high current densities. 


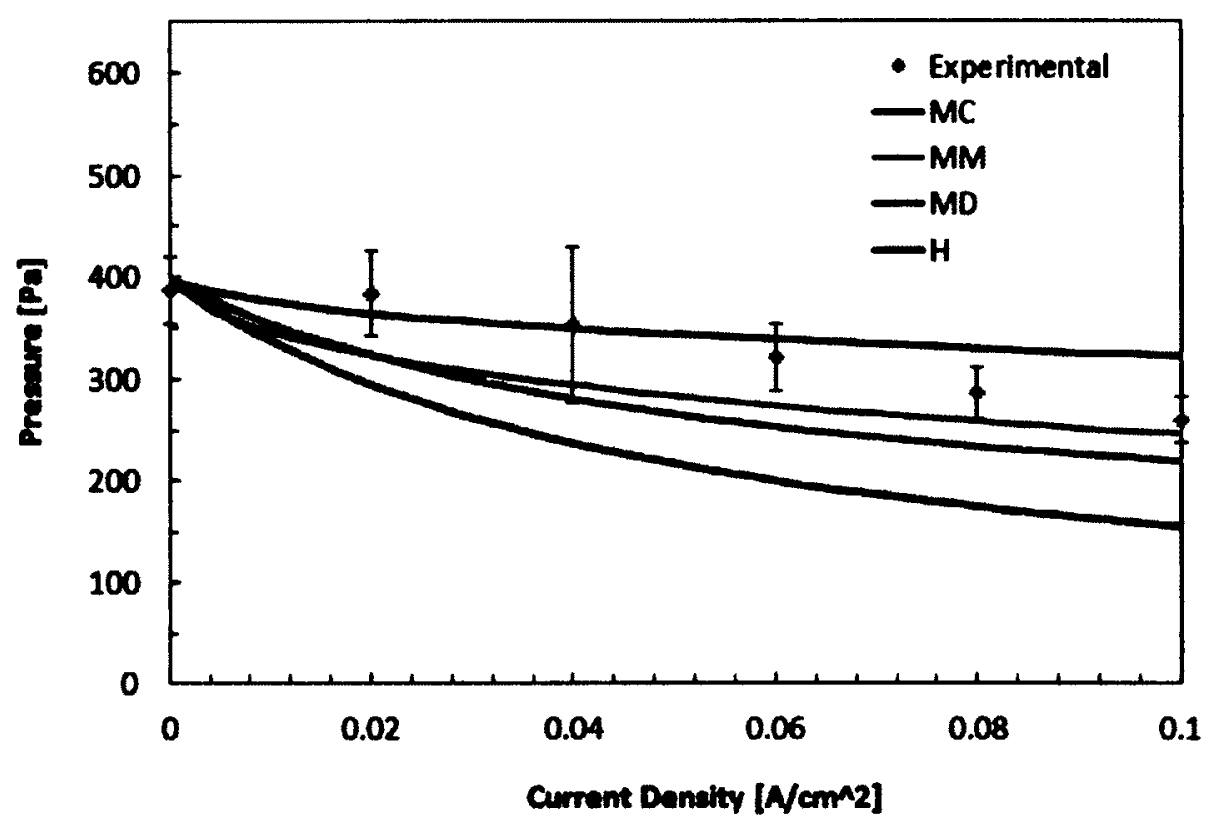

Figure 4.3: Pressure drop versus current density at $10 \mathrm{ml} / \mathrm{min}$ fuel flow rate

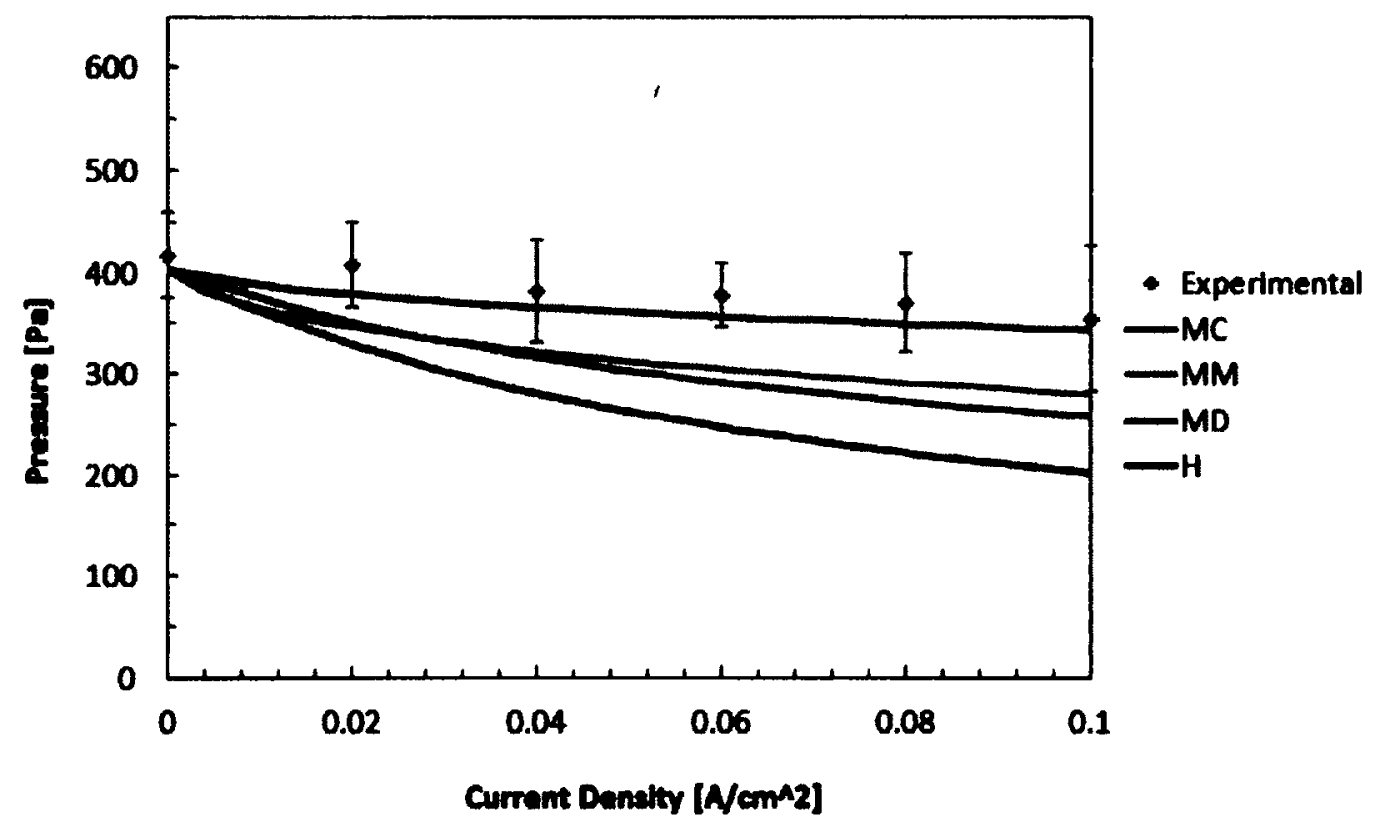

Figure 4.4: Pressure drop versus current density at $15 \mathrm{ml} / \mathrm{min}$ fuel flow rate 


\subsubsection{Stack Outlet Transient Pressure Drop Variations}

In order to further understand the hydrodynamic behavior of the five-cell FEDMFC stack, the outlet transient pressure drop variations were monitored for a full range of operating current densities (Figure 4.5).

Similar to the steady state experimentation, methanol and sulphuric acid concentrations were considered to be $2 \mathrm{M}$. The stack temperature was maintained at $70^{\circ} \mathrm{C}$. Sulphuric acid flow rate was adjusted to $7.5 \mathrm{ml} / \mathrm{min}$, and air was provided to the system at the rate of $2000 \mathrm{ml} / \mathrm{min}$.

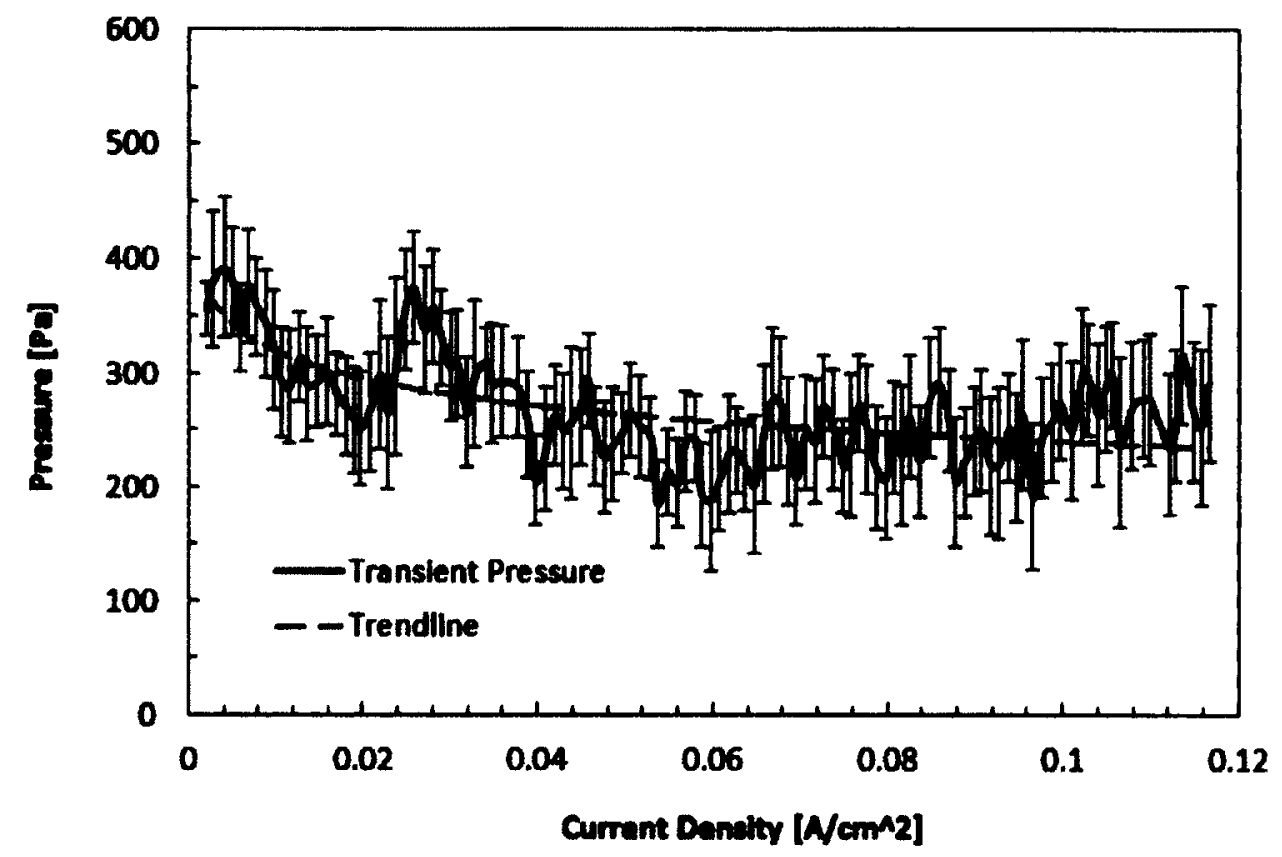

Figure 4.5: Transient pressure drop vs. current density at $10 \mathrm{ml} / \mathrm{min}$ fuel flow rate

Similar to the single cell results, the stack transient pressure profile was found to follow a cyclic pattern. However, a higher bubble formation/detachment frequency rate was observed through the entire curve. This was due to the fact that stack manifolds had large cross-sectional areas. This condition, led to efficient transport of methanol solution and carbon dioxide gas towards the stack outlet, which resulted in higher bubble formation/detachment frequency rate. 
In addition, the frequency spectrum of the stack anode pressure drop signal, was obtained by the Fast Fourier Transform (FFT) analysis. This frequency spectrum was then utilized to identify the actual stack pressure signal and its corresponding frequencies. For more information refer to Appendix C.

\subsubsection{Stack Anode Compartment Hydrodynamics}

In previous sections, the stack modelling results were compared and verified against experimental data, obtained by testing a five-cell FE-DMFC stack unit. Due to both cost and manufacturing limitations, it was not possible to build and test larger stack prototypes in the lab, however, with the aid of the developed hydrodynamic model, we were easily able to acquire crucial information about the hydrodynamic behavior of larger stack units.

In the following sections, the hydrodynamic modelling results of a 50-cell stack unit with a similar flow bed design and manifold configuration, are presented. The methanol solution concentration was considered to be $2 \mathrm{M}$ and, the stack temperature was maintained at $70^{\circ} \mathrm{C}$.

\section{Methanol Concentration Profile Within Stack Outlet Manifold}

In the 50-cell stack unit with U-type manifold configuration, the fuel is directed to every individual cell through the inlet manifold. As methanol solution travels within the fuel channels of each individual cell, its concentration starts to vary. This variation in concentration although negligible, is mainly due to methanol consumption at the anode catalyst layer and methanol crossover through the membrane.

All the remaining methanol solution as well as carbon dioxide gas are then accumulated in the stack outlet manifold and directed towards the outlet. Using the in-house hydrodynamic model, methanol concentration variations within the stack outlet manifold are presented in Figure 4.6, at different current densities. The stack inlet fuel flow rate was considered to be $60 \mathrm{ml} / \mathrm{min}$. 


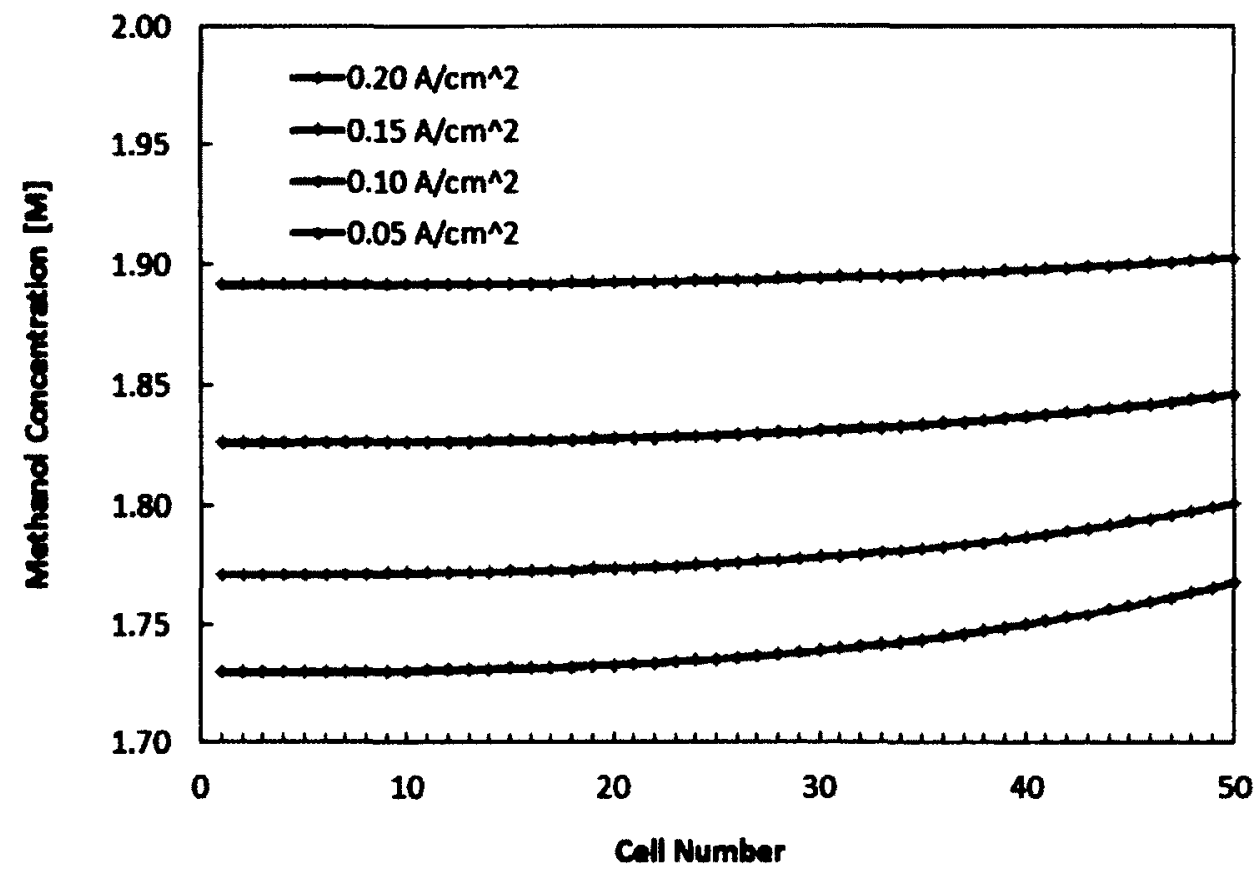

Figure 4.6: Methanol concentration profile variations within stack outlet manifold

At all operating current densities, methanol concentration declined from the last cell ( $50^{\text {th }}$ cell) towards the stack outlet (first cell). By increasing the operating current density however, the rate at which methanol concentration diminished was faster. This was due to the fact that, at high operating current densities, methanol consumption and crossover rates were elevated and thus greater non-uniformity was observed in concentration profiles.

\section{Volumetric Void Fraction Variations Within Stack Outlet Manifold}

As mentioned above, at non-zero current densities, methanol consumption and thus $\mathrm{CO}_{2}$ production are started as soon as the fuel enters the fuel channels from the inlet manifold. Therefore, the flow within the stack inlet manifold remains in single phase at all stack operating conditions except at very high temperatures. Once methanol solution enters the fuel channels, $\mathrm{CO}_{2}$ bubbles are formed and two-phase flow regimes emerge. Using the in-house hydrodynamic model, the volumetric void fraction variations within the stack outlet manifold are demonstrated in Figure 4.7, at various current densities. The stack inlet fuel flow rate was also considered to be $60 \mathrm{ml} / \mathrm{min}$. 


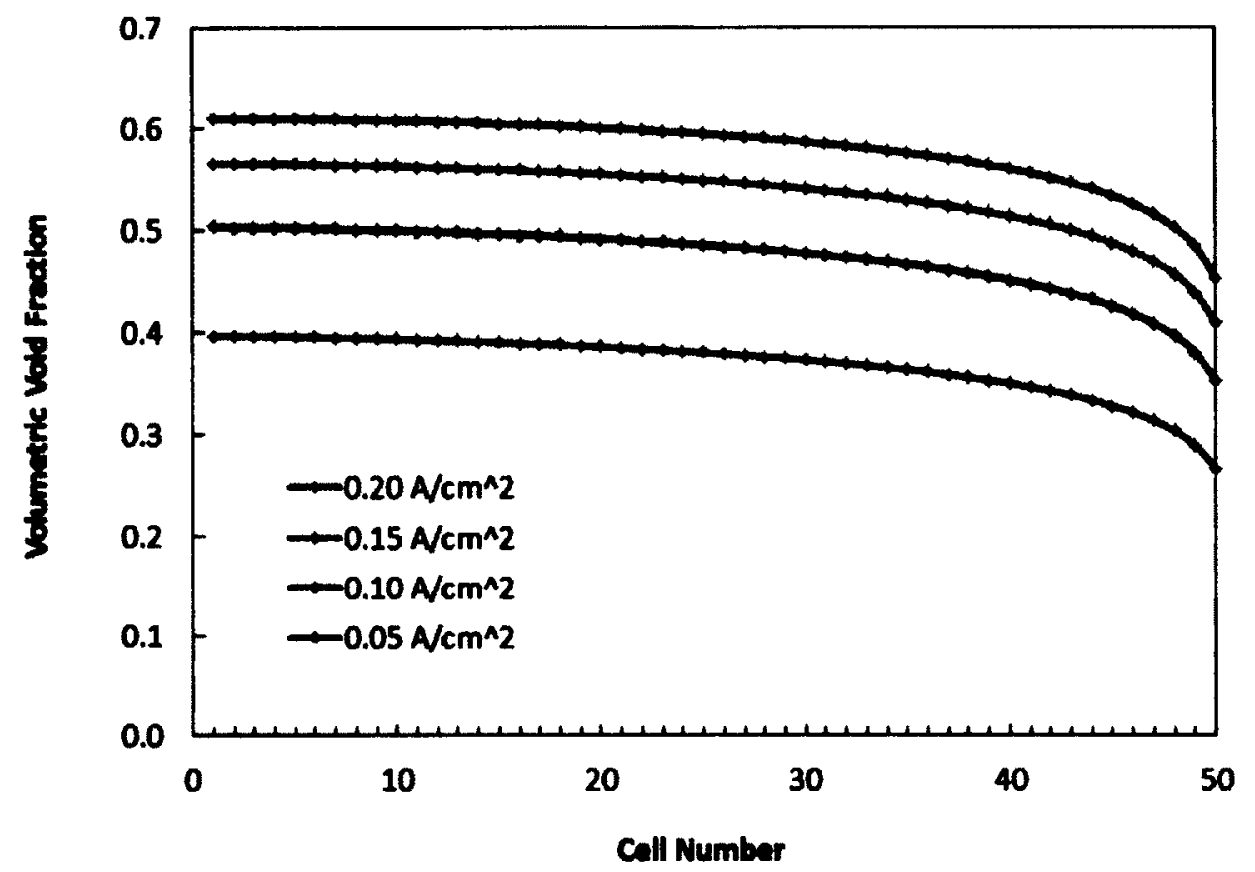

Figure 4.7: Volumetric void fraction variations within stack outlet manifold

As shown in Figure 4.7, the volumetric void fraction within the stack outlet manifold increased from the last cell $\left(50^{\text {th }}\right.$ cell) towards the inlet. By increasing the stack operating current density, higher void faction was observed and thus, the curves shifted upwards. This was because, the increase in current density resulted in higher gas generation rate and thus, higher void fraction.

\section{Stack Overall Flow Distribution}

The simulation results for stack overall flow distribution at operating current densities of $0.1,0.2$ and $0.3 \mathrm{~A} / \mathrm{cm}^{2}$ are shown in Figure 4.8. The inlet methanol solution flow rate was considered to be $200 \mathrm{ml} / \mathrm{min}$.

As illustrated above, the flow distribution within the stack was not uniform. At first, higher inlet flow rates were observed, however, the inlet flow dropped rapidly as the number of cells increased. Finally, more uniform flow distributions were observed towards the last cells in the stack unit. This variations in cell inlet flow, could be explained by analyzing the pressure and flow characteristics inside the stack inlet/outlet manifolds. 


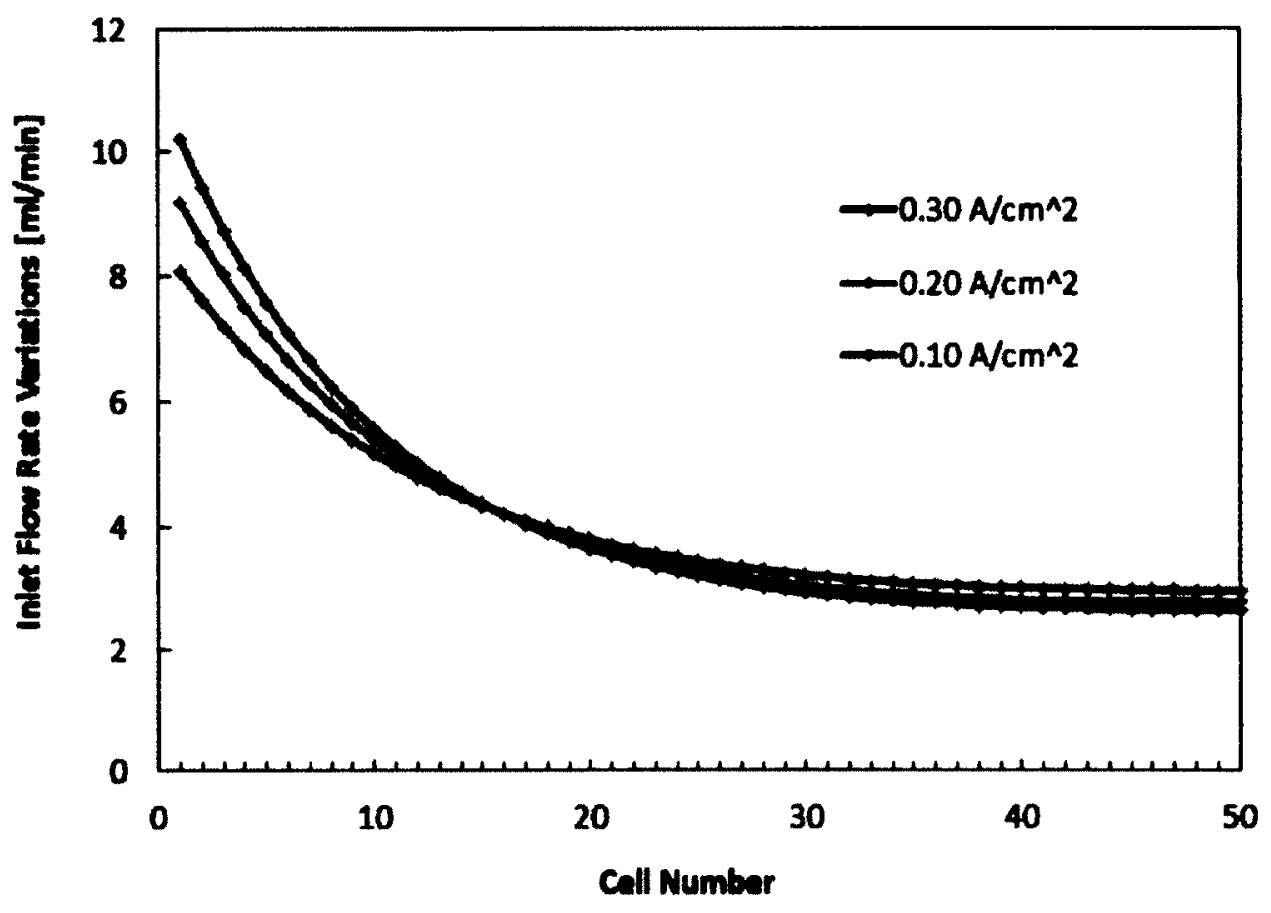

Figure 4.8: Cell inlet flow rate variations within the stack

As methanol solution traveled through the stack inlet manifold, its velocity was diminished at each cell-manifold junction due to flow division all the way up to the last cell ( $50^{\text {th }}$ cell). Besides, since the flow back pressure decreased along the stack length, the first group of cells received larger flow quantities than the succeeding ones. This resulted in rapid inlet flow drop along the stack length which could effectively reduce the stack performance.

Furthermore, the non-uniformity in flow distribution was enhanced by increasing the stack operating current density. This was due to the fact that increasing the current density augmented the two-phase pressure drop values within the stack individual cells and thus, negatively impacted the flow distribution.

\section{Stack Overall Pressure Distribution}

The pressure variations inside the stack inlet and outlet manifolds (top and bottom graphs respectively) are presented in Figure 4.9 for operating current densities of 0.1 , 0.2 and $0.3 \mathrm{~A} / \mathrm{cm}^{2}$. The inlet methanol solution flow rate was also considered to be 


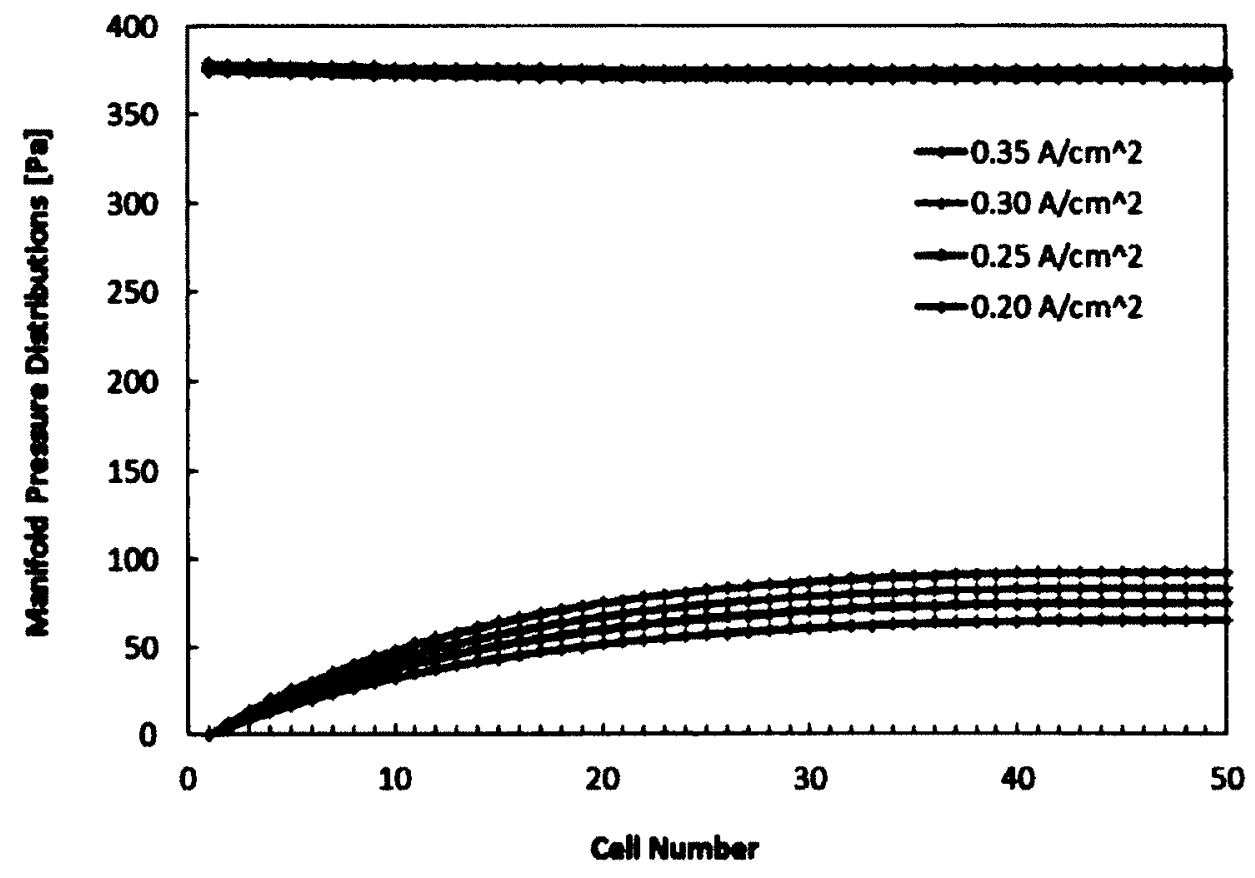

Figure 4.9: Stack overall pressure distributions at various current densities

$200 \mathrm{ml} / \mathrm{min}$.

As mentioned earlier, the flow within the inlet manifold was always single phase and thus, by increasing the operating current density, the pressure profile within the stack inlet manifold did not vary significantly. On the other hand, higher pressure drops were observed within the stack outlet manifold. This was due to the fact that, the flow inside the outlet manifold was two-phase with greater acceleration, frictional and form pressure components.

The two-phase effects were magnified by increasing the stack operating current density, due to larger $\mathrm{CO}_{2}$ production rate. In addition, as shown in Figure 4.9, zero outlet pressure was obtained at all operating current densities. As mentioned earlier, this boundary condition was imposed prior to simulation, in order to solve the system of equations. As a result, all the pressure values inside the stack unit, were calculated with respect to atmospheric pressure. 


\section{Chapter 5}

\section{FE-DMFC Stack Experimental Analysis}

As mentioned in Chapter 2, in addition to proper gas management within the anode compartment, preventing methanol crossover through the membrane is also important for improving the performance of DMFCs. This chapter has two sections. The first part, focuses on the design and manufacturing of a small scale (five cells) FE-DMFC stack and explains the experimental setup for its testing. The second part, describes the performance of the stack unit at various operating conditions such as fuel/air flow rate, flowing electrolyte flow rate, methanol concentration and operating temperature.

\subsection{FE-DMFC Stack Components}

In order to assess the performance characteristics of direct methanol fuel cell stacks with flowing electrolyte, a five-cell FE-DMFC stack prototype is manufactured inhouse at Carleton University. The stack unit is comprised of the following components.

\subsubsection{Current Collectors}

The anode current collector, collects the generated electrons from the anode catalyst layer via the anode graphite plate, and pass them through an external load towards the cathode current collector. The cathode current collector on the other hand, transfers the electrons to the cathode catalyst layer via the cathode graphite plate, where they participate in a reduction reaction with oxygen and protons to form water. 
In this study as can be seen in Figure 5.1, two copper plates at a $3.2 \mathrm{~mm}$ thickness were used as current collectors. A 1 micron gold plating layer was applied over the surface of the plates to improve their corrosion resistance characteristics.

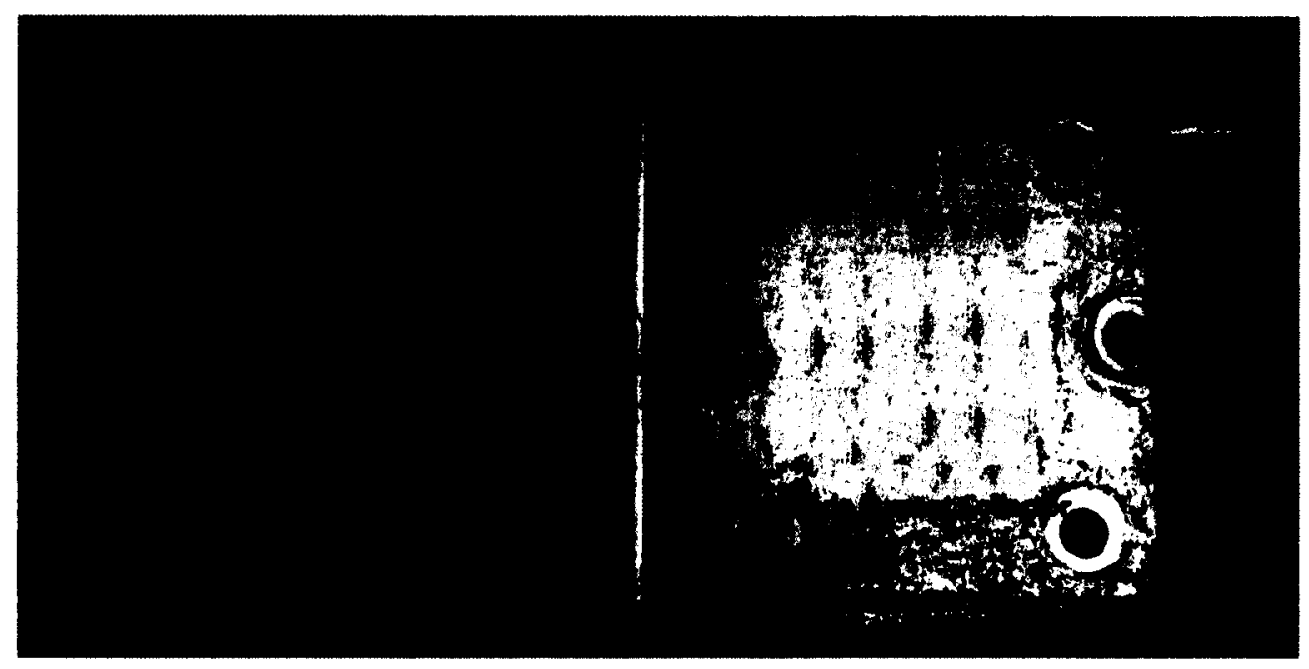

Figure 5.1: FE-DMFC current collectors

\subsubsection{Flow Distribution Plates}

As mentioned earlier, the flow distribution plates ensure that fuel and oxygen are uniformly distributed over the fuel cell reaction area and remove any generated reaction by-products from the system. In this work, a parallel serpentine design with a $25 \mathrm{~cm}^{2}$ reaction area was considered for the fuel channels. The plates were made from graphite AR-08, and manufactured at Carleton University (Figure 5.2). For more information about the physical, mechanical and electrical properties of graphite AR-08, please refer to Appendix A.

Figure 5.3 shows a three dimensional view of the graphite plates. For better gas management at the anode and water management at the cathode, and as indicated by the labels, methanol travels through the fuel channels from bottom to top and air flows through its corresponding channels from top to bottom. 


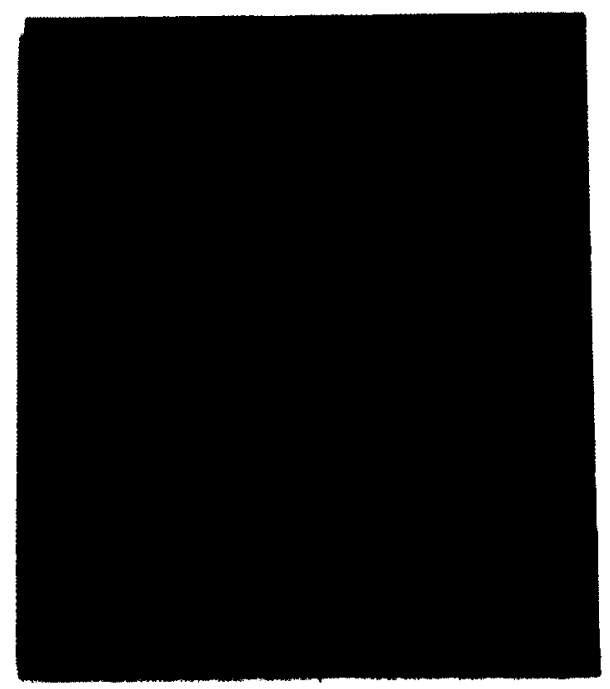

Figure 5.2: FE-DMFC flow distribution plate

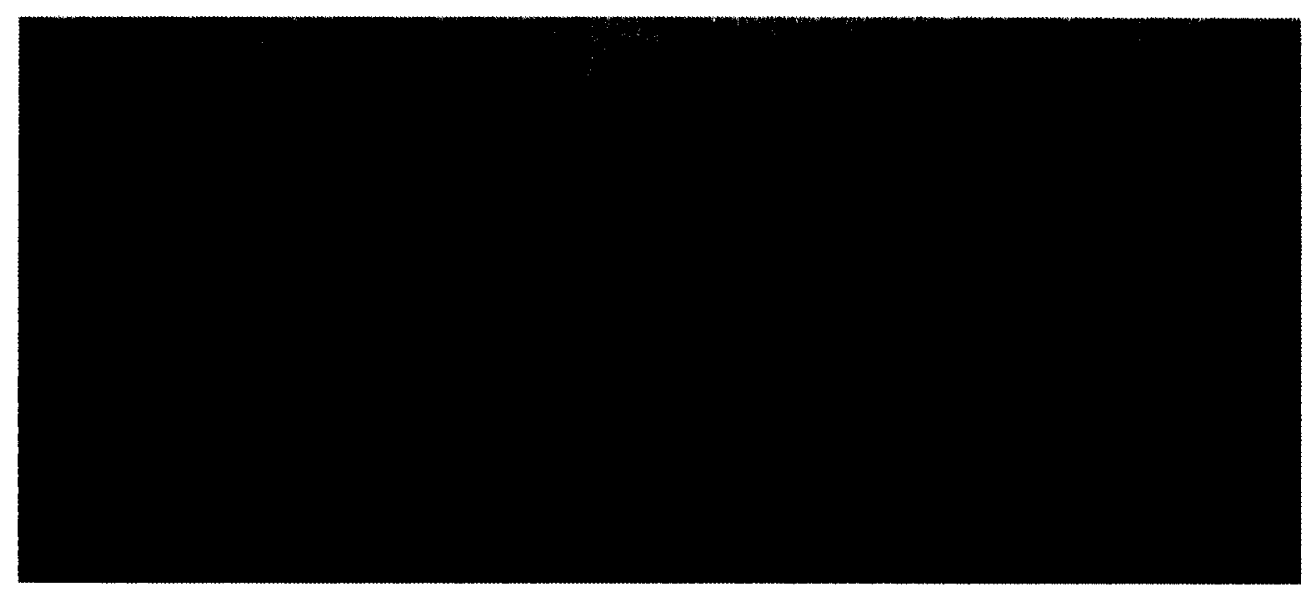

Figure 5.3: Three-dimensional solid model views of the graphite plates

\subsubsection{Electrodes}

The half-MEA for each fuel cell consists of three distinct layers. As shown in Figure 5.4, the first layer is the gas diffusion layer (GDL) which is responsible for the transport of reactants to the catalyst layers and removal of reaction by-products to the cell channels. Attached to the GDL is the catalyst layer which provides a suitable medium for redox reactions. The combination of the GDL and catalyst layers is called the "electrode". 


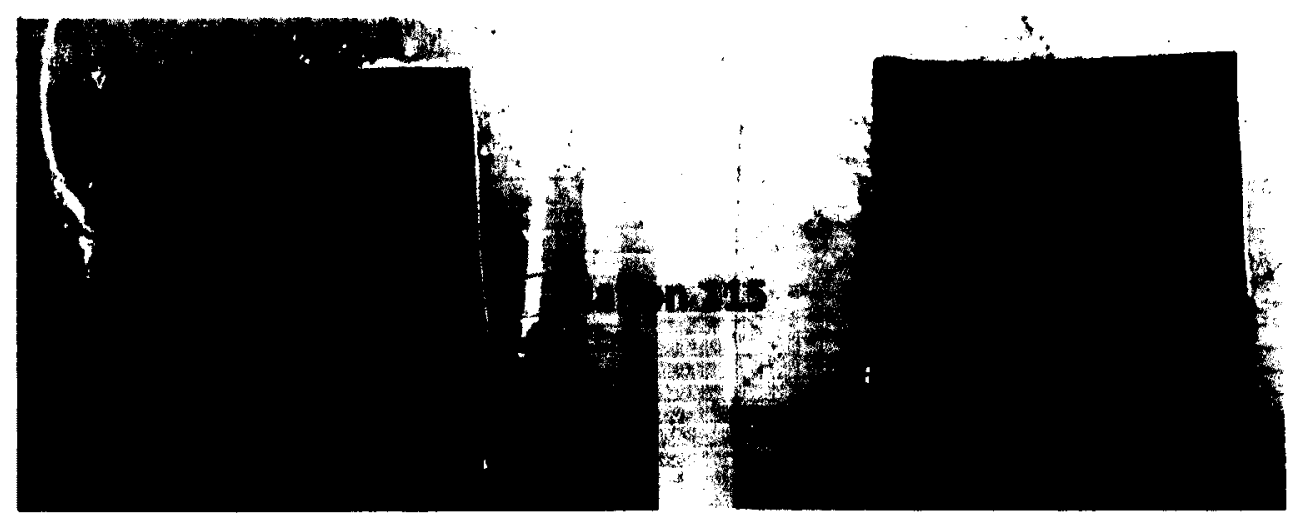

Figure 5.4: Membrane electrode assembly used in FE-DMFC stack

In this study, commercially available electrodes were utilized in both the anode and cathode compartments. The gas diffusion layers were made from Toray carbon paper (TGP-H-090) coated with $2.0 \mathrm{mgPt} / \mathrm{cm}^{2}$ on the cathode and $2.7 \mathrm{mgPt} / \mathrm{cm}^{2}$ plus 1.35 $\mathrm{mgRu} / \mathrm{cm}^{2}$ on the anode [45]. Table 5.1 [45] represents the percent composition of the electrodes.

Table 5.1: Electrode percent composition

\begin{tabular}{|c|c|}
\hline Components & $\%$ \\
\hline Non-woven carbon fiber & 60 \\
\hline Catalyst & 25 \\
\hline Carbon black & 5 \\
\hline Polytetrafluoroethylene (PTFE) & 5 \\
\hline Polyfluorosulphonicacid (PFSA) ionomer & 5 \\
\hline
\end{tabular}

\subsubsection{Membranes}

Another important feature in direct methanol fuel cells is the proton exchange membrane. It facilitates the transport of hydronium ions (protons) from the anode catalyst layer to the cathode catalyst layer while preventing electrons or any other species to pass through. The most commercially used membrane is Nafion ${ }^{\circledR}$, which is manufactured by DuPont. 
In this work, Nafion ${ }^{\circledR} \mathrm{N}-115$ which has a 5 mil thickness is utilized. Each mil is equivalent to one thousandth of an inch.

\subsubsection{Gaskets}

Leakage is one of the most important issues when dealing with fuel cell stacks. Since the flowing electrolyte direct methanol fuel cell (FE-DMFC) stack employs an extra manifold system for electrolyte circulation, the issue of fluid leakage within the system becomes more probable.

In this study, PTFE tape and Viton gaskets (Figure 5.5) were utilized to seal the stack from any internal/external leakage. The PTFE tape was used to attach the MEA over the serpentine channels of the flow distribution plates. The tape had $89 \mu \mathrm{m}$ thickness and $9000 \mathrm{~V}$ dielectric strength. The Viton gaskets consisted of numerous layers of fluoroelastomer sheets, which made them resistant to sulphuric acid (as flowing electrolyte) at elevated temperatures [45].

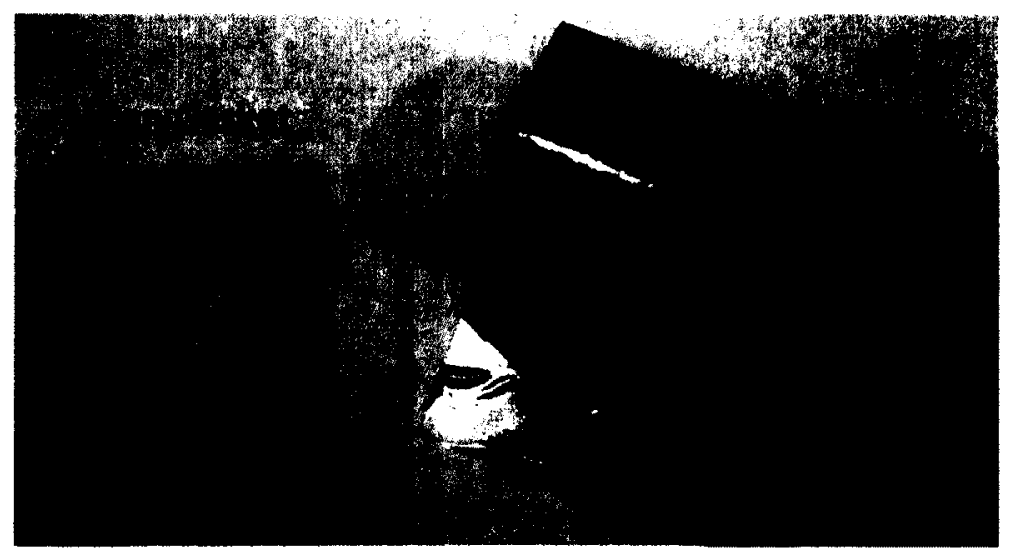

Figure 5.5: Viton gasket (left) and PTFE tape (right) used in FE-DMFC stack

\subsubsection{Flowing Electrolyte Channel}

As methanol solution and air travel through the anode and cathode compartments of an operating cell, a back pressure is created under the two Nafion ${ }^{3}$ layers. This back pressure along with the existence of humidity, cause the membranes to swell and 
thus distort the shape of the flowing electrolyte (FE) channel. In order to prevent such condition, a hydrophilic porous polyethylene sheet (POREX) was selected to serve as the flowing electrolyte channel (Figure 5.6).

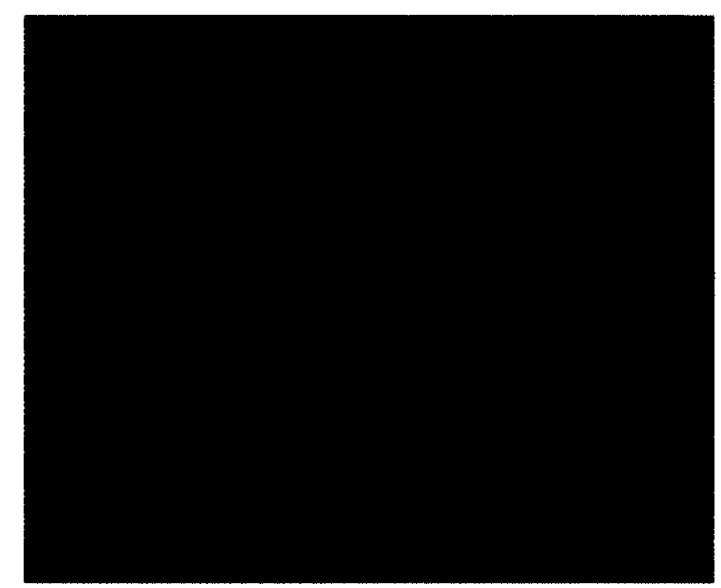

Figure 5.6: Porous polyethylene sheet (POREX)

The hydrophilic and porous characteristics of POREX, ensured an easy transfer of protons between the anode and cathode compartments while creating a passage way for flowing electrolyte. It should be noted that polyethylene is also resistant to sulfuric acid (Table $5.2[45]$ ).

Table 5.2: POREX specifications

\begin{tabular}{|c|c|c|}
\hline Brand & Thickness $[\mathrm{mm}]$ & Pore Size $[\mu \mathrm{m}]$ \\
\hline POREX & 0.61 & $75-110$ \\
\hline
\end{tabular}

\subsubsection{Stack Fabrication and Assembly}

The following procedures were applied during stack fabrication and assembly:

\section{Nafion ${ }^{\circledR}$ Hydration}

As mentioned earlier, for effective proton conduction, Nafion ${ }^{\circledR}$ membranes have to be hydrated prior to use in the fuel cell stack. The hydration process involves 
maintaining the membranes in solutions of $3 \%$ hydrogen peroxide (one hour), distilled water (one hour), $0.5 \mathrm{M}$ sulphuric acid (one hour) and distilled water again (one hour) at temperatures between 80 to $100^{\circ} \mathrm{C}$.

It is important to note that hydrogen peroxide $\left(\mathrm{H}_{2} \mathrm{O}_{2}\right)$ was used to remove any organic contaminants from the surface of the membrane. In addition, distilled water was used for hydration and sulfuric acid solution was utilized for activation of the Nafion ${ }^{\circledR}$ membranes.

\section{Heat Pressing}

In order to create sufficient interfacial contact between the Nafion ${ }^{\circledR}$ membranes and electrodes, heat pressing is typically used. In this work, the Carver Laboratory Press (Model No: 2697-5) was used for heat pressing (Figure 5.7).

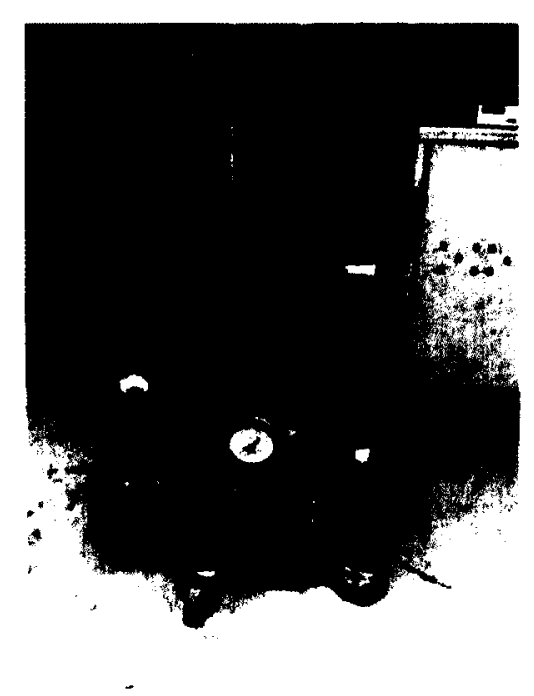

Figure 5.7: Heat press instrument for MEA fabrication

For full impregnation of the catalyst particles into the Nafion ${ }^{\circledR}$ membranes, the two layers were heat pressed together at a pressure and temperature of $3 \mathrm{MPa}$ and $180^{\circ} \mathrm{C}$, respectively, for 3 minutes. 


\section{Stack Bi-polar Plate Manufacturing}

A three-dimensional solid model of the stack bi-polar plate was developed using Pro/Engineer software (Figure 5.8). The CAD information were then imported into Pro/Engineer manufacturing module to create the corresponding "G-code". This "G-code" was then utilized by the department's CNC machine, to manufacture four sets of bi-polar plates for stack. For three view drawings of the bi-polar plates refer to Appendix A.

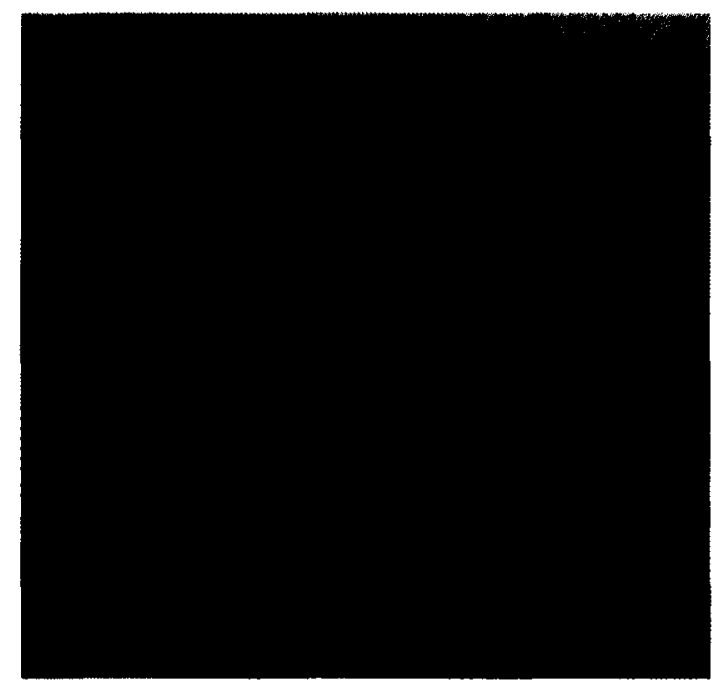

Figure 5.8: Three-dimensional solid model view of the stack bi-polar plate

\section{Assembly}

For the five-cell FE-DMFC stack unit, four bi-polar plates and two end-plates were fabricated. As shown in Figure 5.9, the MEAs were attached over the parallel serpentine channel area of the graphite plates by the PTFE tape. For every unit cell in the stack, a proper size POREX sheet was sandwiched between the two graphite plates. In addition, to contain the FE channels and prevent any external leakage, Viton gaskets were applied.

All the stack components were held together by means of six M5 carbon steel threaded-rods. All rods were electrically insulated by applying PTFE heat shrink 


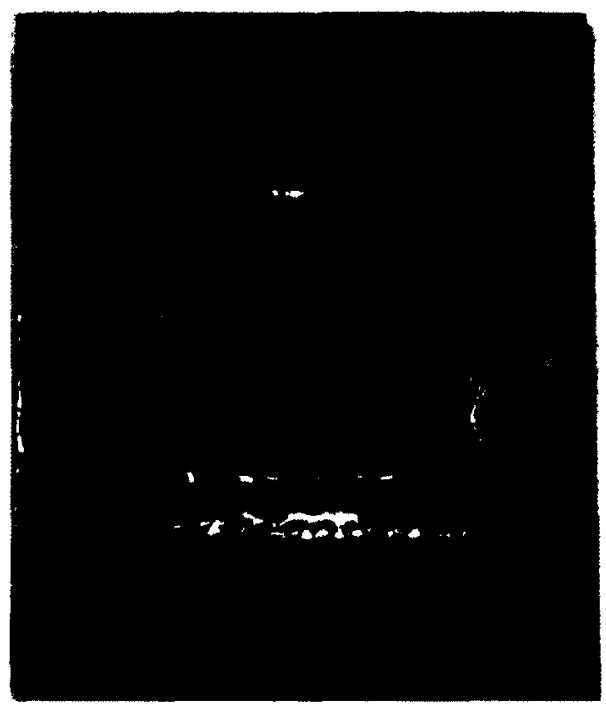

Figure 5.9: Half-cell assembly

tubing. Through testing, it was observed that the optimal stack clamping torque was found to be $7.9 \mathrm{~N}-\mathrm{m}$ (70 lb-in). It is important to note that, lower compression forces led to external leakages, while higher compression forces crushed the electrodes (Figure 5.10).

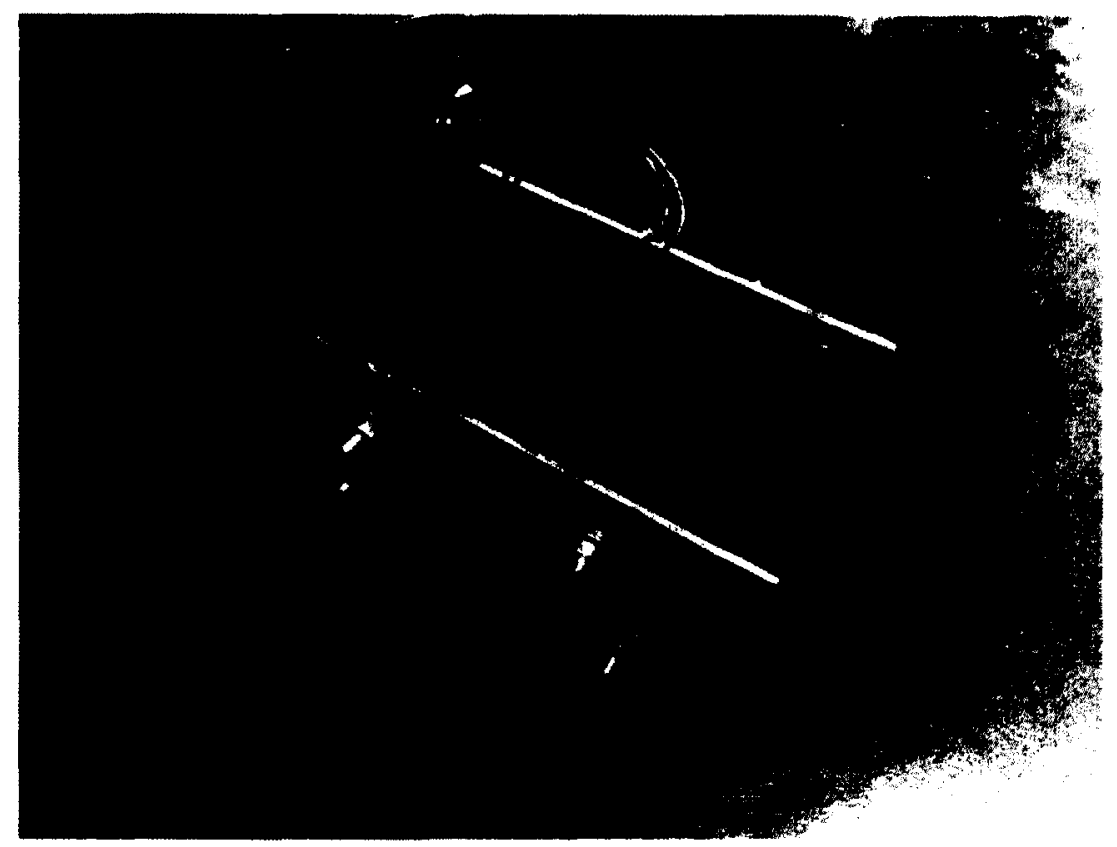

Figure 5.10: Full stack assembly 


\subsection{Experimental Setup}

The experimental setup in this work was developed in-house at Carleton University MAE department. As can be seen in Figure 5.11, the test station had four major sections:

- Fluid Control

- Temperature Control

- Load Control

- Pressure Control

The fluid control section included two pumping systems, a rotameter, a compressor, and an air filtering system. It was responsible for delivering methanol solution, sulphuric acid solution and air to the FE-DMFC stack and removing the reaction by-products. The temperature control section included a temperature controller, a $\mathrm{K}$-type thermocouple and two electric heaters. It was responsible for maintaining the temperature at a desired value during the stack operation by regulating the electric heaters. Finally, the load control section included a digital load bank which allowed testing the stack unit at different operating modes such as constant current, constant voltage and constant power. As mentioned in Chapters 3 and 4, the pressure control system included a high precision differential pressure transducer from OMEGA (Model No: PX409-001DWU5V) and a data acquisition card (DAQ) from National Instruments (Model No: NI USB-6009). For further detail about the experimental equipments, refer to Appendix B.

Both methanol and sulphuric acid solutions were pumped through the system from the blue lid containers, as shown in Figure 5.12, and the waste was collected in beakers. It is important to note that, all experimentation was carried out under the fume hood for preventing the exposure to toxic vapors of methanol and sulphuric acid. In addition, the fuel cell unit was placed inside a Faraday cage to eliminate any external signal effects on the cell performance. 


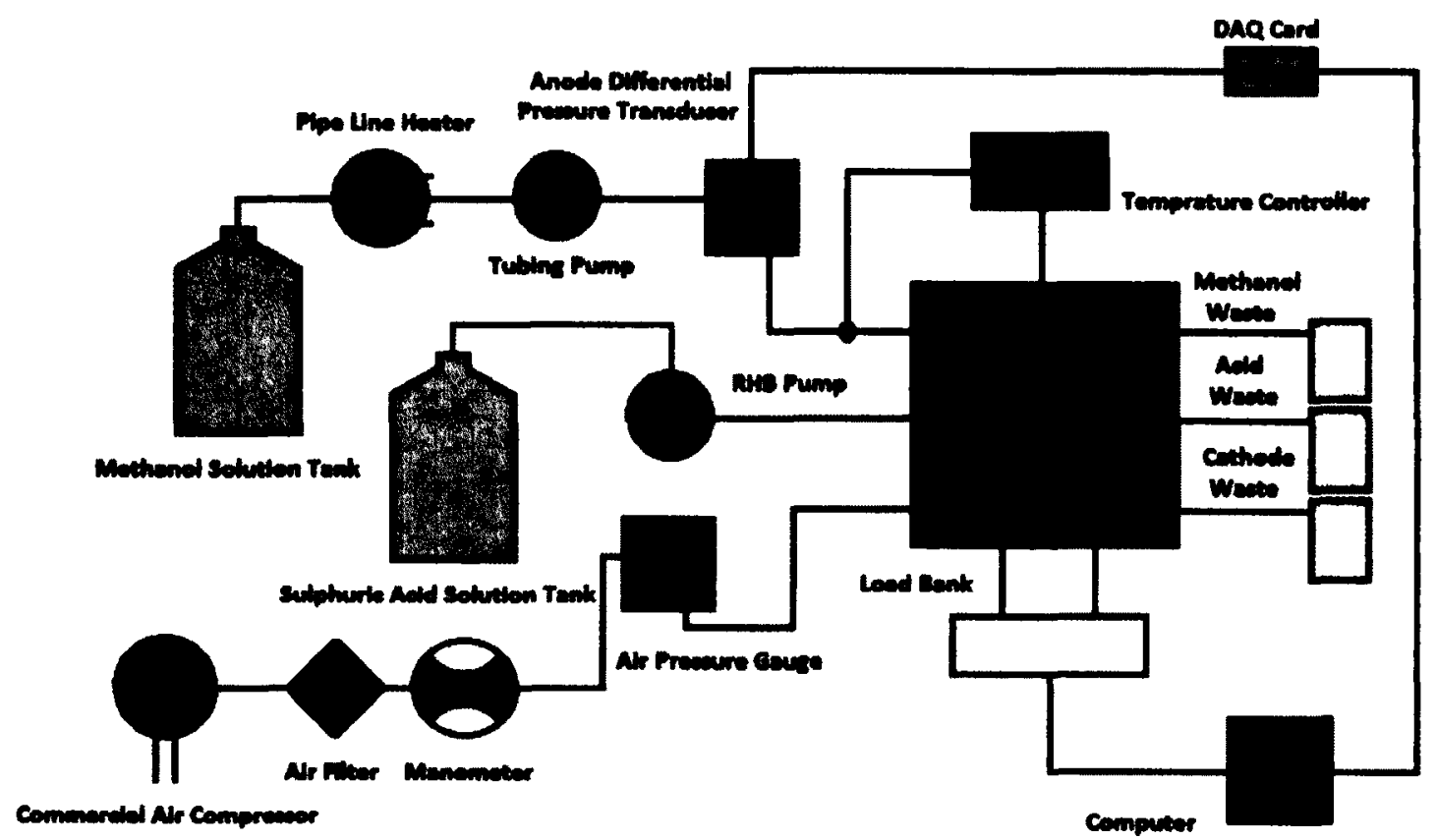

Figure 5.11: Schematic of the experimental setup

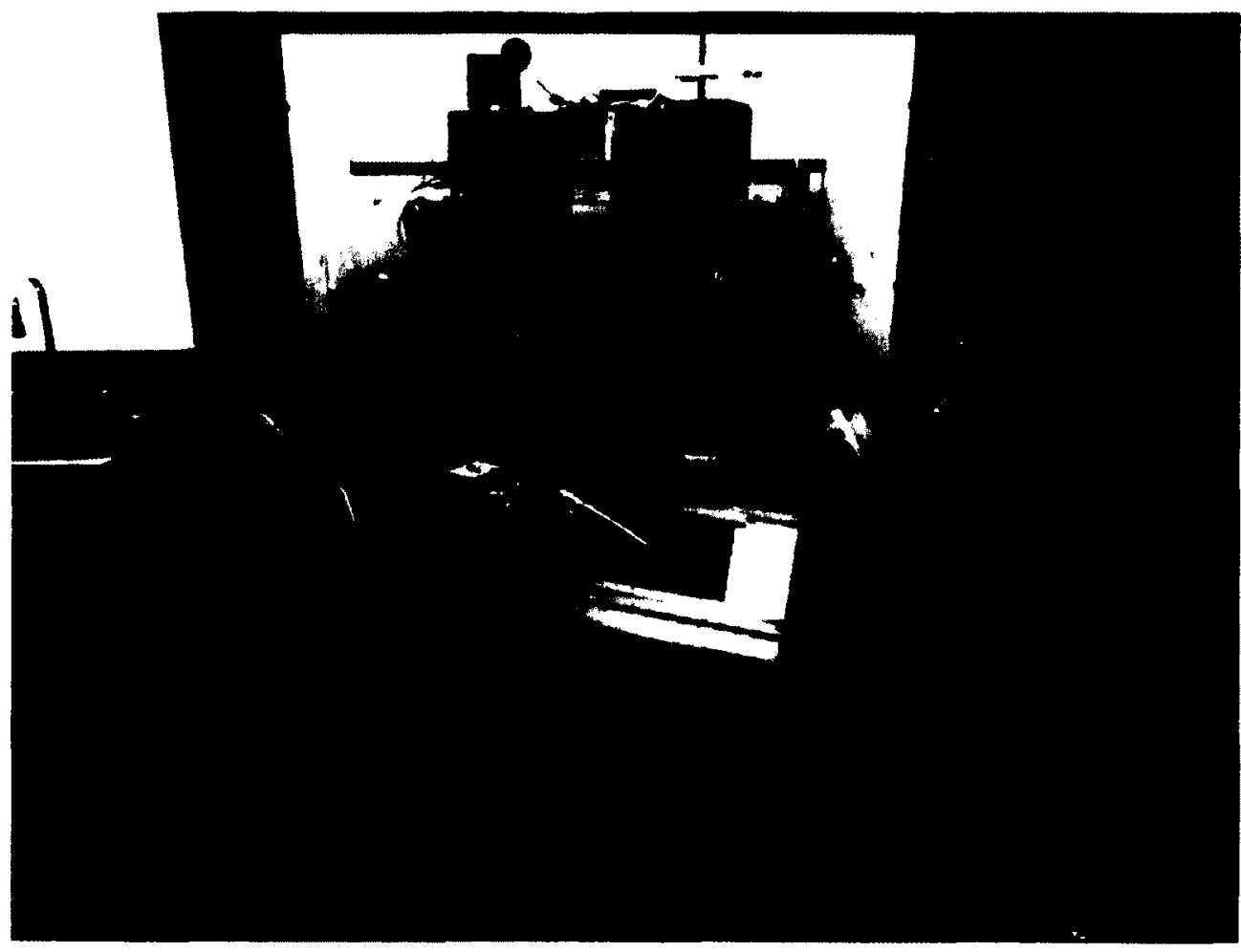

Figure 5.12: Experimental setup 


\subsection{Uncertainty Analysis}

Any measurement process contains some level of error, which can be introduced throughout various stages of an experiment. In order to better understand the quality of the experimental results, uncertainty analysis is performed. It aids in estimating an interval around the measured value, within which the true value falls with a stated probability. As mentioned by Figliola and Beasley et al. [59], errors are a property of the measurement, whereas, uncertainty is a property of the result. In other words, errors are the effects that cause a difference between the measured value and the true vale, whereas, the uncertainty is an assigned numerical value that quantifies the probable range of these errors [59].

In this section, an error/uncertainty analysis based on the ANSI/ASME PTC 19.1 [60] was performed (Appendix D). In this methodology, the corresponding elemental systematic and random errors were identified for the measurement process (stack performance testing). The main sources of error, affecting the stack output current and voltage were found to be due to stack temperature, anode, cathode and flowing electrolyte flow rates, fuel and flowing electrolyte concentrations, load bank measurements, $\mathrm{FE}$ channel thickness and stack clamping torque.

Using the uncertainty analysis, the systematic and random errors for stack output voltage were found to be 60.79 and $73.78 \mathrm{mV}$, respectively. On the other hand, the systematic and random errors for stack output current were found to be 109 and $115.95 \mathrm{~mA}$, respectively. In addition, for stack maximum power output, the overall uncertainties for $68 \%$ and $95 \%$ confidence levels, were found to be 0.268 and 0.535 $\mathrm{W}$, respectively. For further information with regards to stack uncertainty analysis, refer to Appendix D.

\subsection{Results and Discussions}

The experimental results for the five-cell FE-DMFC stack unit (developed in-house at Carleton University MAE department) are presented in this section. The overall aim of these experiments was to evaluate the performance of the FE-DMFC stack at various operating conditions which would aid in future development of such systems. 
At first, the MEAs were activated by operating the stack unit at a fixed voltage of $0.3 \mathrm{~V}$ for six hours, until the corresponding current became stable. The stack temperature was maintained at $70^{\circ} \mathrm{C}$. Furthermore, $10 \mathrm{ml} / \mathrm{min}$ of $2 \mathrm{M}$ methanol solution and $2000 \mathrm{ml} / \mathrm{min}$ of air, were passed through the anode and cathode compartments, respectively. For the flowing electrolyte, $12.5 \mathrm{ml} / \mathrm{min}$ of $2 \mathrm{M}$ sulphuric acid solution was passed through the $0.61 \mathrm{~mm}$ thick FE channel.

\subsubsection{Repeatability of Results}

As mentioned earlier, the fuel cell performance is determined by the amount of generated current at a certain voltage. For all the experiments in this work, the load bank was initially set to $0 \mathrm{~mA}$ (OCV condition) and the current was then increased by $10 \mathrm{~mA}$ increments, until it reached the upper limit. The sweep time was set to two minutes and three sweeping cycles were considered for every testing.

In addition, every set of experiments were repeated in two different days, in order to ensure the repeatability of the outcome. Majority of the presented experimental graphs in this work, contain average data values and their corresponding standard deviations (error bars).

\subsubsection{Temperature Effects}

Figure 5.13 represents the stack performance at operating temperatures of 50,60 and $70^{\circ} \mathrm{C}$. Methanol and sulphuric acid concentrations were considered to be $2 \mathrm{M}$, and their flow rates were adjusted to 5 and $7.5 \mathrm{ml} / \mathrm{min}$, respectively. In addition, air was provided to the system at the flow rate of $2000 \mathrm{ml} / \mathrm{min}$.

In general, increasing the operating temperature improved the stack performance. This was due to the fact that, at higher operating temperatures, the redox reactions inside every individual cell proceeded at a faster rate. This overall increase in reaction kinetics, reduced the activation overpotential specially at lower current density region of the polarization curve.

Furthermore, increasing the operating temperature promoted crossover by enhancing the permeability of Nafion ${ }^{(\rightarrow)}$ membranes to methanol molecules. In this stack 


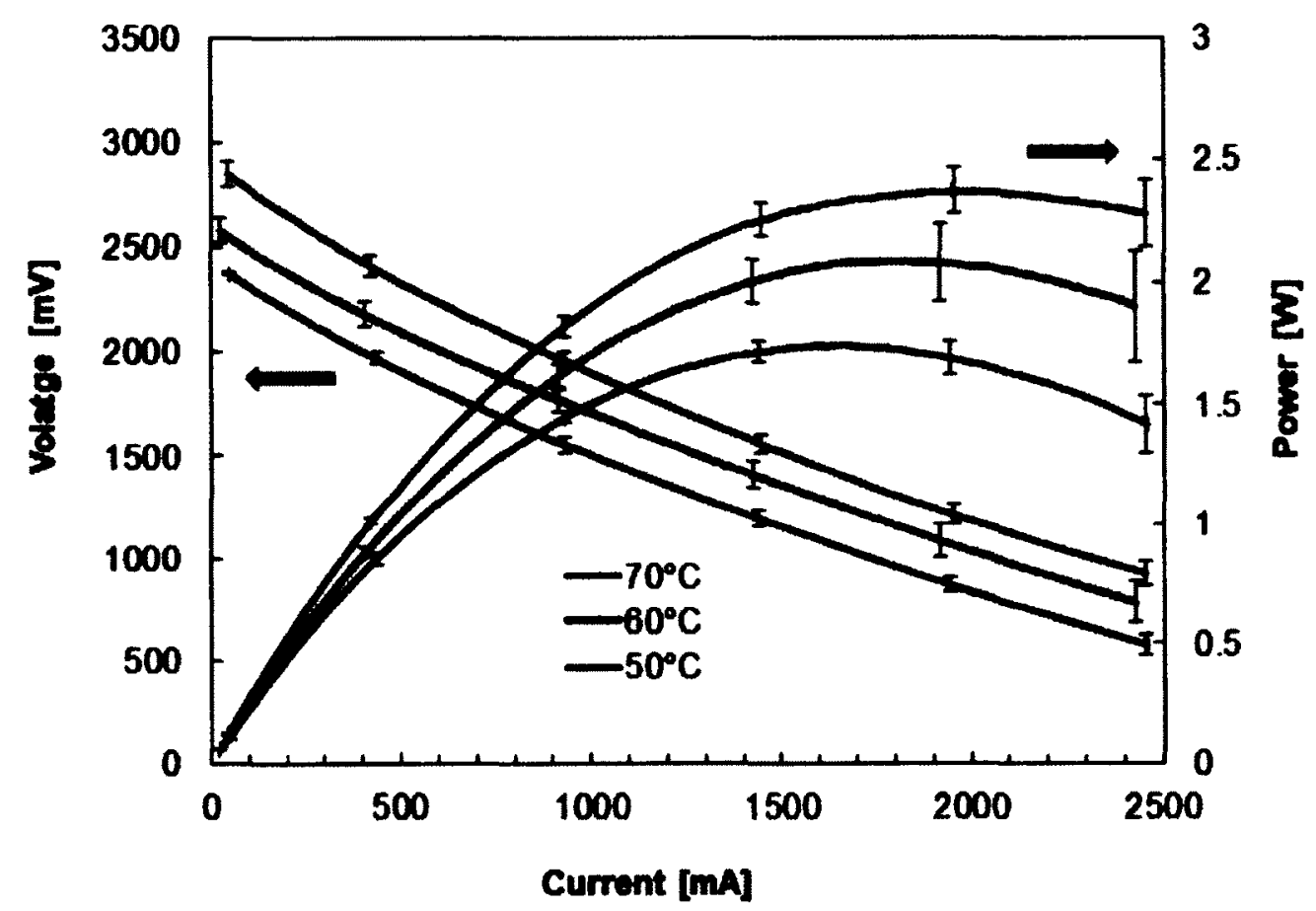

Figure 5.13: Polarization/power curve variations with temperature

prototype, the flowing electrolyte was continuously circulated between the anode and cathode compartments of each cell to remove any crossed-over methanol. As a result, methanol crossover did not degraded the stack performance due to the temperature increase.

\subsubsection{Methanol Concentration Effects}

Figure 5.14 demonstrates the stack performance at methanol concentrations of 1,2 and $4 \mathrm{M}$. Methanol and sulphuric acid solution flow rates were adjusted to 5 and 7.5 $\mathrm{ml} / \mathrm{min}$, respectively. The stack temperature was kept constant at $70^{\circ} \mathrm{C}$. Sulphuric acid concentration was considered to be $2 \mathrm{M}$, and air was provided to the system at the rate of $2000 \mathrm{ml} / \mathrm{min}$.

Methanol solution concentration was another important parameter that affected the stack performance. As can be seen in Figure 5.14, at low methanol concentrations (1 M), the polarization curve dropped faster. This was due to the fact that, when current 


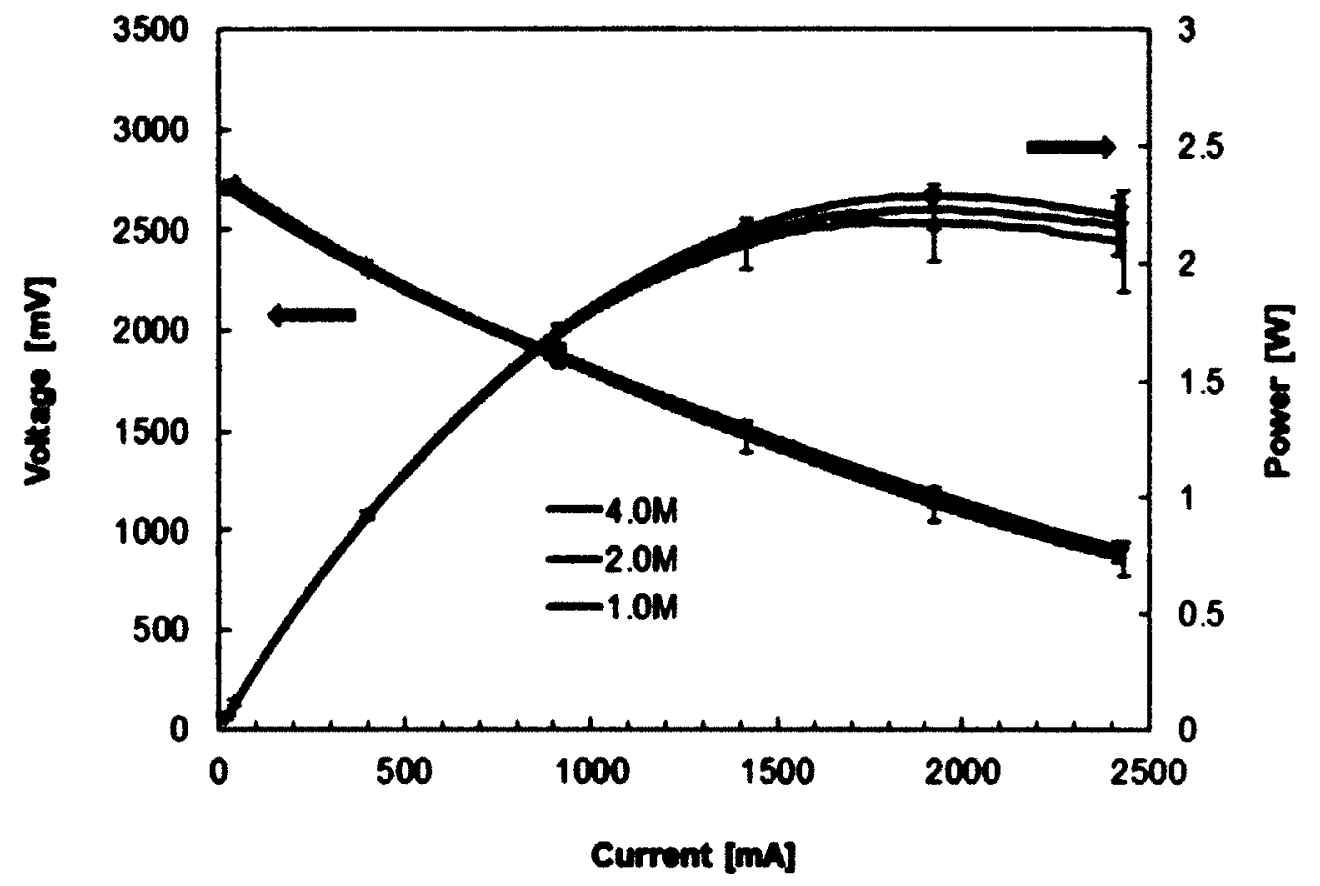

Figure 5.14: Polarization/power curve variations with methanol concentration

density was increased at low methanol concentrations, the rate at which methanol molecules were consumed at the catalyst layer superseded their supply rate and thus, polarization curve descended faster.

At high methanol concentrations (4 M), the stack performance was also reduced. This was due to the fact that, increasing the concentration at the anode, resulted in higher methanol concentration gradient across every individual cell in the stack. This elevation in concentration gradient promoted methanol crossover which led to lower stack performance.

It is also important to note that the highest OCV was achieved with $1 \mathrm{M}$ methanol concentration due to lower crossover effects. During the stack testing, the optimum methanol concentration was found to be $2 \mathrm{M}$. 


\subsubsection{Methanol Solution Flow Rate Effects}

As can be seen in Figure 5.15, the stack performance was evaluated at methanol solution flow rates of 5,15 and $20 \mathrm{ml} / \mathrm{min}$. Methanol and sulphuric acid concentrations were considered to be $2 \mathrm{M}$. The stack temperature was kept constant at $70^{\circ} \mathrm{C}$. Sulphuric acid flow rate was adjusted to $7.5 \mathrm{ml} / \mathrm{min}$, and air was provided to the system at the rate of $2000 \mathrm{ml} / \mathrm{min}$.

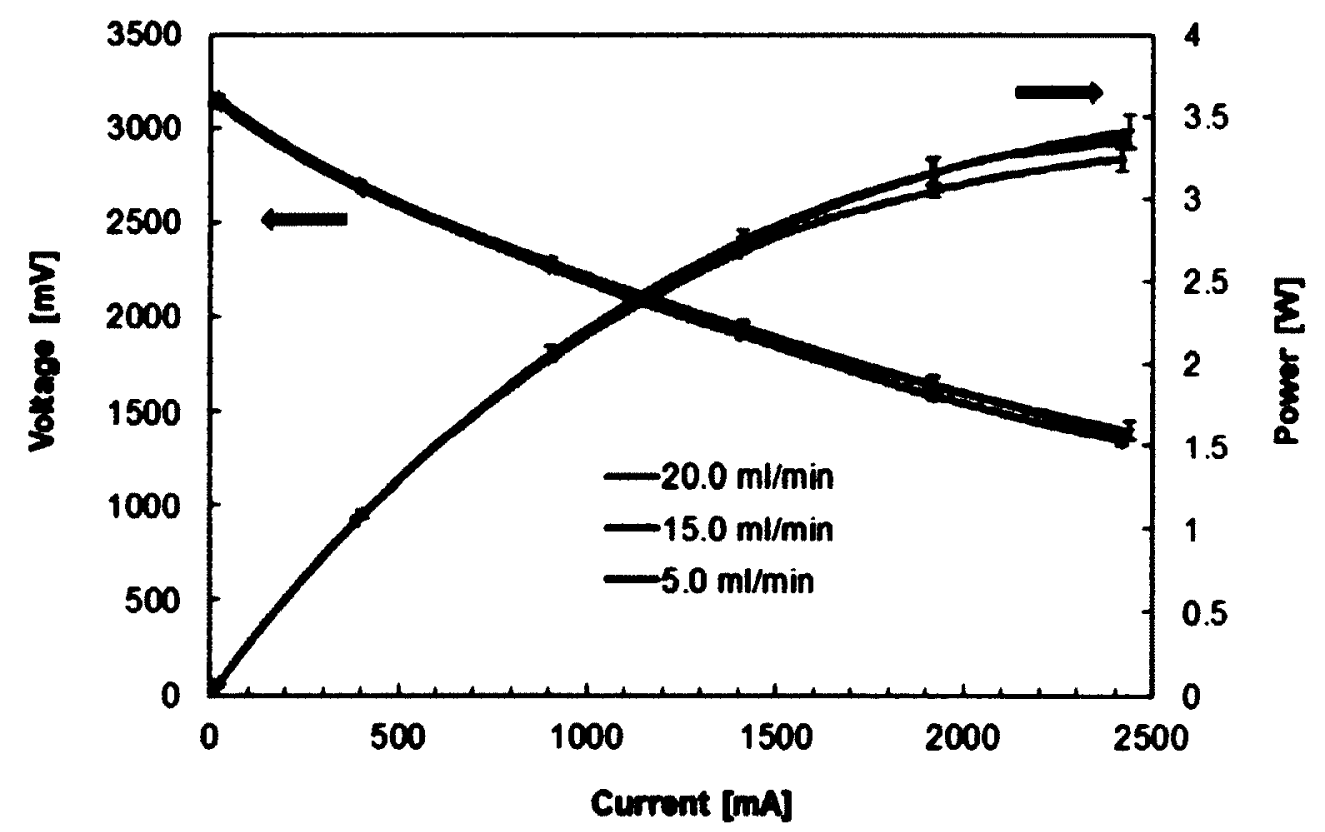

Figure 5.15: Polarization/power curve variations with methanol solution flow rate

Based on Figure 5.15, it can be concluded that the stack performance was improved by increasing the fuel flow rate up to a certain limit (from 5 to $15 \mathrm{ml} / \mathrm{min}$ ). In fact, further increase in methanol solution flow rate reduced the stack performance.

This was due to the fact that increasing the fuel flow rate, resulted in better gas management at the stack anode compartment and thus, improved the performance. However, by further increasing the methanol solution flow rate $(20 \mathrm{ml} / \mathrm{min}$ in this case), an uneven flow distribution was created within the system which in return, reduced the performance. 
It is important to note that the temperature equilibrium in the anode catalyst layer was also altered by excessive increase in fuel flow rate, which led to a reduction in stack performance.

\subsubsection{Flowing Electrolyte Flow Rate Effects}

The effects of FE flow rate on the stack performance has been shown in Figure 5.16. The unit was tested with sulphuric acid flow rates of $7.5,12.5$ and $17.5 \mathrm{ml} / \mathrm{min}$. The stack temperature was kept constant at $70^{\circ} \mathrm{C}$. Methanol and sulphuric acid concentrations were considered to be $2 \mathrm{M}$. Methanol solution flow rate was adjusted to $5 \mathrm{ml} / \mathrm{min}$, and air was provided to the system at the rate of $2000 \mathrm{ml} / \mathrm{min}$.

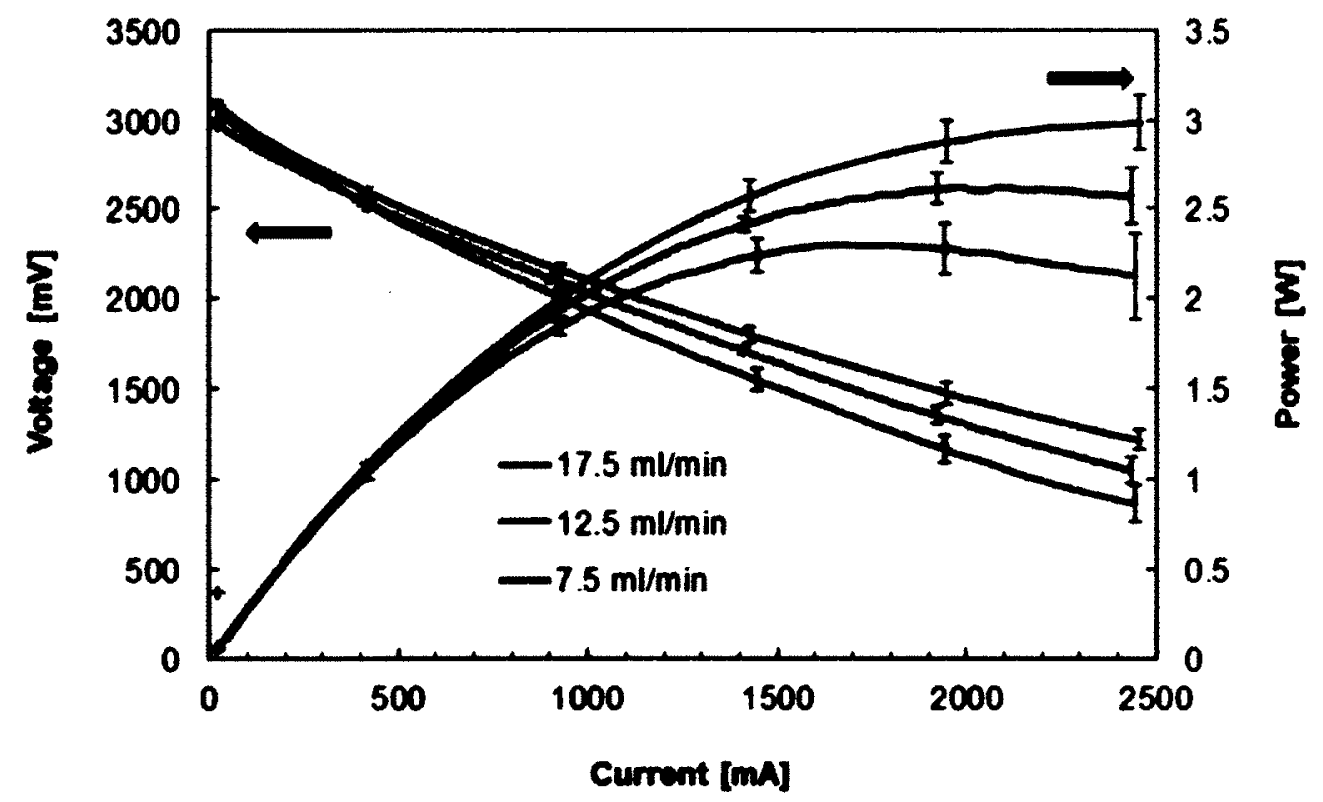

Figure 5.16: Polarization/power curve variations with flowing electrolyte flow rate

By increasing the sulphuric acid flow rate, the stack performance improved significantly. This was because, at higher sulphuric acid flow rates, the rate at which crossed-over methanol molecules were removed from the system was enhanced and thus, the performance was cultivated. In fact, this observation supports the importance of addressing methanol crossover issue in DMFCs. 


\subsubsection{Air Flow Rate Effects}

Figure 5.17 illustrates the stack performance at air flow rates of 2000, 2500 and $3000 \mathrm{ml} / \mathrm{min}$. Methanol and sulphuric acid concentrations were considered to be 2 $\mathrm{M}$, and their flow rates were adjusted to 5 and $7.5 \mathrm{ml} / \mathrm{min}$, respectively. The stack temperature was kept constant at $70^{\circ} \mathrm{C}$.

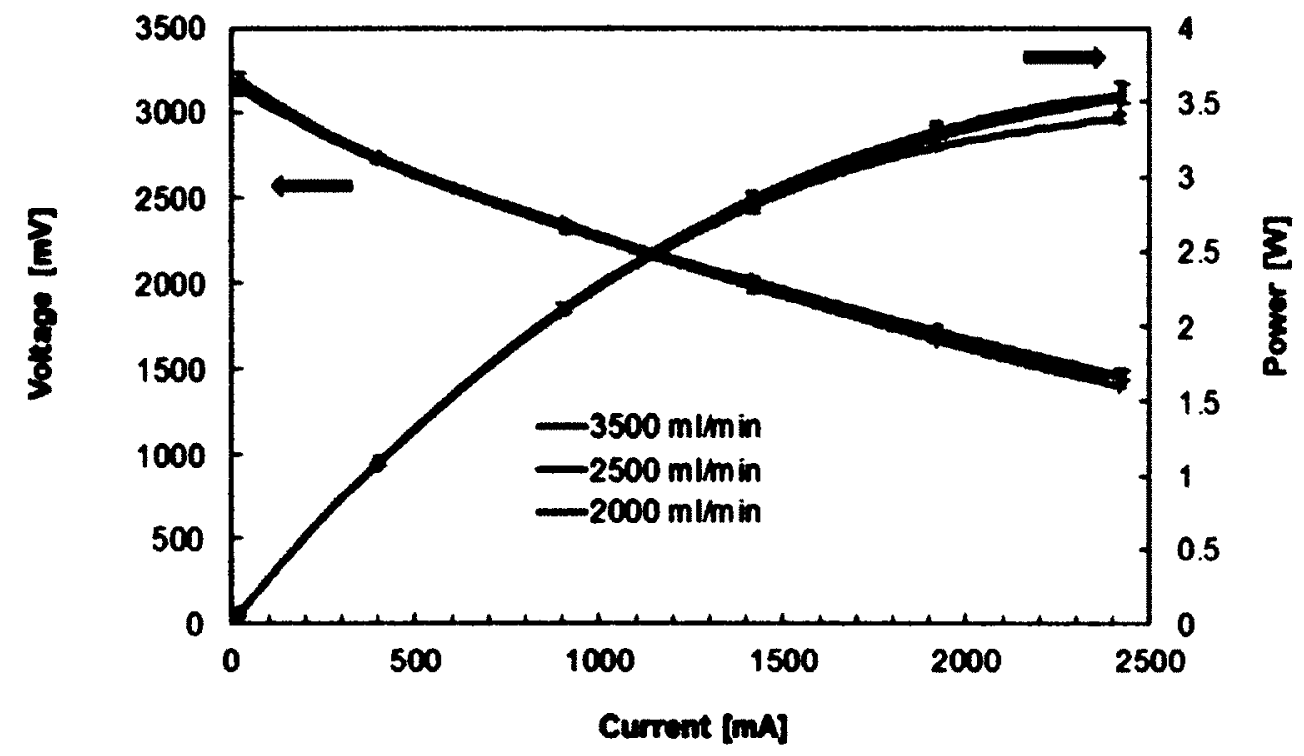

Figure 5.17: Polarization/power curve variations with air flow rate

Increasing the air flow rate from 2000 to $2500 \mathrm{ml} / \mathrm{min}$ improved the stack performance. This was due to the fact that at elevated air flow rates, the generated water molecules at the stack cathode compartment were effectively separated and removed from the cathode reaction sites and thus, the overall stack performance was enhanced.

On the other hand, increasing the air flow rate beyond a certain point, led to the dehydration of cathode membranes. This condition negatively affected the proton transfer within the system and thus, reduced the stack performance. 


\subsubsection{Stack Voltage Distribution}

In order to further study the stack performance, the voltage variations in every unit cell within the system were monitored at different operating conditions. The stack temperature was maintained at $70^{\circ} \mathrm{C}$. Methanol and sulphuric acid concentrations were considered to be $2 \mathrm{M}$, and their respective flow rates were adjusted to 5 and 7.5 $\mathrm{ml} / \mathrm{min}$. In addition, air was provided to the system at the flow rate of $2000 \mathrm{ml} / \mathrm{min}$. As can be seen in Figure 5.18, the voltage distribution across the stack unit was found to be non-uniform.

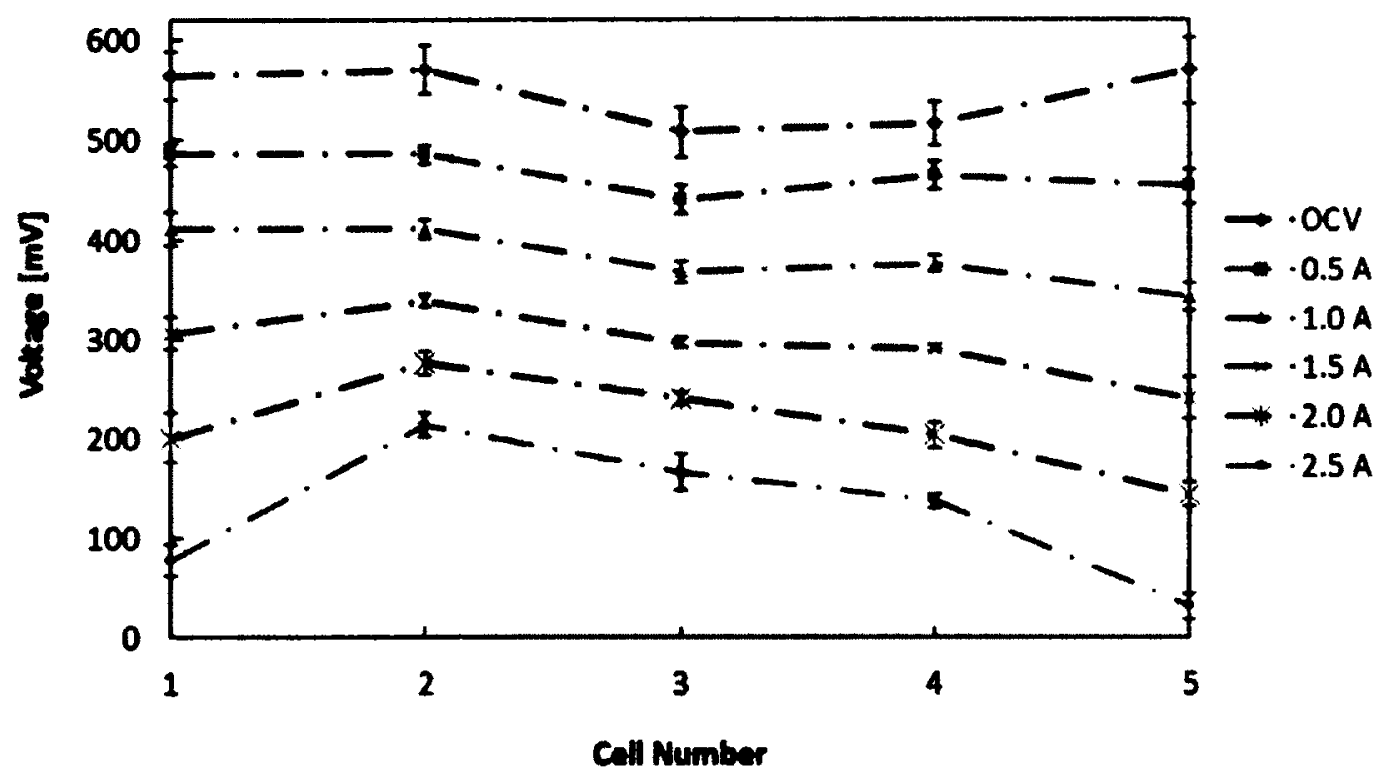

Figure 5.18: Stack voltage distributions at various operating currents

This voltage maldistribution partly occurred due to non-uniform flow distribution inside the individual cells of the stack unit. This condition, influenced the gas management at the anode, water management at the cathode and heat transfer through the system. The performance of each individual cell was also influenced by the uneven temperature distribution across the stack (Figure 5.19). 


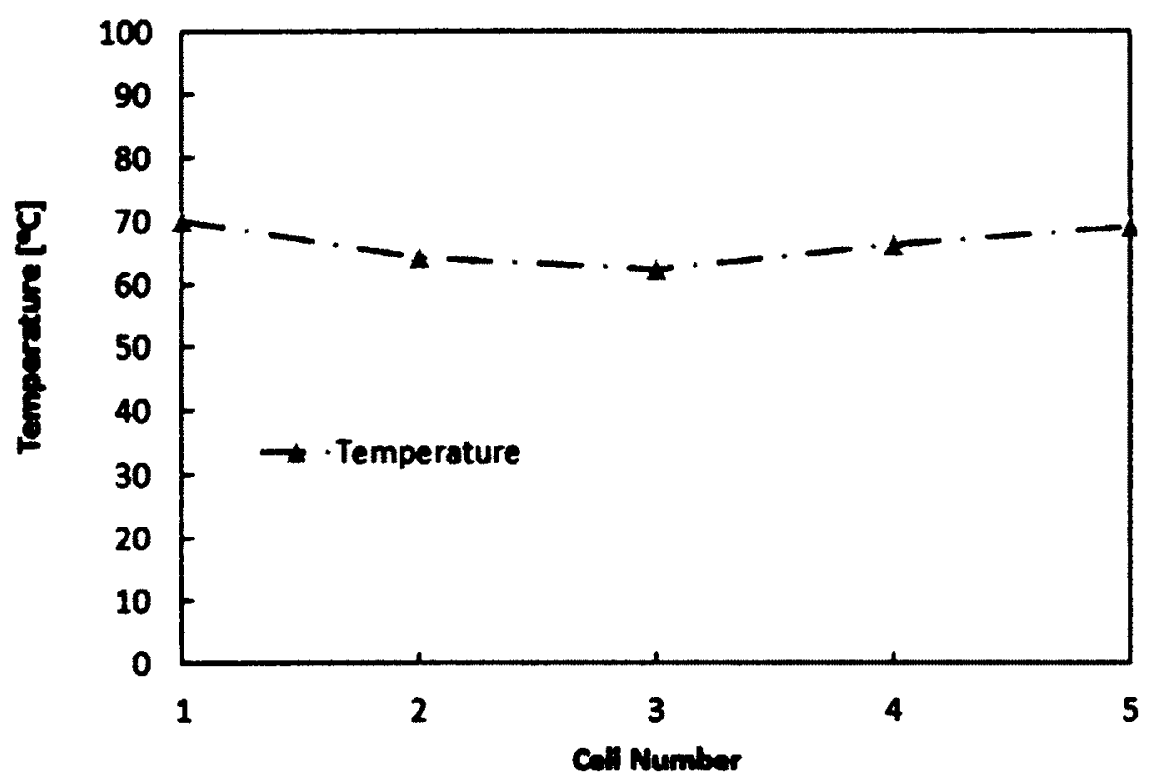

Figure 5.19: Stack temperature distribution

The temperature maldistribution occurred by variations in ohmic heating due to differences in material resistivities. Another important factor that influenced the performance of individual cells in the stack, was the maldistribution of the compression force across the stack unit. The variation in compression force resulted in uneven MEA deflection and thus, a non-uniform voltage output across the stack unit.

As illustrated in Figure 5.18, by increasing the operating current, the voltage variations across the stack unit were magnified. This was due to the fact that at elevated currents, carbon dioxide and water generation rates were significantly high. In such condition, the stack thermal and hydrodynamic equilibrium were altered and thus, higher voltage variations were observed.

\subsubsection{FE Effects on Stack Startup/Shutdown}

Figure 5.20 demonstrates the effects of the flowing electrolyte on the stack output voltage at operating currents of 0,1 and $2 \mathrm{~A}$. Methanol and sulphuric acid concentrations were considered to be $2 \mathrm{M}$, and their flow rates were adjusted to 5 and 7.5 $\mathrm{ml} / \mathrm{min}$, respectively. The stack temperature was maintained at $70^{\circ} \mathrm{C}$ and, air was 


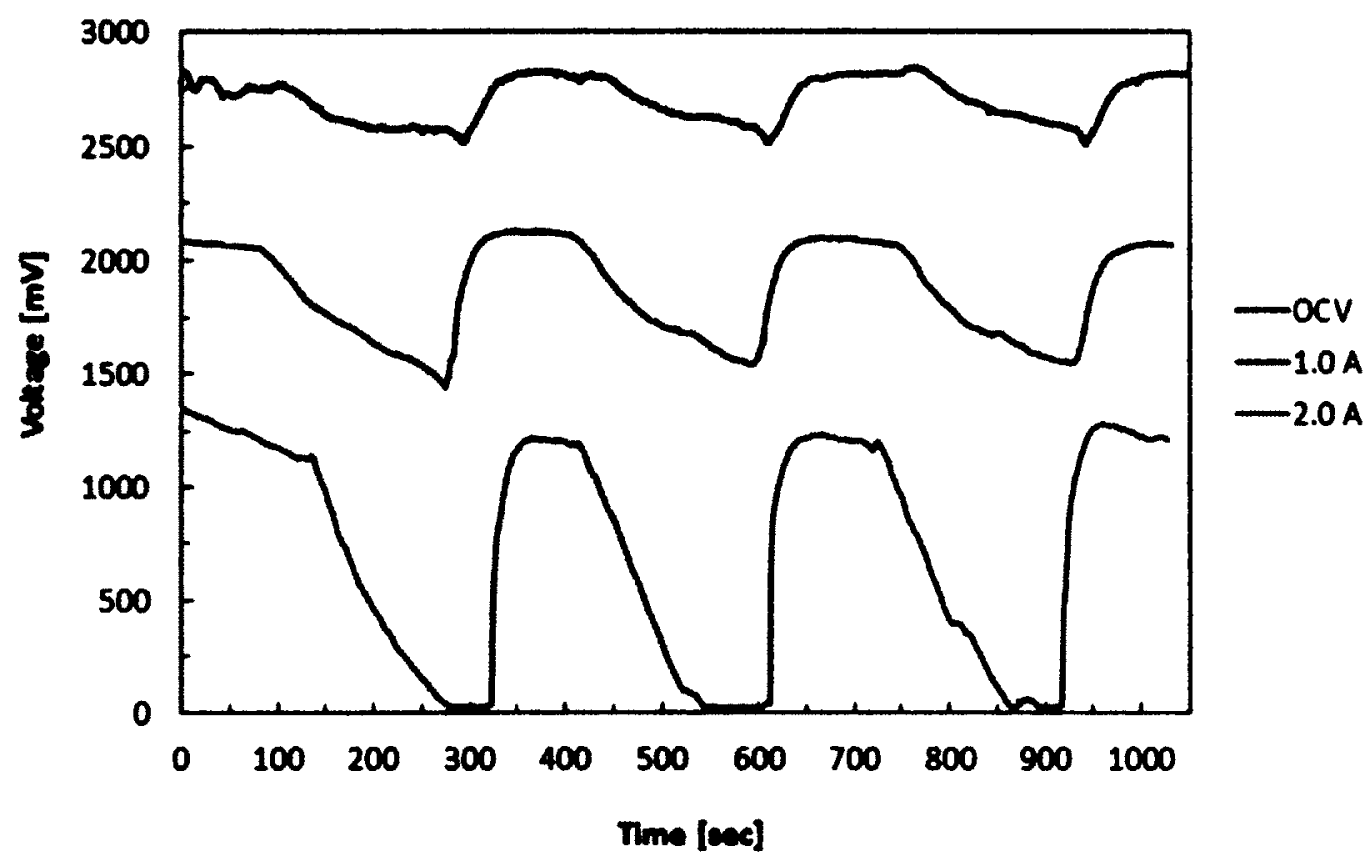

Figure 5.20: Stack startup/shutdown curves at various operating currents

provided to the system at the flow rate of $2000 \mathrm{ml} / \mathrm{min}$.

In every experiment, the flowing electrolyte was stopped for three minutes and then turned back on. This process was repeated three times at each operating current in order to ensure the consistency of the results.

By stopping the flow of sulphuric acid at the stack operating currents of 0,1 and 2 A, the voltage drops of 500,1000 and $1500 \mathrm{mV}$ were observed, respectively. This was due to the fact that, at high operating currents, methanol crossover rate was elevated and thus, shutting down the flowing electrolyte stream drastically reduced the stack voltage. 


\section{Chapter 6}

\section{Conclusions and Recommendations}

As mentioned in Chapter 1, in order to further increase the performance of DMFCs, the issues of gas management at the anode compartment and methanol crossover through the membrane, have to be properly addressed.

In order to effectively remove the generated carbon dioxide gas from the reaction sites, the two-phase flow characteristics inside the anode fuel channels have to be accurately understood. This issue becomes even more important when dealing with DMFC stacks. Managing the two-phase flow within the stack manifolds and cell channels, has proven to be extremely vital in order to achieve a uniform flow distribution inside the system and to improve the stack performance.

Another important problem with regards to DMFCs is the methanol crossover phenomenon. It has been discovered that the permeability of Nafion ${ }^{\circledR}$ membranes to methanol molecules is increased over time, especially when the fuel cell is constantly operated at high current densities. Similar to the gas management problem, the negative consequences of methanol crossover are magnified when dealing with DMFC stacks. In order to prevent methanol molecules from passing through the membrane and reaching the cathode side, different strategies should be applied. One effective method for minimizing methanol crossover in DMFCs is to utilize an acidic flowing electrolyte between the anode and cathode compartments. The flowing electrolyte direct methanol fuel cell (FE-DMFC) concept, was first introduced by Kordesch et al. $[43,44]$ and was later verified in the work of Sabet-Sharghi et al. [45] for a single cell. 


\subsection{Contributions and Conclusions}

Chapters 3 and 4 of this work explored the hydrodynamic characteristics of the DMFC anode compartment in single cell and in stack levels, respectively. In order to predict the two-phase flow behavior within the anode compartment, a numerical hydrodynamic model was developed using various pressure modelling approaches and different void fraction correlations. Different sets of experimental data were utilized to verify the models at various operating conditions.

In Chapter 5, a unique design for a five-cell FE-DMFC stack was presented. Majority of the stack components were fabricated and assembled in-house at Carleton University. The performance of the five-cell FE-DMFC stack was evaluated at various operating conditions such as: air/fuel flow rates, sulphuric acid solution flow rate, methanol solution concentration and operating temperature. In addition, the flowing electrolyte startup/shutdown influence on stack performance was investigated.

The following sections, describe the important contributions/conclusions of each chapter.

\section{Chapter Three}

- A quasi two-dimensional numerical hydrodynamic model was developed to predict the two-phase flow behavior within the DMFC anode fuel channel;

- Both "homogenous" and "separated" flow modelling approaches with corresponding correlations for void fraction were utilized to determine the pressure profile within the DMFC anode compartment;

- The separated flow model was combined with three different void fraction correlations (Martinelli, Drift Flux and CISE), in order to find the best combination;

- The modelling results were compared against two sets of experimental data for verification purposes. The first data set was obtained by in-house testing of a single FE-DMFC unit, and the second data set was obtained from the work of Yang et al. [32];

- It was found that the homogenous flow modelling approach in general, underpredicted the overall pressure drop across the DMFC anode compartment; 
- It was also concluded that the separated flow modelling approach with CISE correlation for void fraction provided the best results at different fuel cell operating conditions;

- The two-phase gravitational pressure, proved to be the most dominant component in determining the overall two-phase pressure drop across the DMFC anode compartment;

- Increasing the fuel cell operating current density, diminished the overall twophase pressure drop across the DMFC anode compartment;

- Increasing the fuel cell operating temperature, also reduced the overall twophase pressure drop across the DMFC anode compartment;

- Higher fuel flow rates resulted in higher pressure drops across the anode compartment while, reducing the influence of the two-phase gravitational pressure component;

- The two-phase pressure drop across the DMFC anode compartment varied in a periodic fashion with various frequencies at different operating current densities;

- At high operating current densities, less fluctuation in pressure amplitudes were observed. This finding was also verified by FFT analysis on the pressure signal;

- Methanol concentration did not vary significantly along the fuel channel, even at very high operating current densities and;

- The volumetric void fraction increased along the fuel channel, especially when the fuel flow rate is relatively low.

\section{Chapter Four}

- A numerical hydrodynamic model was developed to predict the two-phase flow characteristics within the DMFC stack anode compartment;

- Both "homogenous" and "separated" flow modelling approaches with corresponding correlations for void fraction were applied to determine the pressure profile and flow distribution within the stack anode compartment; 
- The modelling results were compared against the experimental data, obtained by testing an in-house five-cell FE-DMFC stack unit;

- Similar to Chapter 3, the separated flow modelling approach combined with CISE correlation for void fraction, provided the best results at different stack operating conditions;

- In a DMFC stack with U-type manifold configuration, the cells closer to the stack inlet, received greater amounts of fuel with respect to other cells;

- By increasing the stack size (increasing the number of unit cells within the stack), the flow maldistribution in the anode compartment increased;

- By increasing the stack operating current density, the flow distribution within the system was negatively influenced. In other words, more non-uniform flow distribution was observed;

- In addition, increasing the stack operating current density, resulted in lower pressure drop across the stack anode compartment;

- Greater pressure drop values were observed for the cells closer to the stack inlet;

- The two-phase pressure drop variations across the stack anode compartment, was found to follow a cyclic pattern;

- The two-phase pressure variations along the stack outlet manifold, was found to be significantly larger than the single phase pressure variations along the stack inlet manifold;

- Methanol concentration along the stack outlet manifold, diminished from the last cell towards the outlet. By increasing the stack operating current density, the entire concentration profile shifted downwards (decreased) and;

- The volumetric void fraction along the stack outlet manifold, increased from the last cell towards the outlet. By increasing the stack operating current density, the entire void fraction curve shifted upwards (increased). 


\section{Chapter Five}

- A five-cell FE-DMFC stack prototype was designed, fabricated and successfully tested in-house at Carleton University;

- It was shown that the implementation of an acidic flowing electrolyte, effectively improved the stack performance by removing any crossed-over methanol from the system, while aiding in the transport of protons to the cathode side;

- Elevating the operating temperature enhanced the overall stack performance by increasing the reaction kinetics at the catalyst layers;

- Increasing the sulphuric acid flow rate drastically improved the stack performance by increasing the removal rate of crossed-over methanol molecules;

- Increasing methanol concentration improved the stack performance up to a certain limit. Further elevation in methanol concentration, was found to be detrimental to the stack performance;

- Increasing the air flow rate enhanced the stack performance up to a certain limit. Further increase in air flow rate, diminished the stack performance since it promoted Nafion ${ }^{\circledR}$ dehydration;

- Similarly, increasing the methanol solution flow rate improved the overall stack performance up to a certain limit. Further elevation in methanol solution flow rate decreased the stack performance by creating a flow maldistribution inside the stack manifolds and cell channels;

- The voltage distribution along the stack was found to be non-uniform with greater variations at higher operating currents and;

- By stopping the flowing electrolyte stream, the overall stack output voltage dropped considerably, particularly at higher operating currents.

\subsection{Recommendations}

A list of recommendations are presented below, in order to provide some guidelines for future research on DMFC anode hydrodynamics, and FE-DMFC concept: 
- To further study the hydrodynamic performance of DMFCs, it would be beneficial to design and test various fuel flow beds with different channel geometries;

- It is also important to investigate the influence of GDL hydrophobic/hydrophilic characteristics on the two-phase flow behavior in the DMFC anode compartment;

- The influence of methanol solution surface tension on the overall pressure drop across the DMFC anode compartment, should also be examined;

- It is beneficial to visually study the two-phase flow characteristics within the FE-DMFC anode compartment at various operating conditions;

- In order to increase the accuracy of the developed hydrodynamic model, one can include the effects of methanol vaporization and carbon dioxide condensation;

- To reduce the size and weight of the FE-DMFC stack, thinner bi-polar plates have to be designed and manufactured;

- In order to reduce flow maldistribution inside the stack anode compartment, it would be beneficial to design and test various manifold geometries;

- Since sulphuric acid is highly corrosive, alternative electrolytes with similar proton conductivities have to be identified and tested and;

- Durability and longevity tests have to be performed on the FE-DMFC stack, in order to monitor and test the long term variations in the performance and potential effects of sulfuric acid on the catalysts. 


\section{List of References}

[1] K. Kordesch and S. G., Fuel Cells and Their Applications. VCH, 1996.

[2] R. O'Hayre, S. Cha, and W. Colella, Fuel Cell Fundamentals. John Wiley \& Sons, INC., 2006.

[3] X. Li, Principles of Fuel Cells. Taylor \& Francis, 2006.

[4] V. Bagostsky, Fuel Cells: Problems and Solutions. John Wiley \& Sons, INC., 2009.

[5] H. Liu and J. Zhang, Electrocatalysis of Direct Methanol Fuel Cells: From Fundamentals to Applications. John Wiley \& Sons, INC., 2009.

[6] C. MacDonald, Effect of Compressive Force on PEM Fuel Cell Performance. $\mathrm{PhD}$ thesis, University of Waterloo, February 2009.

[7] S. Litster and G. McLean, "Pem fuel cell electrodes," Journal of Power Sources, vol. 130, pp. 61-76, 2004.

[8] C. Spiegel, Designing and Building Fuel Cells. McGraw-Hill, 2007.

[9] N. DeLuca, Nafion Blend Membranes for the Direct Methanol Fuel Cell. PhD thesis, Drexel University, February 2008.

[10] J. Wang, J. Yan, J. Yuan, and B. Sundn, "On flow maldistribution in pemfc stacks," International Journal of Green Energy, vol. 8, pp. 585-606, 2011.

[11] J. Wang, "Review of flow maldistribution in channels of pemfc stacks," International Journal of Green Energy, vol. 8, 2011.

[12] V. Oliveira, C. Rangel, and A. Pino, "Effect of anode and cathode flow field design on the performance of a direct methanol fuel cell," Chemical Engineering Journal, vol. 157, pp. 174-180, 2010.

[13] V. Oliveira, C. Rangel, and A. Pino, "Modelling and experimental studies on a direct methanol fuel cell working under low methanol crossover and high methanol concentrations," International Journal of Hydrogen, vol. 34, pp. 6443-6451, 2009.

[14] D. Gleason, Proton Exchange Membranes and Membrane Electrode Assemblies for Enhanced Direct Methanol Fuel Cell Performance. PhD thesis, Worcester Polytechnic Institute, April 2008. 
[15] N. Vladimir, M. Jonathan, W. Haijiang, and Z. Jiujun, "A review of polymer electrolyte membranes for direct methanol fuel cells," Jouarnal of Power Sources, vol. 169, pp. 221-238, 2007.

[16] J. Ling and O. Savadogo, "Comparison of methanol crossover among four types of nafion membranes," Journal of The Electrochemical Society, vol. 151, pp. A1604A1610, 2004.

[17] T. Tschinder, T. Schaffer, S. Fraser, and V. Hacker, "Electro-osmotic drag of methanol in proton exchange membranes," Journal of Applied Electrochemistry, vol. 37, pp. 711-716, 2007.

[18] D. Jung, C. Lee, C. Kim, and D. Shin, "Performance of a direct methanol polymer electrolyte fuel cell," Jouarnal of Power Sources, vol. 71, pp. 169-173, 1998.

[19] S. Narayanan, A. Kinder, B. Jeffries-Nakamura, H. F. W. Chun, M. Smart, T. Valdez, S. Surampudi, and G. Halpert, "Recent advances in pem liquid-feed direct methanol fuel cells," Battery Conference on Applications and Advances, vol. 11, pp. 113-122, 1996.

[20] M. Li, J. Liang, C. Liu, G. Sun, and G. Zhao, "Effects of anode flow field design on carbon dioxide bubble behavior in micro-dmfc," Sensors, vol. 9, pp. 33143324, 2009.

[21] W. Bousman, J. McQuillen, and L. C. Witte, "Gas-liquid flow patterns in microgravity: effects of tube diameter, liquid viscosity and surface tension," Journal of Multiphase Flow, vol. 22, pp. 1035-1053, 1996.

[22] A. Arico, P. Creti, V. Baglio, E. Modica, and V. Antonucci, "Influence of flow field design on the performance of a direct methanol fuel cell," Chemical Engineering Journal, vol. 91, pp. 202-209, 2000.

[23] J. G.Collier and J. J. R.Thome, Convective Boiling and Condensation. Oxford, 1994.

[24] B. Field and P. Hrnjak, Two-Phase Pressure Drop and Flow Regime of Refrigerants and Refrigerant-Oil Mixtures in Small Channels. University of Illinois at Urbana-Champaign, 2007.

[25] M. Awad and Y. Muzychka, "Two-phase flow modeling in micro-channels and mini-channels," Journal of Heat Transfer Engineering, vol. 31, pp. 1023-1033, 2010.

[26] D. Beattie and P. Whalley, "A simple two-phase frictional pressure drop calculation method," International Journal of Multiphase Flow, vol. 8, pp. 83-87, 1983.

[27] P. Chung and M. Kawaji, "The effect of channel diameter on adiabatic two-phase flow characteristics in micro-channels," Journal of Multiphase Flow, vol. 30, pp. 735-761, 2004. 
[28] A. Salim, M. Fourar, J. Pironon, and J. Sausse, "Oil-water two-phase flow in microchannels: Flow patterns and pressure drop measurements," The Canadian Journal of Chemical Engineering, vol. 86, pp. 978-988, 2008.

[29] C. T. Crowe, Multiphase Flow Handbook. Taylor \& Francis, 2005.

[30] J. Lee and I. Mudawar, "Two-phase flow in high-heat-flux micro-channel heat sink for refrigeration cooling applications, part one: pressure drop characteristics," International Journal of Heat and Mass Transfer, vol. 48, pp. 928-940, 2005.

[31] T. Bewer, T. Beckmann, H. Dohle, J. Mergel, and D. Stolten, "Novel method for investigation of two-phase flow in liquid feed direct methanol fuel cells using an aqueous hydrogen peroxide solution," Journal of Power Sources, vol. 125, pp. 1-9, 2004.

[32] H. Yang, T. Zhao, and Q. Ye, "Pressure drop behavior in the anode flow field of liquid feed direct methanol fuel cells," Journal of Power Sources, vol. 142, pp. 117-124, 2005.

[33] Q. Liao, X. Zhu, X. Zheng, and Y. Ding, "Visualization study on the dynamics of carbon dioxide bubbles in anode channels and performance of a dmfc," Journal of Power Sources, vol. 171, pp. 644-651, 2007.

[34] P. Argyropoulos, K. Scott, and W. Taama, "Pressure drop modelling for liquid feed direct methanol fuel cells," Chemical Engineering Journal, vol. 73, pp. 229 245, 1999.

[35] S. Maharudrayya, S. Jayanti, and A. Deshpande, "Pressure losses in laminar flow through serpentine channels in fuel cell stacks," Journal of Power Sources, vol. 138, pp. 1-13, 2004.

[36] M. Kim, W. Lim, M. Lee, and I. Moon, "3-dimensional cfd simulation modeling for optimal flow field design of direct methanol fuel cell bipolar plate," ICCASSICE, pp. $5463-5468,2009$.

[37] Z. Wang and C. Wang, "Mathematical modeling of liquid-feed direct methanol fuel cells," Journal of The Electrochemical Society, vol. 150, pp. 508-519, 2003.

[38] A. Heinzel and V. Barragan, "A review of the state-of-the-art of the methanol crossover in direct methanol fuel cells," Journal of Power Sources, vol. 84, pp. 7074, 1999.

[39] P. Kauranen and E. Skou, "Methanol permeability in perfluorosulfonate proton exchange membranes at elevated temperatures," Journal of Applied Electrochemistry, vol. 26, pp. 909-917, 1996.

[40] M. Gao, Q. Gao, J. Jiang, C. Cui, W. Yao, and S. Yu, "A methanol-tolerant pt/cose2 nanobelt cathode catalyst for direct methanol fuel cells," Angewandte Chemie International Edition, vol. 50, pp. 4905-4908, 2011. 
[41] C. Pu, W. Huang, K. Ley, and E. Smotkin Jouarnal of Electrochemical Society, vol. 143, p. 2601, 1996.

[42] A. Kuver and W. Vielstich, "Investigation of methanol crossover and single electrode performance during pemdmfc operation: A study using a solid polymer electrolyte membrane fuel cell system," Journal of Power Sources, vol. 74, pp. 211-218, 1998.

[43] K. Kordesch, V. Hacker, and U. Bachhiesl, "Direct methanol-air fuel cells with membranes plus circulating electrolyte," Journal of Power Sources, vol. 96, pp. 200-203, 2001.

[44] K. Kordesch, "Direct methanol fuel cell with circulating electrolyte," US Patent US 2003/0170524 A1, 2003.

[45] N. Sabet-Sharghi, C. Cruickshank, and E. Matida, "Experimental analysis of a single cell-flowing electrolyte direct methanol fuel cel," in Proceedings of ESFuelCell2011, ASME, Aug 2011.

[46] N. Sabet-Sharghi, Experimental Analysis of a Single Cell Flowing ElectrolyteDirect Methanol Fuel Cell. PhD thesis, Carleton University, August 2011.

[47] R. B. Bird, W. E. Stewart, and E. N. Lightfoot, Transport Phenomena. John Wiley \& Sons, INC., 2007.

[48] K. Scott, W. Taama, S. Kramer, P. Argyropoulos, and K. Sundmacher, "Limiting current behaviour of the direct methanol fuel cell," Electrochimica Acta, vol. 45, pp. 945-957, 1999.

[49] T. Schaffer, T. Tschinder, V. Hacker, and J. Besenhard, "Determination of methanol diffusion and electroosmotic drag coefficients in proton-exchangemembranes for dmfc," Journal of Power Sources, vol. 153, pp. 210-216, 2006.

[50] C. Colpan, C. Cruickshank, E. Matida, and F. Hamdullahpur, "1d modeling of a flowing electrolyte-direct methanol fuel cell," Journal of Power Sources, vol. 196, pp. 3572-3582, 2011.

[51] B. E. Poling, J. M. Prausnitz, and J. P. O'Connell, The Properties of Gases and Liquids. McGraw-Hill, 2001.

[52] F. M. White, Fluid Mechanics. McGraw-Hill, 2011.

[53] D. S. Viswanath, Viscosity of liquids: theory, estimation, experiment, and data. Springer, 2007.

[54] C. Rice, The Effect of Void Fraction Correlation and Heat Flux Assumption on Refrigerant Charge Inventory Predictions. ASHRAE, 2007.

[55] A. J. G. M. A. Woldesemayat, "Comparison of void fraction correlations for different flow patterns in horizontal and upward inclined pipes," International Journal of Multiphase Flow, vol. 33, pp. 347-370, 2007. 
[56] K. A. Triplett, S. M. Ghiaasiaan, S. I. Abdel-Khalik, A. LeMouel, and B. N. McCord, "Gas-liquid two-phase flow in micro-channels, part two: voidfraction and pressure drop," International Joumal of Multiphase Flow, vol. 25, pp. 395410, 1999.

[57] J. F. Kreider, Handbook of heating, ventilation, and air conditioning. CRC Press, 2000.

[58] J. H. Koh, H. K. Seo, C. G. Lee, Y. S. Yoo, and H. C. Lim, "Pressure and flow distribution in internal gas manifolds of a fuel cell stack," Journal of Power Sources, vol. 115, pp. 54-65, 2003.

[59] R. S. Figliola and D. E. Beasley, Theory and Design for Mechanical Measurements. John Wiley \& Sons, INC., 2010.

[60] ASME, "Measurement uncercainty: Instruments and apparatus," 1985.

[61] R. Moffat, "Describing the uncertainties in experimental results," Experimental Thermal and Fluid Science, vol. 1, pp. 3-17, 1988.

[62] S. Kline and F. McClintock, "Describing uncertainties in single sample experiments," Mechanical Engineering, vol. 75, pp. 3-8, 1953. 


\section{Appendix A}

\section{Stack Bi-Polar Plate Three View Drawings}

All the dimensions are in $\mathrm{mm}$ except for the threaded dimensions that are in inches. All the bi-polar plates have the same dimensions and are made of graphite AR-08. Table A.1 [46] shows further information about the physical, mechanical and electrical properties of graphite AR-08:

Table A.1: Properties of grade AR-08 graphite plate

\begin{tabular}{|c|c|}
\hline \multicolumn{2}{|c|}{ Physical Properties } \\
\hline Apparent Bulk Density & $1.80 \mathrm{gr} / \mathrm{cm}^{3}$ \\
\hline Particle Size & $11.9 \mu \mathrm{m}$ \\
\hline \multicolumn{2}{|c|}{ Mechanical Properties } \\
\hline Hardness, Shore D & 65 \\
\hline Flexural Strength & $51.7 \mathrm{MPa}$ \\
\hline Compressive Strength & $114 \mathrm{MPa}$ \\
\hline \multicolumn{2}{|c|}{ Electrical Properties } \\
\hline Electrical Resistivity & $0.00124 \Omega-\mathrm{cm}$ \\
\hline
\end{tabular}



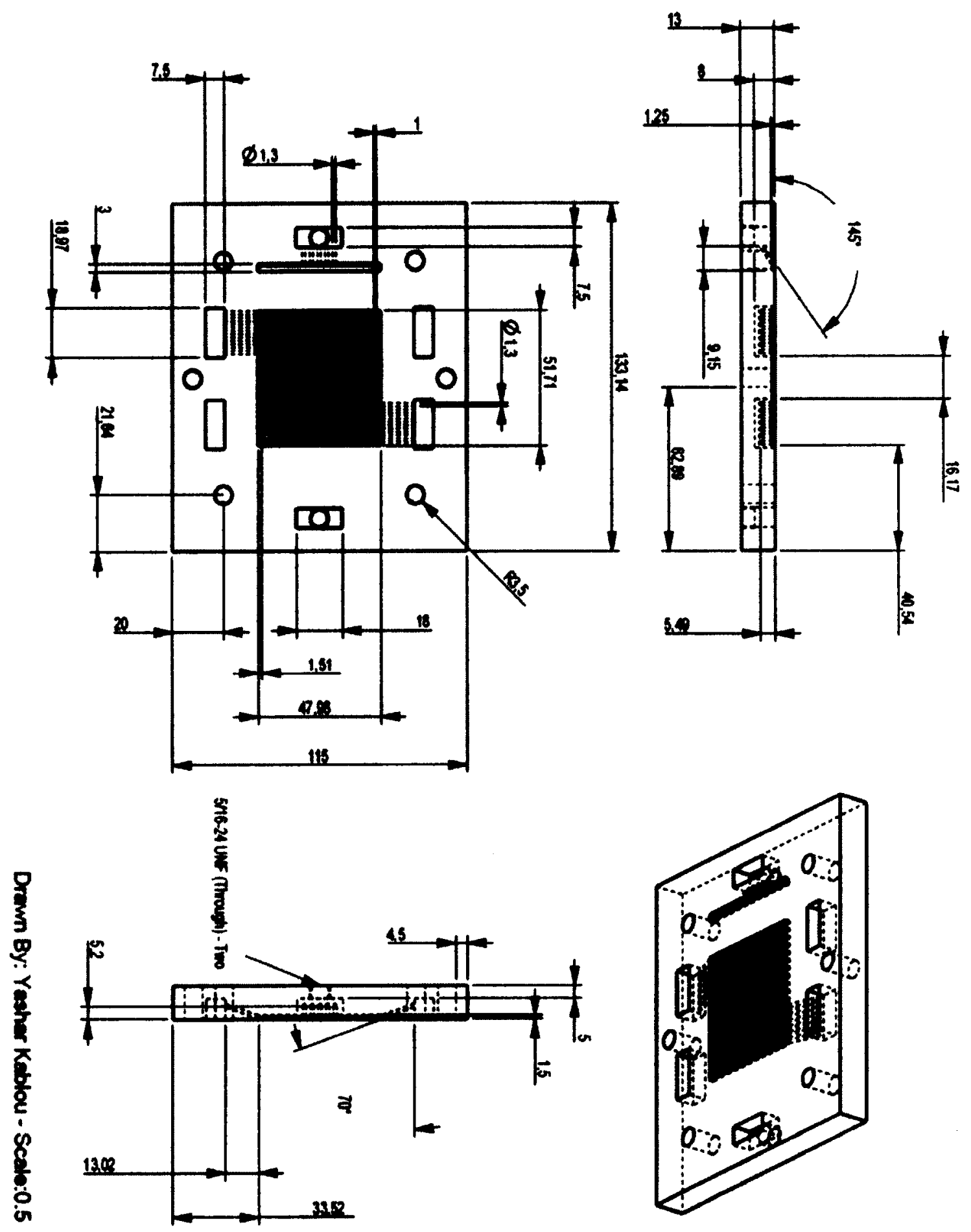

Figure A.1: Three view drawings of the bi-polar plate 


\section{Appendix B}

\section{Details of Stack Experimental Setup}

In this section, further details about the experimental setup are presented.

\section{B.1 Fluid Control}

\section{B.1.1 Pumps}

Two types of pumping systems were utilized. For the methanol solution, a peristaltic pump (MASTERFlex C/L Pump) was used and for sulphuric acid solution, a special positive displacement pump with internal Teflon coating (Fluid Metering Inc. - RHB model) was applied [46].

Table B.1: Pumping system specifications

\begin{tabular}{|c|c|c|}
\hline Brand & MASTERFlex & Fluid Metering Inc. \\
\hline Model & C/L-77122-22 & RHB-PM6013 \\
\hline Speed (rpm) & 50 to 300 & 2200 \\
\hline Electrical Requirement & 115 V AC, 400 mA AC & 12 V DC, 4.3 A \\
\hline Material & $\begin{array}{c}\text { polyphenylene sulphide (PPS), } \\
\text { polyester and stainless steel }\end{array}$ & $\begin{array}{c}\text { wetted parts: } \\
\text { ceramic \& PVDF }\end{array}$ \\
\hline Flow Rate (ml/min) & 0 to 25 & 0 to 260 \\
\hline Temperature range $\left({ }^{\circ} \mathrm{C}\right)$ & $0-40$ & - \\
\hline
\end{tabular}




\section{B.1.2 Rotameter}

In order to monitor and measure the air flow rate, the Gilmont GF-9360 rotameter with following specifications was used [46]:

Table B.2: Rotameter specifications

\begin{tabular}{|c|c|}
\hline & Description \\
\hline Material & PTFE \\
\hline Valve Adjustment & 0.1 to $100 \%$ of maximum flow \\
\hline Precision & 0.3 to $60 \%$ of maximum flow \\
\hline Accuracy & $5 \%$ of reading or $2 \mathrm{~mm}$ of the scale length \\
\hline
\end{tabular}

\section{B.1.3 Air Filter}

An air filter with the following specifications was utilized to clear the air stream from particles with diameter larger than 1 micron [46].

Table B.3: Air filter specifications

\begin{tabular}{|c|c|}
\hline & Description \\
\hline Particle allowance & $1 \mu \mathrm{m}$ \\
\hline Maximum flow rate & $20 \mathrm{scfm}$ of the flow \\
\hline Maximum operating pressure & $100 \mathrm{psi}$ \\
\hline Maximum operating temperature & $125^{\circ} \mathrm{F}$ \\
\hline
\end{tabular}

\section{B.2 Temperature Control}

\section{B.2.1 Temperature Controller}

In order to regulate the fuel cell operating temperature, a temperature controller from OMEGA (Model No: CN-79000) was used. This specific type of temperature 
controller, allowed for controlling the temperatures of methanol solution and fuel cell, separately [46].

Table B.4: Temperature controller specifications

\begin{tabular}{|c|c|}
\hline & Description \\
\hline On/Off differential & Adjustable to $1^{\circ} \mathrm{F}, 1^{\circ} \mathrm{C}$ or 1 count of full scale \\
\hline Supply voltage & 100 to $240 \mathrm{~V} \mathrm{AC}$, nominal, $10-15 \%, 50$ to $400 \mathrm{~Hz}$ \\
\hline Operating temperature range & -10 to $+55^{\circ} \mathrm{C}$ \\
\hline Accuracy & $0.25 \%$ of span \\
\hline
\end{tabular}

\section{B.2.2 Thermocouple}

In order to monitor the temperature variations within the fuel cell unit, a K-type thermocouple from J-KEM SCIENTIFIC INC (Model No: TEF-30-K) was utilized. A thin layer of Teflon coating covered the instrument in order to protect it against corrosive materials such as sulphuric acid [46].

Table B.5: Thermocouple specifications

\begin{tabular}{|c|c|}
\hline & Description \\
\hline Material & Thin chromel-alumel wires with Teflon sealing \\
\hline Dimensions & Diameter: $0.064 \mathrm{~mm}$, Length: $914.4 \mathrm{~mm}$ \\
\hline Response time & $0.1 \mathrm{sec}$ \\
\hline Operating temperature range & -250 to $+204^{\circ} \mathrm{C}$ \\
\hline Precision & The greater of $2.2^{\circ} \mathrm{C}$ or $0.75 \%$ of range \\
\hline
\end{tabular}

\section{B.2.3 Heaters}

In order to increase the fuel cell temperature, a pair of head pads from OMEGA (Model No: SRFG-203/10-P) with the following specifications, were utilized [46]. 
Table B.6: Heater specifications

\begin{tabular}{|c|c|}
\hline & Description \\
\hline Material & Silicone rubber, Kapton \\
\hline Dimensions & 2 in $^{2}$ \\
\hline Circuit design & Etched foil \\
\hline Maximum operating temperature & $120^{\circ} \mathrm{C}$ \\
\hline Operating voltage & $115 \mathrm{~V} \mathrm{AC}$ \\
\hline Heat flux & $10 \mathrm{~W} / \mathrm{in}^{2}$ \\
\hline
\end{tabular}

\section{B.3 Load Control}

\section{B.3.1 Load Bank}

In order to monitor the fuel cell performance, a Fideris (Innovator Series-250 $\mathrm{kW}$ ) load bank was used. The system was controlled by means of a software called FCPower. The FCPower program provided an interface which allowed the user to operate the fuel cell in various modes, such as: constant current, constant voltage and constant power. In addition, it provided the capacity for the user to vary the current or voltage linearly, between any two arbitrary limits (ramp operation) [46].

Table B.7: Load bank specifications

\begin{tabular}{|c|c|}
\hline & Description \\
\hline Type & MOSFET variable resistance load bank \\
\hline Current measurement & Exchangeable shunts (1, 20 and 50 A) \\
\hline Maximum current rating & $50 \mathrm{~A}$ \\
\hline Maximum voltage rating & $20 \mathrm{~V} \mathrm{DC}$ \\
\hline Maximum power dissipation & $250 \mathrm{~W}$ \\
\hline Load capacitance & Less than $20 \mathrm{pF}$ \\
\hline Electrical requirements & $26-50 \mathrm{~V} \mathrm{DC}$ \\
\hline Communication & Ethernet (requires DHCP) \\
\hline
\end{tabular}




\section{B.4 Pressure Control}

\section{B.4.1 Differential Pressure Transducer}

In order to accurately measure and monitor the pressure drop across the fuel cell anode compartment (single cell and stack), a differential pressure transducer from OMEGA (Model No: PX409-001DWU5V) was utilized. The high and low sides of the transducer were connected to anode inlet and outlet sections, respectively.

Table B.8: Pressure transducer specifications

\begin{tabular}{|c|c|}
\hline & Description \\
\hline Wetted parts material & 316L stainless steel \\
\hline Response time & $0.001 \mathrm{sec}$ \\
\hline CE complaint & Meets EN1326-1: 2006 for industrial locations \\
\hline Bandwidth & DC to $1 \mathrm{kHz}$ typical \\
\hline Pressure cycles & 1 million \\
\hline Pressure Ports & $1 / 4$ NPT male \\
\hline Electrical Terminations & PX409: $2 \mathrm{~m}$ cable \\
\hline Weight & $200 \mathrm{gr}$ \\
\hline Operating temperature range & -45 to $+121^{\circ} \mathrm{C}$ \\
\hline Operating pressure range & 0 to $1 \mathrm{psi}$ \\
\hline Output Impedance & $100 \Omega$ \\
\hline Accuracy & $0.08 \%$ \\
\hline Output voltage & 0 to $5 \mathrm{~V} \mathrm{DC}$ \\
\hline Operating voltage & 10 to $30 \mathrm{~V} \mathrm{DC}$ \\
\hline
\end{tabular}

\section{B.4.2 Data Acquisition (DAQ) Card}

In order to convert the output voltage signal from the transducer, into pressure values readable by the user, a data acquisition card from National Instruments (Model No: NI USB-6009) was used. 
- 8 analog inputs (14-bit, $48 \mathrm{kS} / \mathrm{sec}$ );

- 2 analog outputs (12-bit, $150 \mathrm{~S} / \mathrm{sec}$ ), 12 digital I/O, 32-bit counter;

- Bus-powered for high mobility, built-in signal connectivity;

- Compatible with LabVIEW and SignalExpress softwares. 


\section{Appendix C}

\section{Pressure Signal Fast Fourier Transform (FFT) Analysis}

As shown earlier in Chapters 3 and 4, the measured pressure signal across the DMFC anode compartment is in cyclic form. In order to determine the frequency content of the pressure signal, FFT analysis is performed. FFT analysis is the process of determining the frequency domain representation of a time domain signal. It aids in eliminating any possible noise form the measured data. Various types of FFT algorithms have been suggested in the literature; however in this work, "CooleyTukey" methodology was applied.

In order to obtain the frequency spectrum of the pressure signal, the pressure transducer was set to record data at $1000 \mathrm{~Hz}$ "sampling rate". This high value for sampling frequency was chosen to increase the resolution of the FFT analysis. Using MATLAB software's "fft" function, the finite Fourier transform of the pressure signal was calculated for both FE-DMFC single cell and stack. For each case, the pressure values were recorded at operating currents of $0,1,2$ and $3 \mathrm{~A}$. The following sections describe the details of FFT analysis performed on the in-house FE-DMFC single cell and stack units.

\section{C.1 In-House FE-DMFC Single Cell}

The following frequency spectrums (Figure C.1) were obtained by testing the inhouse FE-DMFC single cell unit. The system was operated at constant temperature of $70^{\circ} \mathrm{C}$. Methanol and sulphuric acid concentrations were considered to be $2 \mathrm{M}$. The 
respective flow rates of sulphuric acid and methanol were adjusted to 7.5 and 0.5 $\mathrm{ml} / \mathrm{min}$, and air was provided to the system at the rate of $400 \mathrm{ml} / \mathrm{min}$. As mentioned earlier, the unit was tested at operating currents of $0,1,2$ and $3 \mathrm{~A}$, and for each case, the pressure data was recorded for $10 \mathrm{sec}$ at the sampling rate of $1000 \mathrm{~Hz}$.
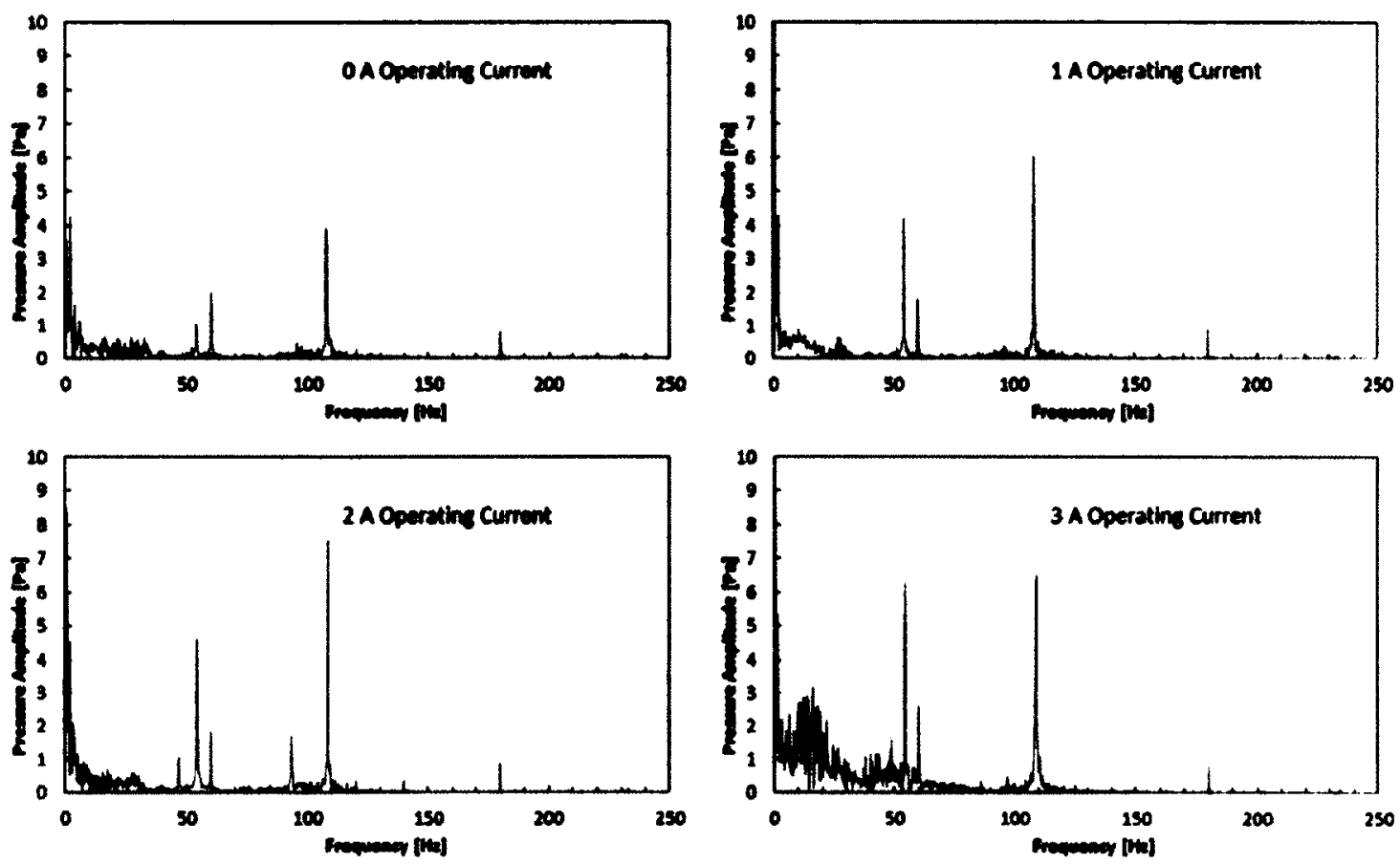

Figure C.1: FE-DMFC single cell frequency spectrums at various currents

In all the above graphs, the $x$-axis corresponded to frequency. To ensure the reliability of the results, the frequency range was selected to be from 0 to $250 \mathrm{~Hz}$ (quarter of the sampling frequency rate). In general, several peaks were observed at low frequencies up to $50 \mathrm{~Hz}$. By increasing the current from 0 to $3 \mathrm{~A}$, the magnitude of the underlying low frequency signals were increased significantly. This was due to the fact that, at high operating currents, the $\mathrm{CO}_{2}$ generation rate was high which in return, created a slug/plug flow regime inside the anode fuel channels with lower formation/detachment rate. This condition, resulted in higher pressure fluctuations across the anode compartment and thus, magnified the low frequency component of the wave form. 
Furthermore, in all spectrums, four major peaks were observed at frequencies of $52,60,104$ and $180 \mathrm{~Hz}$. The presence of a peak in 60 and $180 \mathrm{~Hz}$ frequencies, was most probably due to the interference of external $\mathrm{AC}$ voltage fields on the pressure transducer. On the other hand, both 52 and $104 \mathrm{~Hz}$ frequencies, could be related to system characteristics such as GDL composition, catalyst loading, fuel channel geometry, reaction area and flow bed design.

\section{C.2 In-House FE-DMFC Stack}

As can be seen in Figure C.2, four sets of frequency spectrums were obtained by testing the in-house five-cell FE-DMFC stack. The stack was operated at currents of $0,1,2$, and $3 \mathrm{~A}$, in order to obtain the corresponding frequency spectrums.
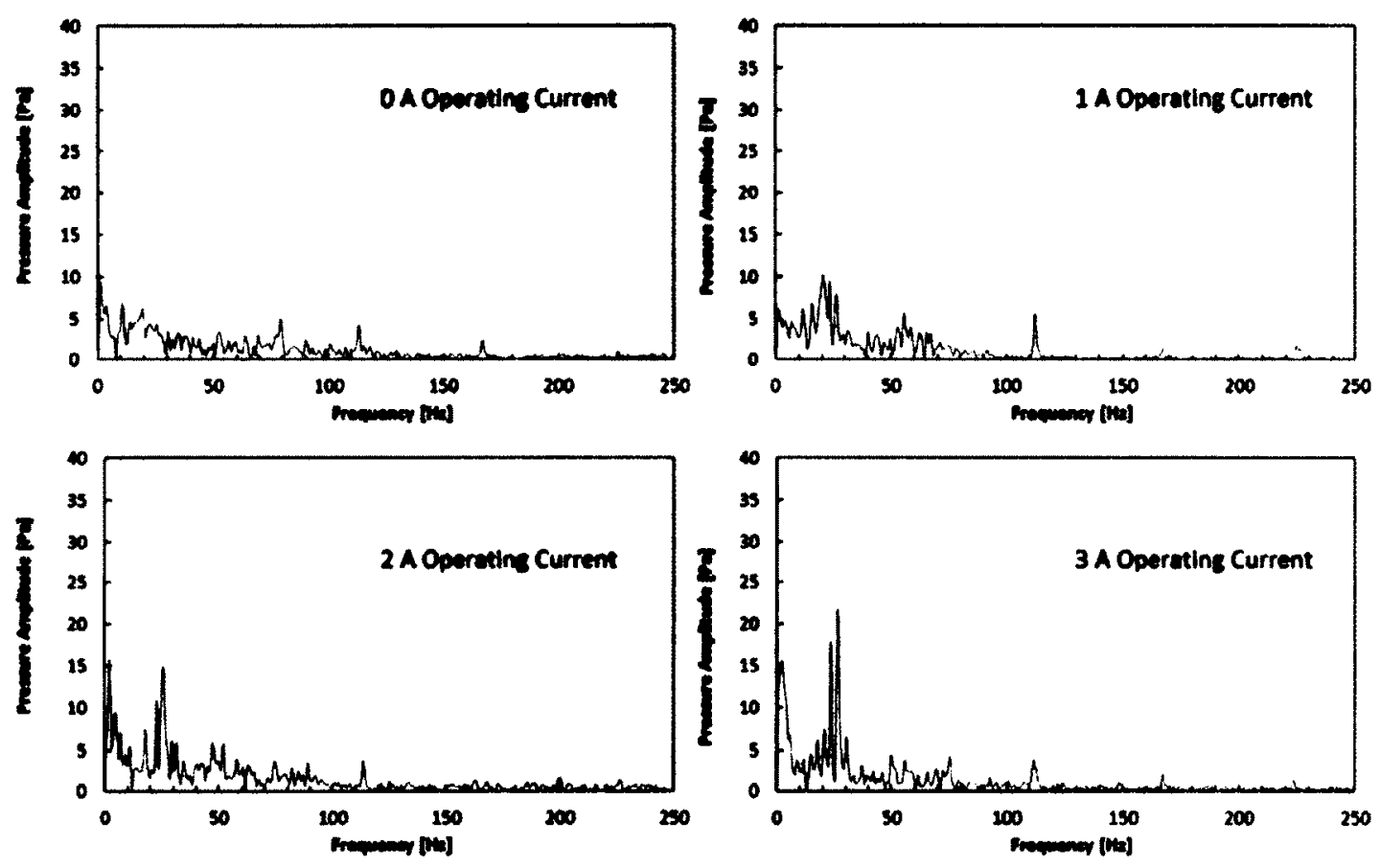

Figure C.2: FE-DMFC stack frequency spectrums at various currents

The stack temperature was maintained at $70^{\circ} \mathrm{C}$. Methanol and sulphuric acid concentrations were considered to be $2 \mathrm{M}$. The respective flow rates of sulphuric acid and 
methanol were adjusted to 7.5 and $10 \mathrm{ml} / \mathrm{min}$, and air was provided to the system at the rate of $2000 \mathrm{ml} / \mathrm{min}$. For each case, the pressure data was recorded for $10 \mathrm{sec}$ at the sampling rate of $1000 \mathrm{~Hz}$.

Similar frequency range was applied for each case (from 0 to $250 \mathrm{~Hz}$ ). As illustrated in Figure C.2, several peaks were identified for frequencies lower than $50 \mathrm{~Hz}$ with amplitudes larger than single cell case. In addition, by increasing the stack operating current, the magnitude of the low frequency wave forms enhanced. This was due to the fact that, by increasing the number of cells and enhancing the operating current, $\mathrm{CO}_{2}$ generation rate was increased drastically (creation of a slug/plug flow regime inside the stack manifolds) and thus, the low frequency component of the wave form dominated other components. 


\section{Appendix D}

\section{Uncertainty Analysis}

In this section, the details of the uncertainty analysis performed on the stack unit and pressure control system, are described.

For stack unit, as illustrated in Chapter 5, the five-cell FE-DMFC stack was connected to a load bank to control its output current and voltage. Methanol and sulphuric acid solutions with $2 \mathrm{M}$ concentration, were pumped through the stack anode compartment and $\mathrm{FE}$ channels at the rates of $5 \mathrm{ml} / \mathrm{min}$ and $7.5 \mathrm{ml} / \mathrm{min}$, respectively, using two peristaltic pumps. The air on the other hand, was passed through the stack cathode compartment at the rate of $2000 \mathrm{ml} / \mathrm{min}$, using a commercial compressor. The stack temperature was maintained at $70^{\circ} \mathrm{C}$.

For pressure control system, as mentioned in Chapters 3 and 4, the overall pressure drop across the anode compartment of the in-house FE-DMFC single cell was measured using a high precision differential pressure transducer (OMEGA - Model No: PX409-001DWU5V) and a DAQ card (National Instruments - Model No: NI USB6009). Same as above, methanol and sulphuric acid concentrations were considered to be $2 \mathrm{M}$, with respective flow rates of $5 \mathrm{ml} / \mathrm{min}$ and $7.5 \mathrm{ml} / \mathrm{min}$. Air was passed through the cathode compartment at the rate of $400 \mathrm{ml} / \mathrm{min}$.

The first step in performing the uncertainty analysis, is to identify all the corresponding sources of error. In general, measurement errors can be grouped into two categories: systematic/bias errors (denoted by $S$ ) and random errors (denoted by $R$ ). The systematic/bias errors always shift the mean measurement value away from the true mean value, by a fixed amount. The random errors on the other hand, 
are always caused by the random distribution of measured values about the sample mean $[59,61,62]$.

\section{D.1 Stack Uncertainty Analysis}

\section{D.1.1 List of Elemental Errors}

The measurement errors can enter during all aspects of experimentation, including: calibration, data acquisition and data reduction. For stack testing, the following elemental sources of error were identified:

- Errors due to temperature control system, including: K-type thermocouple, thermocouple position and temperature controller;

- Errors due to fluid control system, including: MASTERFlex peristaltic pump, RHB pump, compressor, FE channel thickness and stack internal flow distribution;

- Errors due to fuel and flowing electrolyte concentrations;

- Errors due to load control system, including: Fideris load bank and computer;

- Errors due to stack clamping torque and compression force.

\section{D.1.2 Estimation of The Elemental Errors}

As mentioned above, various individual factors influenced the temperature measurement. The overall temperature measurement error was calculated by combining all the individual factors, in the following manner:

Thermocouple, systematic and random errors $\left(S_{1}\right.$ and $\left.R_{1}\right)$ :

$S_{1}= \pm 2.2^{\circ} \mathrm{C} \quad R_{1}= \pm 1.0^{\circ} \mathrm{C}$

Thermocouple position, systematic and random errors $\left(S_{2}\right.$ and $\left.R_{2}\right)$ :

$S_{2}= \pm 1.0^{\circ} \mathrm{C} \quad R_{2}= \pm 0.25^{\circ} \mathrm{C}$

Temperature controller, systematic and random errors $\left(S_{3}\right.$ and $\left.R_{3}\right)$ :

$S_{3}= \pm 0.5^{\circ} \mathrm{C} \quad R_{3}= \pm 0.25^{\circ} \mathrm{C}$

Overall temperature measurement errors (systematic and random):

$S_{T}=\left(2.2^{2}+1.0^{2}+0.5^{2}\right)^{\frac{1}{2}}=2.47^{\circ} \mathrm{C}$

$R_{T}=\left(1.0^{2}+0.25^{2}+0.25^{2}\right)^{\frac{1}{2}}=1.06^{\circ} \mathrm{C}$ 
Both methanol and sulphuric acid solution flow rates were calibrated volumetrically, by a graduated cylinder with a systematic error of $0.25 \mathrm{ml}$. This resulted in, 0.25 $\mathrm{ml} / \mathrm{min}$ systematic error for the flow rate. In this case, a random error of $0.25 \mathrm{ml} / \mathrm{min}$, was chosen to account for human eye error.

In addition, similar equipment was used in order to obtain $1000 \mathrm{ml}$ of $2 \mathrm{M}$ methanol and sulphuric acid solutions. Systematic error of methanol solution concentration $\left(S_{C_{m e}}\right)$, was obtained by the following sets of equations:

$$
S_{C_{m e}}=\left[\sum_{i=1}^{j}\left(\theta_{C_{m e}}(i) S_{C_{m e}}(i)\right)^{2}\right]^{\frac{1}{2}}
$$

where:

$$
\theta_{C_{m e}}(i)=\frac{\partial C_{m e}(i)}{\partial V_{m e}}
$$

thus:

$$
S_{C_{m e}}=\theta_{C_{m e}}\left(V_{m e}\right) \cdot S_{C_{m e}}\left(V_{m e}\right)
$$

where:

$$
\theta_{C_{m e}}\left(V_{m e}\right)=\frac{\partial C_{m e}\left(V_{m e}\right)}{\partial V_{m e}}
$$

and:

$$
C_{m e}\left(V_{m e}\right)=\left(\frac{\rho_{m e}}{V_{s o l} M_{m e}}\right) V_{m e}
$$

thus:

$$
S_{C_{m e}}=\left(\frac{\rho_{m e}}{V_{s o l} M_{m e}}\right)\left(V_{m e}\right)
$$

This correspond to $0.006 \mathrm{M}$ error in methanol concentration. Using the same methodology for sulphuric acid, $0.005 \mathrm{M}$ systematic error was obtained. In both 
cases, similar corresponding random error values were selected, to account for human eye error.

The FE channel thickness was measured with a Mastercraft electronic caliper with $0.02 \mathrm{~mm}$ systematic error. Similar random error was selected to account for human eye error.

Since the load bank was accurately calibrated by the supplier (Fideris Inc.), the systematic error was considered to be negligible. The random error on the other hand, was found to be much larger. This was due to the presence of, contact resistance between the load bank cables and the stack current collectors.

For each element, the effects of both systematic and random errors on the stack current and voltage, are presented in Table D.1. It is important to note that, these values were estimated based on the writer's experience with respect to FE-DMFC performance testing.

Table D.1: Elemental error effects on stack current and voltage

\begin{tabular}{|l|c|c|c|c|c|c|}
\hline & $S$ & $S_{I}$ & $S_{V}$ & $R$ & $R_{I}$ & $R_{V}$ \\
\hline Temperature $\left[{ }^{\circ} \mathrm{C}\right]$ & 2.47 & 50 & 50 & 1.06 & 25 & 50 \\
\hline Anode flow rate $[\mathrm{ml} / \mathrm{min}]$ & 0.25 & 2.5 & 20 & 0.25 & 2.5 & 20 \\
\hline FE flow rate $[\mathrm{ml} / \mathrm{min}]$ & 0.25 & 62.5 & 5 & 0.25 & 62.5 & 5 \\
\hline Air flow rate $[\mathrm{ml} / \mathrm{min}]$ & 20 & 25 & 10 & 50 & 25 & 25 \\
\hline FE thickness [mm] & 0.02 & 62.5 & 10 & 0.02 & 62.5 & 10 \\
\hline Compression torque [N-m] & 0.1 & 25 & 5 & 0.5 & 62.5 & 25 \\
\hline Methanol concentration $[\mathrm{M}]$ & 0.006 & 12.5 & 12 & 0.006 & 12.5 & 12 \\
\hline FE concentration $[\mathrm{M}]$ & 0.005 & 12.5 & 20 & 0.005 & 12.5 & 20 \\
\hline Load bank & - & 1.25 & 1 & - & 12.5 & 25 \\
\hline
\end{tabular}

Where $S_{I}$ is the estimated systematic error for stack current in $[\mathrm{mA}], S_{V}$ is the estimated systematic error for stack voltage in $[\mathrm{mV}], R_{I}$ is the estimated random 
error for stack current in $[\mathrm{mA}]$, and $R_{V}$ is the estimated random error for stack voltage in $[\mathrm{mV}]$.

Based on the values in Table D.1, the overall systematic and random errors for stack current and voltage were obtained, as follows:

The overall systematic errors for stack current and voltage, were calculated by the following equations:

$$
\begin{aligned}
& S_{I}=\left(50^{2}+2.5^{2}+62.5^{2}+25^{2}+62.5^{2}+25^{2}+12.5^{2}+12.5^{2}+1.25^{2}\right)^{\frac{1}{2}} \\
& S_{I}=109 \mathrm{~mA} \\
& S_{V}=\left(50^{2}+20^{2}+5.0^{2}+10^{2}+10^{2}+5.0^{2}+12^{2}+20^{2}+1.0^{2}\right)^{\frac{1}{2}} \\
& S_{V}=60.79 \mathrm{mV}
\end{aligned}
$$

The overall random errors for stack current and voltage, were calculated by the following equations:

$$
\begin{aligned}
& R_{l}=\left(25^{2}+2.5^{2}+62.5^{2}+25^{2}+62.5^{2}+62.5^{2}+12.5^{2}+12.5^{2}+12.5^{2}\right)^{\frac{1}{2}} \\
& R_{I}=115.95 \mathrm{~mA} \\
& R_{V}=\left(50^{2}+20^{2}+5.0^{2}+25^{2}+10^{2}+25^{2}+12^{2}+20^{2}+25^{2}\right)^{\frac{1}{2}} \\
& R_{V}=73.78 \mathrm{mV}
\end{aligned}
$$

Finally, the overall uncertainty for stack current and voltage were calculated, as follows:

$$
\begin{aligned}
& e_{I}=\left(109^{2}+115.95^{2}\right)^{\frac{1}{2}}=159.14 \mathrm{~mA} \\
& e_{V}=\left(60.79^{2}+73.78^{2}\right)^{\frac{1}{2}}=95.6 \mathrm{mV}
\end{aligned}
$$

\section{D.1.3 Stack Power Error Analysis}

The following equation was used to calculate the stack power:

$$
P=V I
$$

As a result, the propagated error for stack power was obtained, using the following sets of equations:

$$
e_{P}=\left[\sum_{i=1}^{j}\left(\theta_{P}(i) e(i)\right)^{2}\right]^{\frac{1}{2}}
$$


and:

$$
e_{P}=\left[\left(\theta_{I} e_{I}\right)^{2}+\left(\theta_{V} e_{V}\right)^{2}\right]^{\frac{1}{2}}
$$

where:

$$
\theta_{P}(I)=\frac{\partial P}{\partial I}=V
$$

and:

$$
\theta_{P}(V)=\frac{\partial P}{\partial V}=I
$$

and thus:

$$
e_{P}=\left[\left(V . e_{I}\right)^{2}+\left(I . e_{V}\right)^{2}\right]^{\frac{1}{2}}
$$

For maximum stack power $(2.37 \mathrm{~W})$, the corresponding current and voltage were found to be $1952 \mathrm{~mA}$ and $1214 \mathrm{mV}$, respectively. By substituting these values into Equation D.12, we have:

$e_{P}=\left[(1.214 \times 0.159)^{2}+(1.952 \times 0.095)^{2}\right]^{\frac{1}{2}}=0.268 \mathrm{~W}$

The above uncertainty value for maximum stack power, is referred to as the "standard" uncertainty. For a normal distribution, the standard uncertainty has $68 \%$ confidence level. In majority of engineering applications, it is common to report the final uncertainty at a $95 \%$ confidence level [59]. This is equivalent to the spread of two standard deviations and thus, for the $95 \%$ confidence level, the stack maximum power uncertainty would be $0.535 \mathrm{~W}$.

\section{D.2 Pressure Uncertainty Analysis}

The uncertainty analysis for pressure has two parts. The first part describes the calculation of the uncertainty associated with the pressure measurement process and the experimental setup and the second part, deals with pressure drop modelling error analysis and the effects of void fraction correlation errors on the estimated overall two-phase pressure drop across the anode compartment. 


\section{D.2.1 Pressure Measurement Uncertainty Analysis}

As mentioned earlier, the measurement errors emerge in various stages of an experiment. The following elemental errors can be identified during experimental pressure measurement:

- Errors due to temperature control system;

- Errors due to fluid control system at the anode compartment;

- Errors due to DAQ card and computer;

- Errors due to differential pressure transducer;

- Errors due to cell position (elevation) and fittings.

As mentioned in Section D.1, the systematic and random errors of temperature control system was found to be $2.47^{\circ} \mathrm{C}$ and $1.06^{\circ} \mathrm{C}$, respectively. Similarly, for fluid control system, the systematic and random errors of $0.25 \mathrm{ml} / \mathrm{min}$ was considered. The minimum voltage accuracy for the data acquisition card by National Instrument (Model No: NI USB-6009) was reported to be $18.75 \mathrm{mV}$. Similarly, the output voltage accuracy for the differential pressure transducer by OMEGA (Model No: PX409001DWU5V) was reported to be $0.8 \mathrm{mV}$. The cell elevation was adjusted using a ruler with $0.5 \mathrm{~mm}$ systematic and random errors.

For each element, the effects of both systematic and random errors on the pressure measurement process are presented in Table D.2. It is important to note that, for cell temperature and anode flow rate, the corresponding pressure error values were estimated based on the writer's experience with respect to FE-DMFC hydrodynamic testing. Also, for data acquisition card and pressure transducer, the corresponding error values were calculated by applying the calibration curve provided by the manufacturer. Finally, the pressure errors associated with cell elevation and fittings were calculated by using conventional fluid mechanic equations.

Where $S_{p r e s s}$ is the estimated systematic error for pressure drop across the anode compartment in $[\mathrm{Pa}]$, and $R_{\text {press }}$ is the estimated random error for pressure drop across the anode compartment in $[\mathrm{Pa}]$. 
Table D.2: Elemental error effects on pressure measurement across the anode compartment

\begin{tabular}{|l|c|c|c|c|}
\hline & $S$ & $S_{\text {press }}$ & $R$ & $R_{\text {press }}$ \\
\hline Temperature $\left[{ }^{\circ} \mathrm{C}\right]$ & 2.47 & 5.0 & 1.06 & 2.5 \\
\hline Anode flow rate $[\mathrm{ml} / \mathrm{min}]$ & 0.25 & 10 & 0.25 & 10 \\
\hline DAQ card voltage $[\mathrm{mV}]$ & 18.75 & 25.85 & 18.75 & 25.85 \\
\hline Transducer voltage $[\mathrm{mV}]$ & 0.8 & 1.1 & 0.8 & 1.1 \\
\hline Cell elevation $[\mathrm{mm}]$ & 0.5 & 4.9 & 0.5 & 4.9 \\
\hline Fitting pressure losses $[\mathrm{Pa}]$ & 5.0 & 5.0 & 5.0 & 5.0 \\
\hline
\end{tabular}

Based on the values in Table D.2, the overall systematic and random errors for the pressure drop across the anode compartment were obtained, as follows:

$$
\begin{aligned}
& S_{\text {press }}=\left(5.0^{2}+10^{2}+25.85^{2}+1.1^{2}+4.9^{2}+5.0^{2}\right)^{\frac{1}{2}} \\
& S_{\text {press }}=29.04 \mathrm{~Pa} \\
& R_{\text {press }}=\left(2.5^{2}+10^{2}+25.85^{2}+1.1^{2}+4.9^{2}+5.0^{2}\right)^{\frac{1}{2}} \\
& R_{\text {press }}=28.72 \mathrm{~Pa}
\end{aligned}
$$

Finally, the overall uncertainty for the two-phase pressure drop across the FEDMFC anode compartment was calculated, as follows:

$e_{\text {press }}=\left(29.04^{2}+28.72^{2}\right)^{\frac{1}{2}}=40.84 \mathrm{~Pa}$

As mentioned earlier, the above uncertainty value for the overall two-phase pressure drop, is referred to as the "standard" uncertainty which corresponds to $68 \%$ confidence level. For the $95 \%$ confidence level, the overall two-phase pressure drop uncertainty would be $81.68 \mathrm{~Pa}$.

\section{D.2.2 Pressure Drop Modelling Uncertainty Analysis}

As mentioned in Chapters 3 and 4, in order to calculate the overall two-phase pressure drop across the anode compartment, void fraction inside the fuel channels have to be properly estimated. On the other hand, the void fraction requires several mathematical correlations for density, viscosity and surface tension. These mathematical equations however, contain some level of uncertainty since they are not an 
exact representation of the physical quantity. As a result, the uncertainty analysis have to be performed in order to investigate the effects of such errors on the overall two-phase pressure drop across the anode compartment.

Using CISE correlation for void fraction, it can be seen that the volumetric void fraction $(\alpha)$ is a function of gas/liquid density, liquid viscosity, surface tension, overall mass flux, vapour quality and channel hydraulic diameter:

$$
\alpha=\alpha\left(\rho_{g}, \rho_{l}, \mu_{l}, \sigma, G, x, d_{h}\right)
$$

Equation D.13 is comprised of three major correlations for liquid density, liquid viscosity and surface tension. By assuming water as the dominant liquid phase and according to White et al. [52], the following error values was considered for water density, viscosity and surface tension correlations at $70^{\circ} \mathrm{C}$ :

Table D.3: Correlation error values for water

\begin{tabular}{|l|c|c|}
\hline & Value & Error \\
\hline Density $\left[\mathrm{kg} / \mathrm{m}^{3}\right]$ & 977.93 & 1.95 \\
\hline Viscosity $[\mathrm{kg} / \mathrm{m} . \mathrm{s}]$ & $0.405 \times 10^{-3}$ & $0.0243 \times 10^{-3}$ \\
\hline Surface Tension $[\mathrm{N} / \mathrm{m}]$ & 0.062 & 0.00062 \\
\hline
\end{tabular}

In order to calculate the void fraction overall error, the following equation is used:

$$
e_{\alpha}=\left[\sum_{i=1}^{j}(\theta(i) e(i))^{2}\right]^{\frac{1}{2}}
$$

and:

$$
e_{\alpha}=\left[\left(\theta\left(\rho_{l}\right) e\left(\rho_{l}\right)\right)^{2}+\left(\theta\left(\mu_{l}\right) e\left(\mu_{l}\right)\right)^{2}+(\theta(\sigma) e(\sigma))^{2}\right]^{\frac{1}{2}}
$$

where:

$$
\theta\left(\rho_{l}\right)=\frac{\partial \alpha}{\partial \rho_{l}}
$$


and:

$$
\theta\left(\mu_{l}\right)=\frac{\partial \alpha}{\partial \mu_{l}}
$$

and:

$$
\theta(\sigma)=\frac{\partial \alpha}{\partial \sigma}
$$

Assuming methanol solution flow rate of $5 \mathrm{ml} / \mathrm{min}$, fuel cell operating temperature and current density of $70^{\circ} \mathrm{C}$ and $0.1 \mathrm{~A} / \mathrm{cm}^{2}$, respectively, the volumetric void fraction error was found to be 0.03 . The same calculation scheme was applied to estimate the error associated with the overall two-phase pressure drop across the anode compartment:

$$
e_{\Delta P}=\left[\left(\theta\left(\rho_{l}\right) e\left(\rho_{l}\right)\right)^{2}+\left(\theta\left(\mu_{l}\right) e\left(\mu_{l}\right)\right)^{2}+(\theta(\alpha) e(\alpha))^{2}\right]^{\frac{1}{2}}
$$

where:

$$
\theta\left(\rho_{l}\right)=\frac{\partial \Delta P}{\partial \rho_{l}}
$$

and:

$$
\theta\left(\mu_{l}\right)=\frac{\partial \Delta P}{\partial \mu_{l}}
$$

and:

$$
\theta(\alpha)=\frac{\partial \Delta P}{\partial \alpha}
$$

By substituting all the corresponding values into Equations D.19, D.20, D.21 and D.22, the overall two-phase pressure drop error was found to be $7.67 \mathrm{~Pa}$ for $68 \%$ confidence level, and $15.34 \mathrm{~Pa}$ for $95 \%$ confidence level. 